CECÍLIA PACHECO ELIAS

CARACTERIZAÇÃO CLÍNICA, METABÓLICA E HORMONAL DE PORTADORES DE LIPODISTROFIA PARCIAL FAMILIAR

BRASÍLIA 
UNIVERSIDADE DE BRASÍLIA

FACULDADE DE CIÊNCIAS DA SAÚDE

CECÍLIA PACHECO ELIAS

CARACTERIZAÇÃO CLÍNICA, METABÓLICA E HORMONAL DE PORTADORES DE LIPODISTROFIA PARCIAL FAMILIAR

Dissertação apresentada ao Curso de PósGraduação em Ciências da Saúde, Universidade de Brasília, como requisito parcial à obtenção do Título de Mestre em Ciências da Saúde.

Orientadora: Dra. Angélica Amorim Amato Co-Orientadora: Dra. Daniela Espíndola Antunes

BRASÍLIA 
Autorizo a reprodução e divulgação total ou parcial deste trabalho, por qualquer meio convencional ou eletrônico, para fins de ensino, estudo ou pesquisa, desde que citada a fonte. 


\title{
CARACTERIZAÇÃO CLÍNICA, METABÓLICA E HORMONAL DE PORTADORES DE LIPODISTROFIA PARCIAL FAMILIAR
}

\begin{abstract}
Dissertação apresentada ao Curso de PósGraduação em Ciências da Saúde, Universidade de Brasília, como requisito parcial à obtenção do Título de Mestre em Ciências da Saúde.
\end{abstract}

Área de concentração: Fisiopatologia Médica

Aprovado em: 21 de agosto de 2015

\section{BANCA EXAMINADORA}

Profa. Dra. Angélica Amorim Amato (Presidente) Universidade de Brasília

Prof. Dr. Luiz Augusto Casulari Roxo de Motta Universidade de Brasília

Prof. Dr. Nelson Rassi

Universidade Federal de Goiás

Profa. Dra. Maria de Fátima de Borin (Suplente) Universidade de Brasília 


\section{AGRADECIMENTOS}

A Deus, meu fiel guardião, por me permitir ser abençoada todos os dias.

Aos meus avós Cecílio (i.m.), Catarina (i.m.) e Alice (i.m.), meus exemplos de vida; a demonstração de que é possível vencer com humildade e simplicidade.

Aos meus pais, Carlos Luz e Maria José, meus exemplos de amor e dedicação, minha eterna gratidão por estarem sempre ao meu lado, me oferecerendo todas as oportunidades para vencer e ser feliz.

À minha irmã Carla, meu exemplo de companheirismo, por também estar sempre ao meu lado, me ensinando a ser mais forte e madura.

Ao meu amor Paulo Júnior, por compreender meus momentos de ausência nesses dois anos e por trazer felicidade e paz à minha vida.

À minha madrinha Rosane, a quem tanto admiro, obrigada pela felicidade de tê-la sempre presente nas minhas conquistas, com sua torcida sincera.

À minha orientadora, professora Angélica, que se tornou um exemplo não apenas de profissional, mas de ser humano. Foi um grande presente de Deus e sorte ter alguém tão especial nessa conquista. Obrigada pelos ensinamentos, dedicação, paciência e por me confortar nos meus momentos de ansiedade.

À minha co-orientadora, professora Daniela, meu sincero agradecimento por me confiar sua idéia original do projeto e por essa oportunidade de estudo, pelas orientações e pelos ensinamentos de didática durante as atividades em docência.

À Michella e Caroline, pela ajuda e dedicação na área de biologia molecular, obrigada por fazerem parte da nossa equipe de pesquisa e pela oportunidade de prosseguir os estudos nessa área genética.

À amiga Ana Paula, essencial nesta conquista, muito obrigada, de coração, por me acrescentar e acalmar com suas palavras de sabedoria nos meus momentos de inexperiência, pela companhia e ajuda durante o curso das matérias, enfim, por contar com sua amizade nesta trajetória.

Aos queridos amigos que moram em Brasília (Patrícia, Pedro, Ana Luiza, Camila e Luciana), que me acolheram com tanto carinho em suas casas. Agradeço a amizade verdadeira e o apoio especial de vocês.

Ao Dr. Leonardo Normanha, que gentilmente cedeu a oportunidade de relização dos exames de DEXA no Instituto Goiano de Radiologia.

Ao Laboratório Núcleo, pelo apoio na realização dos exames laboratoriais. 
À amiga Roberta a ao Dr. Vinícius, pelo apoio na avaliação cardiológica dos pacientes. À Clínica Ser e à colega Cristine, por completar o apoio para realização dos exames de ultrassom.

À Dra. Patrícia Mory e Dra. Regina Moisés, pela oportunidade de realização do estudo do gene LMNA em duas pacientes do estudo.

Aos meus ex-preceptores da residência de Endocrinologia do HGG, meus exemplos de profissionais, obrigada por todos os ensinamentos médicos e de vida, que até hoje me oferecem. Agradeço, em especial, ao Dr. Haroldo Souza, que me ajudou (de forma incondicional) nos períodos em que precisei me ausentar das atividades do HGG.

Às queridas amigas da Endocrinologia (Letícia, Cassiana, Juliana e Suzeth), que estão presentes de forma especial em minha vida pessoal e profissional, com palavras alegres, de amizade, carinho e incentivo.

Aos pacientes, que participaram de forma voluntária, prestativa e com o olhar de esperança e humildade. 
"Humildade não é se declarar pequeno. Humildade é reconhecer suas forças e suas fraquezas e, perante isso, buscar o seu melhor." 


\section{RESUMO}

Introdução: As lipodistrofias são condições raras, caracterizadas por redistribuição anormal da gordura corporal. A lipodistrofia parcial familiar (LPF) caracteriza-se por perda variável de tecido adiposo subcutâneo periférico (membros e glúteos) e acúmulo de gordura em outras regiões. Há seis variantes de LPF descritas e foram identificadas mutações em cinco genes. Manifestações clínicas incluem resistência insulínica (RI) e outros componentes da síndrome metabólica (SM).

Objetivo: Caracterização clínica, metabólica e hormonal de portadores de LPF. Métodos: Foram selecionados pacientes com achados clínicos sugestivos de LPF, acompanhados em dois hospitais públicos de Goiânia. Foram avaliadas medidas antropométricas [índice de massa corporal (IMC), circunferência abdominal (CA), relação cintura/quadril e índice de adiposidade corporal], variáveis bioquímicas e hormonais (glicemia, hemoglobina glicada, perfil lipídico, transaminases, PCR, cálcio, fósforo, PTH, 25OHD, insulina, leptina, TSH, T4 livre, T3, gonadotrofinas e androgênios; resistência insulínica foi avaliada com o índice HOMA-IR). O eixo hipotálamo-hipófise-adrenal (HHA) foi avaliado com medidas basais (cortisol, ACTH, cortisol salivar noturno e cortisol livre urinário) e dinâmicas (testes de supressão com 0,5 e $1 \mathrm{mg}$ de dexametasona). Foi realizado ultrassom (US) pélvico nas mulheres, para avaliação de Síndrome dos Ovários Policísticos (SOP), e US de abdome para rastreamento de esteatose hepática (EH). Avaliação cardiovascular foi considerada através de exames de ecodopplercardiograma e teste ergométrico. A composição corporal foi avaliada pelo método de absorciometria radiológica de dupla energia (DEXA), incluindo a razão de massa de gordura troncular sobre a dos membros inferiores (FMR). A correlação de medidas antropométricas e relacionadas à composição corporal, com variáveis bioquímicas e hormonais, foi avaliada pelo teste de Spearman. Resultados: Foram analisados 6 pacientes (5 mulheres e 1 homem), entre 17 e 42 anos. Observou-se heterogeneidade fenotípica e perda menos acentuada de tecido adiposo periférico nos pacientes mais jovens. $O$ único paciente do sexo masculino incluído foi o que apresentou o fenótipo menos grave. Todos os pacientes apresentaram resistência insulínica $(\mathrm{RI})$ e 3 exibiram redução da concentração circulante de leptina. SOP foi diagnosticada nas 5 mulheres avaliadas. Todos os pacientes apresentaram EH e componentes da SM. RI acentuada foi observada em 4 pacientes, dos quais 3 não apresentavam obesidade. Nenhum dos pacientes apresentou hipercortisolismo. O estudo da composição corporal por DEXA envidenciou aumento da quantidade de gordura central e redução da quantidade de gordura periférica (FMR > 1,2 e aumento da taxa androide/ginoide). Não houve correlações significativas entre medidas antropométricas e da composição corporal com variáveis bioquímicas ou hormonais, embora a FMR tenha se correlacionado melhor com alterações bioquímicas e hipoleptinemia, quando comparada à CA. Conclusão: Foram observadas RI e componentes da SM em todos os pacientes. O fenótipo lipodistrófico foi mais leve nos indivíduos mais jovens. Não foram observadas alterações do eixo HHA. A avaliação da composição corporal por DEXA foi mais sensível que as medidas antropométricas para evidenciar as modificações da distribuição de gordura na LPF. Não foram observadas correlações significativas entre medidas antropométricas e relacionadas à composição corporal com variáveis bioquímicas e hormonais nos pacientes investigados.

Palavras-chave: tecido adiposo; lipodistrofia; resistência insulínica; síndrome metabólica; composição corporal; eixo hipotálamo-hipófise-adrenal. 


\begin{abstract}
Background: Lipodystrophies are rare conditions characterized by abnormal redistribution of body fat. Familial partial lipodystrophy (FPL) is associated with a variable loss of peripheral subcutaneous adipose tissue (legs, arms and gluteal reagion) and fat accumulation in other regions. Six FPL variants associated with mutations at 5 loci have been described. Clinical manifestations include insulin resistance (IR) and other components of the metabolic syndrome (MS). This study aims to describe clinical, metabolic and hormonal features of FPL.

Methods: Patients with clinical features of the syndrome followed at two public hospitals in Goiania were included, and had anthropometric (body mass index, IMC, abdominal circumference, AC, waist to hip ratio, WHR, and body adiposity index), biochemical and hormonal (fasting glucose, glycated hemoglobin, lipid profile, liver enzymes, CRP, calcium, phosphorus, PTH, 25OHD, insulin, leptin, TSH, free T4, T3, gonadotrophis and androgens) measures analyzed. The hypothalamic-hypophysealadrenal (HHA) axis was assessed by both basal (cortisol, ACTH, nocturnal cortisol and urinary free cortisol) and dynamic (0.5 and $1 \mathrm{mg}$ dexamethasone suppression tests) tests. Polycistic ovary syndrome (POS) was investigated by pelvic ultrasound and hepatic steatosis was assessed with an abdominal ultrasound. Cardiovascular evaluation was considered through echocardiogram and ergometric test. Body composition was analyzed with dual X-ray energy absorciometry (DEXA), including the ratio of troncular fat and legs (FMR). Correlation between clinical, anthropometric, biochemical, hormonal and body composition-related variables was analyzed by Spearman's tests. Results: Six (five female and 1 male) patients aged 17 to 42 years were included. Fat distribution was heterogeneous and younger patients had lower intensity loss of peripheral adipose tissue. The only male patient included was the one with the less severe phenotype. All patients exhibited insulin resistance (IR) and 3 exhibited reduced serum leptin levels. POS syndrome was present in all 5 female patients included. All patients had components of metabolic syndrome and hepatic steatosis. None of the patients had biochemical signs of hypercortisolism. Body composition assessed by DEXA showed an increase in central body fat and reduced peripheral body fat (FMR $>1.2$ and increased android/ginoid rate). There were no significant correlations between clinical, anthropometric, biochemical, hormonal and body composition-related variables, although FMR seemd to correlate better with biochemical abnormalities and hypoleptinemia than AC. Conclusion: IR and features of MS were seen in all 6 patients with FPL, and the lipodystrophic phenotype was less severe in younger patients. There were no abnormalities in HHA activity. Body composition assessed by DEXA showed increased sensitivity to detect abnormalities in fat distribution when compared to anthropometric measures. There were no significant correlations between clinical, anthropometric, biochemical, hormonal and body composition-related variables.
\end{abstract}

Keywords: adipose tissue; lipodystrophy; insulin resistance; metabolic syndrome; body composition; hypothalamic-hypophyseal-adrenal axis. 


\section{LISTA DE FIGURAS}

Figura 1. Aspectos fisiológicos das adipocinas secretadas pelo tecido adiposo.

Figura 2. Formação da gotícula de gordura no adipócito.

Figura 3. Fotografias da paciente $\mathrm{P} 1$, com fenótipo típico da lipodistrofia (perda de gordura em regiões de membros e glúteo), evidenciando o aspecto de pseudohipertrofia muscular e flebomegalia.

Figura 4. Fotografias da paciente $\mathrm{P} 3$, também com fenótipo típico de perda adiposa periférica da lipodistrofia parcial familiar. Nota-se o acúmulo adiposo dorsocervical, troncular e abdominal.

Figura 5. Fotografias da paciente P5, com apresentação fenotípica lipodistrófica. Os locais de acúmulo anormais de gordura são evidentes (face, pescoço, supraclavicular, troncular e abdominal), com aspecto cushingoide.

Figura 6. Fotografias das pacientes P3 (A, B) e P4 (C, D), mostrando acantose nigricans acentuada em regiões cervical e axilar. 


\section{LISTA DE TABELAS}

Tabela 1. Características clínicas dos seis pacientes com diagnóstico clínico sugestivo de lipodistrofia parcial familiar.

Tabela 2. Características antropométricas dos seis pacientes com diagnóstico clínico sugestivo de lipodistrofia parcial familiar.

Tabela 3. Características bioquímicas dos seis pacientes com diagnóstico clínico sugestivo de lipodistrofia parcial familiar.

Tabela 4. Características hormonais dos seis pacientes com diagnóstico clínico sugestivo de lipodistrofia parcial familiar.

Tabela 5. Comorbidades metabólicas e resultado da avaliação cardiovascular dos seis pacientes com diagnóstico clínico sugestivo de lipodistrofia parcial familiar.

Tabela 6. Avaliação do eixo hipotálamo-hipófise-adrenal dos seis pacientes com diagnóstico clínico sugestivo de lipodistrofia parcial familiar.

Tabela 7. Avaliação da composição corporal por DEXA dos seis pacientes com diagnóstico clínico sugestivo de lipodistrofia parcial familiar.

Tabela 8. Correlação entre a idade e variáveis antropométricas, medidas da composição corporal (DEXA) e metabólicas, nos seis pacientes com diagnóstico clínico de LPF.

Tabela 9. Correlação entre a FMR e variáveis metabólicas, nos seis pacientes com diagnóstico clínico de LPF.

Tabela 10. Correlação entre a CA e variáveis metabólicas, nos seis pacientes com diagnóstico clínico de LPF. 


\section{LISTA DE ABREVIATURAS E SIGLAS}

\%TBF - percentual de gordura corporal total

$11 \beta H S D 1$ - 11 $\beta$-hidroxiesteroide desidrogenase tipo 1

AACE - American Association of Clinical Endocrinologists - Associação Americana de Endocrinologistas Clínicos

ACTH - hormônio adrenocorticotrófico

AGL- ácidos graxos livres

AGPAT2 - gene que codifica a 1-acylglycerol-3-phosphate O-acyltransferase 2 AKT2 - gene $v$-AKT murine thymoma oncogen homolog 2 (AKT2) ou gene da proteinoquinase $B(P K B)$

ALT- Aspartato alaninotransferase

AST - Aspartato aminotransferase

BIA- bioimpedanciometria

BSCL2- gene codificador da seipina

C/EBP- proteínas de ligação ao acentuador CCAAT

CA- circunferência abdominal

CAV1 - gene codificador da caveolina 1

CBG- cortisol-binding globulin - globulina ligadora do cortisol

CCAAT - citosina-citosina-adenina-adenina- timina

CIDEC- gene que codifica a proteína cell death-inducing Dffa-like effector $C$

CLU- cortisol livre urinário de 24 horas

CPD- cortisol pós-dexametasona oral

$C Q$ - circunferência do quadril

CT- colesterol total

DAC- doença arterial coronariana

DEXA - dual-energy $x$-ray absorptiometry - absorciometria de raio $\mathrm{X}$ de dupla energia

Dexa- dexametasona

DHEA- deidroepiandrosterona

DLP - dislipidemia

DM - diabetes mellitus

$\mathrm{EH}$ - esteatose hepática 
FMR - fat mass ratio -razão de massa de gordura (tronco/ membros inferiores)

FSH- hormônio folículoestimulante

GGT - Gamaglutamiltransferase

GH- growth hormone - hormônio do crescimento

Gj- glicemia de jejum

GPP-glicemia pós-prandial

HAS- hipertensão arterial sistêmica

HbA1c - hemoglobina glicada A1c

HC-UFG - Hospital das Clínicas da Universidade Federal de Goiás

HDL- lipoproteína de alta densidade

HGG- Hospital Geral de Goiânia - Dr. Alberto Rassi

HHA- eixo hipotálamo-hipófise-adrenal

HIV - Human Immunodeficiency Virus - Vírus da Imunodeficiência Humana

HOMA-IR- homeostatic model assessement, insulin resistance - modelo de avaliação

da homeostase para resistência à insulina

IAC - índice de adiposidade corporal

IDF- International Diabetes Federation - Federação Internacional de Diabetes

IGF-1- insulin-like growth fator 1- Fator de crescimento semelhante à insulina

IGFBPs- insulin-like growth factor-binding protein - fator de crescimento ligada a proteína semelhante a insulina

IL-1 $\beta$ - interleucina $1-\beta$

IL-6 - interleucina 6

IMC- índice de massa corporal

LDL lipoproteína de baixa densidade

LH- hormônio luteinizante

LMNA - gene codificador da lamina nuclear A/C

LPF- lipodistrofia parcial familiar

MCP-1- proteína quimiotáxica do monócito- 1

MMII- membros inferiores

PAl-1 - inibidor do ativador de plasminogênio-1

PCRUS- proteína $C$ reativa ultrassensível

PLIN1- gene que codifica a perilipina 1

PPARY ou PPARG - peroxisome proliferator-activated receptor gamma - receptor gama ativado por proliferadores peroxissomais 
PTH- paratormônio

PTRF- fator de transcrição da caveolae

$R C Q$ - relação cintura/quadril

$\mathrm{RI}$ - resistência insulínica

RM- ressonância magnética

SC- síndrome de Cushing

SDHEA- sulfato de deidroepiandrosterona

SHBG - sex hormone binding globulin - globulina ligadora de hormônios (esteroides) sexuais

SM- síndrome metabólica

SOP- síndrome dos ovários policísticos

SREBP-1 - sterol-regulatory elemento-binding protein $1 \mathrm{C}$

T3L - hormônio triiodotironina - fração livre

T4L - hormônio tetraiodotironina- fração livre

Taxa A/G - taxa de massa de gordura androide/ ginoide

TC - tomografia computadorizada

TG - triglicerídeos

TNF- $\alpha$ - fator de necrose tumoral $\alpha$

TOTG - teste oral de tolerância a glicose

TSH- hormônio tireotrófico (tireoestimulante)

US- ultrassom

Vaspin - visceral adipose tissue-derived serpin - serpina derivada do tecido adiposo visceral 


\section{SUMÁRIO}

1 INTRODUÇÃO

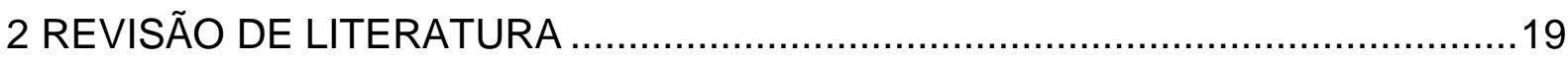

2.1 TECIDO ADIPOSO E SUA RELEVÂNCIA CLÍNICA.....................................19

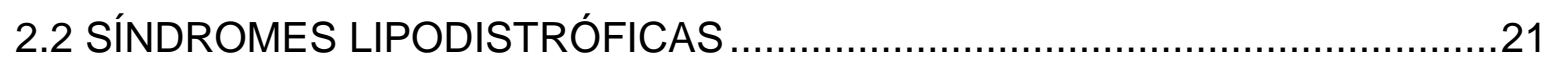

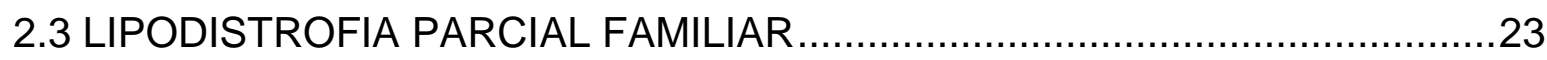

2.3.1 Achados Clínicos para Suspeita Diagnóstica ........................................27

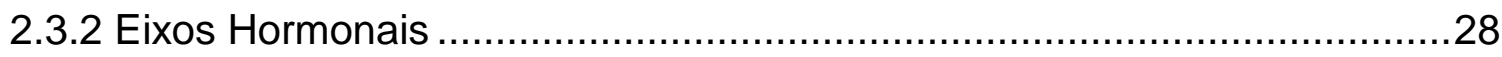

2.3.2.1 Eixo Hipotálamo-Hipófise-Adrenal ...............................................28

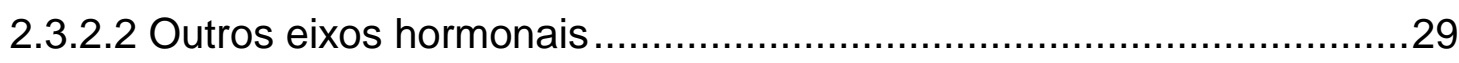

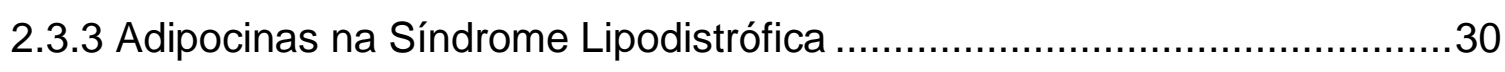

2.3.4 Métodos de Avaliação da Composição Corporal .....................................30

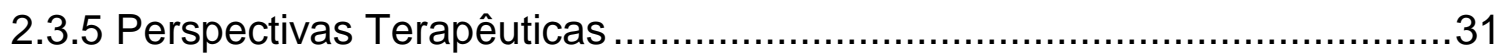

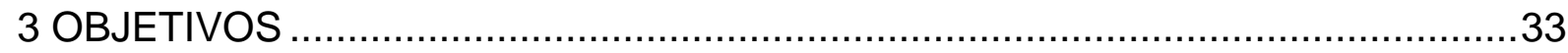

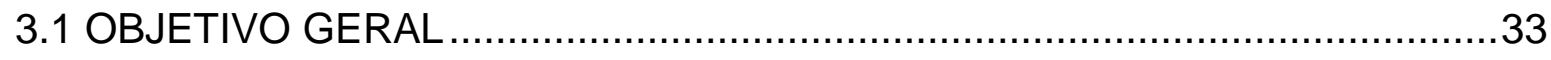

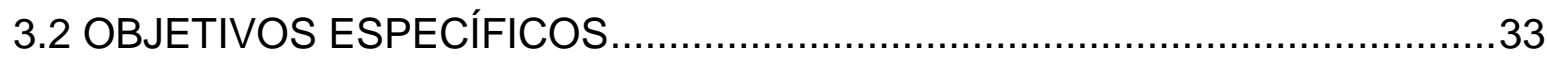

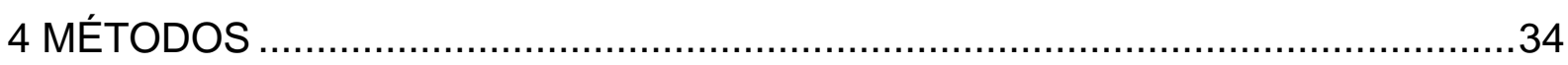

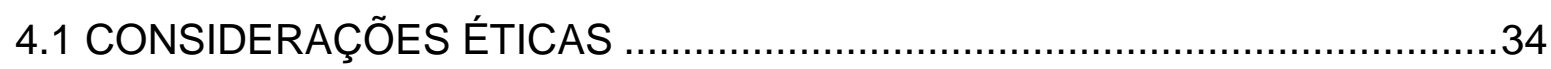

4.2 DESENHO DO ESTUDO E CRITÉRIOS DE SELEÇÃO ................................34

4.3 CARACTERÍSTICAS CLÍNICAS E ANTROPOMÉTRICAS ............................35

4.4 AVALIAÇÃO BIOQUÍMICA E HORMONAL BASAL …..................................

4.5 AVALIAÇÃO DO EIXO HIPOTÁLAMO-HIPÓFISE-ADRENAL ........................39

4.6 AVALIAÇÃO DA COMPOSIÇÃO CORPORAL ............................................. 40

4.7 AVALIAÇÃO ULTRASSONOGRÁFICA E CARDIOVASCULAR ....................41

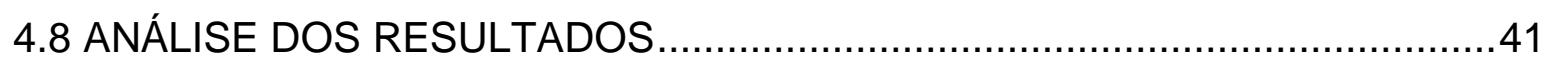

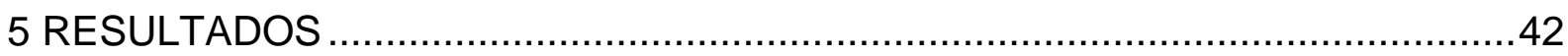

5.1 CARACTERÍSTICAS CLÍNICAS DOS PORTADORES DE LIPODISTROFIA PARCIAL FAMILIAR ESTUDADOS ...........................................................

5.2 CARACTERÍSTICAS BIOQUÍMICAS DOS PORTADORES DE LIPODISTROFIA PARCIAL FAMILIAR ESTUDADOS …..................................48

5.3 CARACTERÍSTICAS HORMONAIS DOS PORTADORES DE LIPODISTROFIA PARCIAL FAMILIAR ESTUDADOS .............................................................. 49 
5.4. AVALIAÇÃO DE OUTRAS COMORBIDADES METABÓLICAS E DOENÇA

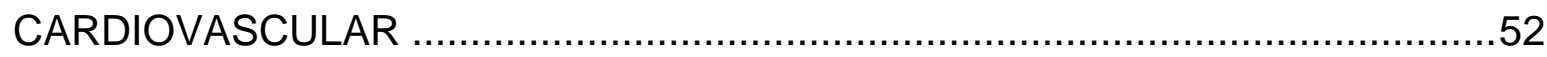

5.5 AVALIAÇÃO DO EIXO HIPOTÁLAMO-HIPÓFISE-ADRENAL …...................54

5.6 ANÁLISE DA COMPOSIÇÃO CORPORAL POR DEXA.................................56

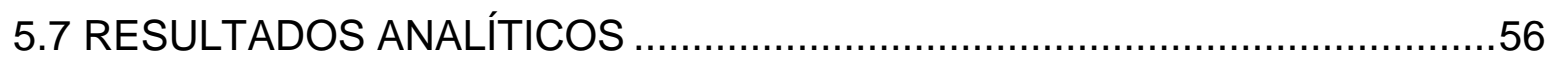

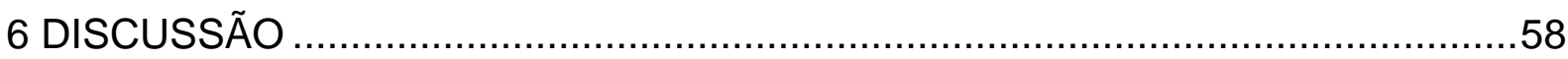

6.1 RECONHECIMENTO CLÍNICO DA LIPODISTROFIA PARCIAL FAMILIAR ...58

6.2 ACHADOS BIOQUÍMICOS E METABÓLICOS ............................................59

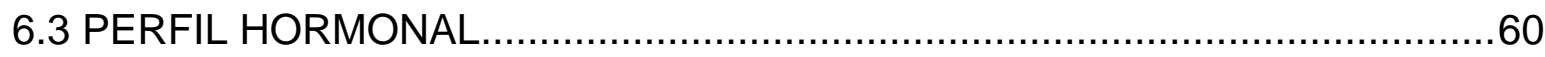

6.3.1 Leptinemia

6.3.2 Atividade do Eixo Hipotálamo-Hipófise-Adrenal ......................................62

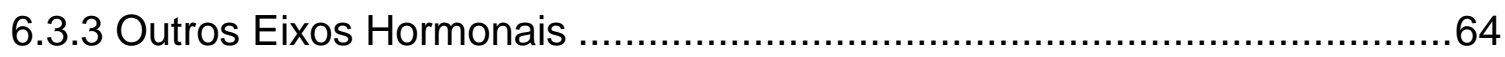

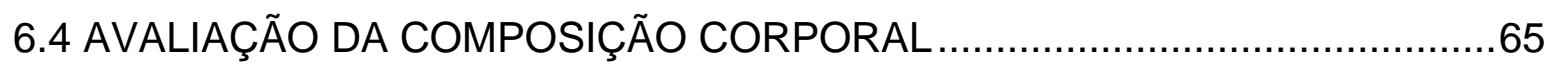

6.5 CONSIDERAÇÕES FINAIS E PERSPECTIVAS FUTURAS .........................67

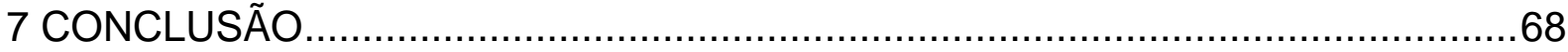

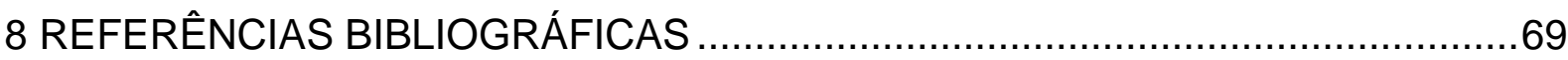




\section{INTRODUÇÃO}

A maior compreensão do tecido adiposo como órgão endócrino permitiu o reconhecimento de síndromes relacionadas a anormalidades na distribuição da gordura corporal, denominadas lipodistrofias. A condição clínica lipodistrófica envolve um grupo bastante heterogêneo de doenças raras, caracterizado por diferentes graus de perda de tecido adiposo, essencialmente subcutâneo, além de poder estar associado a depósitos aumentados de gordura em outros segmentos corporais, como tronco e abdome. A classificação das síndromes lipodistróficas é baseada na extensão ou padrão de perda de gordura (generalizada ou parcial), assim como em seu caráter genético ou adquirido (1-6).

Dentre as síndromes lipodistróficas hereditárias, o subtipo parcial demonstra importância científica por representar um modelo "natural" para compreensão das funções metabólicas dos diferentes depósitos de tecido adiposo. Pacientes com lipodistrofia parcial familiar (LPF) apresentam grande diversidade fenotípica $(2,5,6)$. São descritas seis variantes clínicas, conforme as decobertas genéticas. Até 0 momento, já foram identificados cinco genes envolvidos, com destaque para o gene codificador da lamina nuclear $\mathrm{A} / \mathrm{C}(L M N A)$ e o gene que codifica o receptor gama ativado por proliferadores peroxissomais (PPARY) (1-3). A perda de gordura subcutânea nas extremidades e região glútea, classicamente próxima ao período puberal, representa característica comum das variantes clínicas da doença. Contudo, a perda adiposa pode se iniciar em qualquer fase da vida, desde a infância até a idade adulta $(1,6,7)$.

Alterações metabólicas são frequentes na LPF, destacando-se a resistência insulínica (RI) e componentes da síndrome metabólica (SM), como diabetes mellitus tipo 2 (DM 2) de início precoce, hipertrigliceridemia grave e baixas concentrações séricas de lipoproteína de alta densidade (HDL). Outras manifestações comuns são hipertensão arterial (HAS), esteatose hepática $(\mathrm{EH})$, Síndrome dos Ovários Policísticos (SOP) e acantose nigricans (2,3,6-8).

A gravidade das complicações parece estar mais relacionada ao grau de perda de gordura subcutânea, o que é consistente com o papel protetor deste depósito, do ponto de vista metabólico $(2,3)$. A redistribuição e deposição ectópica da gordura corporal, com maior acúmulo de triglicerídeos em órgãos como fígado, 
coração e músculo esquelético, contribuem para o desenvolvimento de resistência insulínica aumentada $(3,9)$. Além disso, a alteração da liberação de adipocinas nos pacientes lipodistróficos, como redução da liberação de adiponectina e leptina, apresentam importante papel no comprometimento à sensibilidade insulínica $(7,10)$. A RI acentuada é observada mesmo na ausência de obesidade (2,3,9).

Os indivíduos com LPF frequentemente são confundidos com portadores de síndrome de Cushing (SC), dada a sua similaridade fenotípica com o hipercortisolismo $(1,2,11)$. É possível que exista uma hiperativação do eixo hipotálamo-hipófise-adrenal (HHA), à semelhança do que ocorre na obesidade comum (12), mas este aspecto ainda não foi estudado especificamente na LPF, para nosso conhecimento.

A diversidade de fenótipos na LPF pode estar associada a mutações autossômicas dominantes (mais comum) ou recessivas. Os estudos em biologia molecular, envolvendo a síndrome, ainda são insuficientes para elucidação completa de suas bases genéticas, uma vez que quantidade considerável de pacientes com fenótipo clínico não apresenta mutação em nenhum dos genes candidatos $(2,3,13)$.

A grande variabilidade fenotípica e clínica da LPF, com formas típicas e atípicas descritas na literatura, tornam necessários mais estudos envolvendo a caracterização clínica, bioquímica e hormonal de portadores desta condição, visto que o diagnóstico ainda é essencialmente clínico, devido à dificuldade prática do diagnóstico molecular. É possível, também, que a raridade da doença deva-se, em parte, ao subdiagnóstico, uma vez que muitos pacientes são considerados portadores de obesidade ou síndrome metabólica comum (2,7,9). Nesse contexto, documentos que auxiliem o reconhecimento desta condição pela comunidade clínica se fazem necessários.

A melhor caracterização clínica, bioquímica e hormonal de portadores de lipodistrofias, assim como de sua fisiopatologia, poderá contribuir para o reconhecimento mais precoce da doença e de suas complicações e, consequentemente, para melhor abordagem terapêutica, possível prevenção de consequências graves (como mortalidade por doença cardiovascular precoce), estudo e orientação dos familiares. Além disso, a caracterização de eixos hormonais em pordadores de LPF apresenta o potencial de contribuir para melhor entendimento das funções metabólicas do tecido adiposo e de suas interferências com outros eixos hormonais e sistemas orgânicos (14). 


\section{REVISÃO DE LITERATURA}

\subsection{TECIDO ADIPOSO E SUA RELEVÂNCIA CLÍNICA}

O tecido adiposo humano tem se revelado tema de grande interesse científico, sobretudo a partir da década de 1990, quando deixou de ser interpretado como um simples isolante térmico e depósito de gordura e ganhou destaque como um verdadeiro órgão endócrino $(15,16)$. A importância metabólica do tecido adiposo, em grande parte, advém da sua capacidade de secretar hormônios e apresentar receptores, de modo a influenciar o balanço energético (incluindo mecanismos de fome e saciedade), sensibilidade e secreção insulínica, metabolismo lipídico e função endotelial, além de desempenhar funções em respostas inflamatórias e imunológicas, conforme apresentado na Figura 1 (16,17). Os hormônios secretados pelo tecido adiposo recebem a denominação de adipocinas e suas ações interferem em órgãos como fígado, coração, pâncreas e músculo esquelético $(17,18)$.

Entre as adipocinas, a leptina foi a primeira a ser identificada, em 1994, e destacou o importante papel do tecido adiposo na homeostase enérgica corporal. $A$ partir de então houve a identificação de diversos desses hormônios. Os efeitos fisiológicos das adipocinas deixaram clara a relação entre obesidade e doenças do tecido adiposo com desfechos metabólicos e cardiovasculares (18).

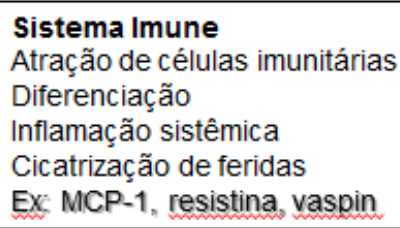

Figura 1. Aspectos fisiológicos das adipocinas secretadas pelo tecido adiposo. Adaptado de 17.
Sistema Nervoso Central

Apetite

Saciedade

Gasto energético

Ex: leptina

Pâncreas

Secreção insulínica

Secreção de glucagon

Sensibilidade insulínica

Ex adiponectina, leptina.

visfatina

Fígado

Sensibilidade insulínica

Metabolismo lipidico

Fatores de crescimento
Ex adiponectina, vaspin
Contratilidade musculatura cardiaca

EX: PAl-1, angiotensinogênio
Coração e vasos

Pressão arterial

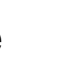
. 
A compreensão de doenças associadas ao tecido adiposo, sobretudo aquelas de etiologia genética, envolve o conhecimento do processo de adipogênese e toda sua complexidade envolvendo a determinação e diferenciação adipocitária. Os adipócitos são derivados das células tronco do mesoderma e o processo de adipogênese é regulado por fatores de transcrição (dentre eles, destacamos o PPAR $\gamma$ e as proteínas de ligação ao acentuador CCAAT, C/EBP), além de sofrer influência de fatores ambientais e de vias de sinalização endógenas $(15,19)$.

É importante ressaltar que nem todos os adipócitos são iguais do ponto de vista morfofuncional e nem sempre é a quantidade de gordura que será o determinante do processo saúde-doença, mas sim o local onde se deposita. As diferenças metabólicas entre distintos depósitos de tecido adiposo são hoje bem estabelecidas, assim como suas correlações clínicas peculiares (19-21,24), conforme apresentado no Quadro 1.

Quadro 1 - Comparação entre o adipócito visceral e o subcutâneo $(20,21,24)$

\begin{tabular}{|c|c|c|}
\hline Característica & Adipócito Visceral & Adipócito Subcutâneo \\
\hline Volume & Maior & Menor \\
\hline $\begin{array}{c}\text { Capacidade de diferenciação } \\
\text { e proliferação }\end{array}$ & Baixa & Alta \\
\hline $\begin{array}{c}\text { Número de receptores } \\
\text { beta-adrenérgicos }\end{array}$ & Maior & Menor \\
\hline $\begin{array}{c}\text { Número de receptores de } \\
\text { insulina }\end{array}$ & $\begin{array}{c}\text { Menor } \\
\text { (maior RI) }\end{array}$ & $\begin{array}{c}\text { Maior } \\
\text { (maior RI) }\end{array}$ \\
\hline Lipólise & $\begin{array}{c}\text { Maior taxa de liberação } \\
\text { de AGL }\end{array}$ & $\begin{array}{c}\text { Menor taxa de liberação de } \\
\text { AGL }\end{array}$ \\
\hline $\begin{array}{c}\text { Capacidade de armazenar } \\
\text { gordura }\end{array}$ & Menor & Maior \\
\hline
\end{tabular}

RI: resistência insulínica; AGL: ácidos graxos livres

O adipócito visceral, devido à sua menor capacidade de armazenamento lipídico, libera quantidade relevante de ácidos graxos livres, que se depositam de forma anormal em órgãos como fígado, pâncreas e músculo esquelético, acarretando disfunção mitocondrial e resistência insulínica nestes tecidos (22-24). Esse processo é denominado deposição ectópica de gordura e suas consequências metabólicas adversas são conhecidas como lipotoxicidade. A gordura visceral representa, assim, importante fator preditor de complicações associadas à resistência insulínica e síndrome metabólica, enquanto a gordura subcutânea, especialmente gluteofemoral, demonstra apresentar um efeito protetor do ponto de 
vista metabólico $(20-22,24)$.

Esses aspectos, em conjunto, indicam a relevância clínica do tecido adiposo, extensamente estudado nos últimos 20 anos, não somente pelas condições associadas à sua disfunção, mas também pelo potencial terapêutico das adipocinas na abordagem dessas patologias $(17,18)$.

\subsection{SÍNDROMES LIPODISTRÓFICAS}

No processo de descobertas científicas relacionadas ao tecido adiposo, emergiu o conhecimento de um grupo de doenças associadas à distribuição da gordura corporal que, embora raras, representam um modelo particular de estudo da biologia do adipócito. Esse grupo de doenças corresponde às lipodistrofias, condições que se caracterizam essencialmente pela perda, seletiva ou total, de tecido adiposo (1-6). Nas formas seletivas, associado à lipoatrofia, pode haver acúmulo anormal (hipertrofia) de tecido adiposo em outras regiões, também de forma variável $(2-7,11)$.

As síndromes lipodistróficas foram descritas na literatura há mais de 100 anos, mas os progressos nos estudos de biologia molecular se tornaram mais evidentes nas últimas duas décadas, no intuito de elucidar suas bases genéticas. As lipodistrofias genéticas apresentam prevalência estimada menor do que 1 a cada 1 milhão de casos detectados. Entretanto, especula-se que somente 1/4 dos pacientes sejam reconhecidos (2).

A classificação dessas doenças é baseada na extensão ou padrão de perda de gordura (generalizada ou parcial/seletiva), assim como em seu caráter genético ou adquirido. Dessa forma, uma classificação simplificada permite destacar quatro subtipos: (i) lipodistrofia congênita generalizada (Síndrome de Berardinelli-Seip); (ii) lipodistrofia adquirida generalizada (Síndrome de Lawrence); (iii) lipodistrofia parcial familiar (LPF) e (iv) lipodistrofia parcial adquirida, destacando-se neste grupo a lipodistrofia mais frequente, associada ao tratamento antirretroviral em pacientes com vírus da imunodeficiência humana (HIV), e a Síndrome de Barraquer-Simons, de possível etiologia autoimune $(2-7,11)$.

A característica central das lipodistrofias é a perda do tecido adiposo subcutâneo e, com isso, são comuns resistência insulínica e alterações metabólicas a ela associadas, como diabetes mellitus, hipertrigliceridemia e esteatose hepática. 
A gravidade das complicações metabólicas parece ser proporcional ao grau de perda da gordura subcutânea $(2,3,7,9)$. No entanto, essas alterações metabólicas podem não estar presentes ou acontecer de forma leve em alguns subtipos de lipodistrofia, como na Síndrome de Barraquer-Simons $(7,9)$. O quadro 2 apresenta, resumidamente, os aspectos clínicos das principais síndromes lipodistróficas.

Quadro 2 - Classificação e aspectos clínicos das principais lipodistrofias (9)

\begin{tabular}{|c|c|c|}
\hline Classificação & Etiologia & Principais aspectos \\
\hline \multicolumn{3}{|l|}{ Lipodistrofias Genéticas } \\
\hline \multicolumn{3}{|l|}{ 1. Generalizada } \\
\hline Síndrome de Berardinelli-Seip & $\begin{array}{c}\text { Mutações nos genes } \\
\text { AGPAT2, BSCL2, PTRF e } \\
\text { CAV1 }\end{array}$ & $\begin{array}{l}\text { Lipodistrofia generalizada } \\
\text { grave, acantose nigricans, } \\
\text { hiperfagia, hiperlipidemia, } \\
\text { hiperinsulinemia, diabetes }\end{array}$ \\
\hline \multicolumn{3}{|l|}{ 2. Lipodistrofia Parcial Familiar } \\
\hline Tipo 1 (Kobberling) & Desconhecida & \multirow{4}{*}{$\begin{array}{c}\text { Perda adiposa subcutânea em } \\
\text { membros e glúteos; } \\
\text { lipohipertrofia em regiões de } \\
\text { face, pescoço e/ou tronco; } \\
\text { diabetes e hipertrigliceridemia }\end{array}$} \\
\hline Tipo 2 (Dunnigan) & Mutações no gene $L M N A$ & \\
\hline Tipo 3 & Mutação no gene PPARG & \\
\hline Tipos 4,5 e 6 & $\begin{array}{c}\text { Mutação nos genes } A K T 2, \\
\text { PLIN1 e CIDEC }\end{array}$ & \\
\hline \multicolumn{3}{|l|}{ Lipodistrofias Adquiridas } \\
\hline \multicolumn{3}{|l|}{ 1. Generalizada } \\
\hline \multirow{2}{*}{ Síndrome de Lawrence } & Desconhecida & \multirow{2}{*}{$\begin{array}{c}\text { Ausência generalizada de } \\
\text { tecido adiposo, resistência } \\
\text { insulínica, diabetes, esteatose } \\
\text { hepática }\end{array}$} \\
\hline & Associada a paniculite & \\
\hline \multicolumn{3}{|l|}{ 2. Parcial } \\
\hline \multirow{2}{*}{ Síndrome Barraquer-Simons } & Desconhecida & \multirow{2}{*}{$\begin{array}{l}\text { Perda assimétrica da gordura } \\
\text { subcutânea, desordens } \\
\text { metabólicas leves }\end{array}$} \\
\hline & Associada a autoimunidade & \\
\hline Lipodistrofia associada ao HIV & Drogas antirretrovirais & $\begin{array}{l}\text { Lipoatrofia periférica e face, } \\
\text { lipohipertrofia dorsocervical e } \\
\text { central, diabetes, dislipidemia }\end{array}$ \\
\hline
\end{tabular}

Os instrumentos para classificação das lipodistrofias parecem simples e de fácil compreensão. Entretanto, nem sempre são suficientes para o reconhecimento 
da doença, visto que se trata de um grupo heterogêneo tanto no quesito clínico (com padrões variáveis de perda adiposa e manifestações clínicas em um mesmo subtipo de lipodistrofia), quanto genético (7). Considerando as dificuldades diagnósticas e na tentativa de organizar achados clínicos que permitam o reconhecimento das lipodistrofias, foi desenvolvido um consenso pela Associação Americana de Endocrinologistas Clínicos, publicado no ano de 2013, e apresentado no Quadro 3 (7).

Quadro 3 - Características que aumentam a suspeita clínica das lipodistrofias (7)

Característica central da lipodistrofia

- Perda ou ausência de gordura

Característica clínica central para a lipodistrofia parcial familiar

- Perda da gordura subcutânea corporal, tipicamente próxima ou pouco depois da puberdade, em extremidades e/ou glúteos

- Acúmulo de gordura em face, pescoço ou região intra-abdominal

Características de suporte clínico para lipodistrofia

- Presença de diabetes com evidência de resistência insulínica grave

- Outras evidências de resistência insulínica grave

- acantose nigricans

- SOP ou sintomas de hiperandrogenismo, oligomenorreia e/ou ovários policísticos

- Presença de hipertrigliceridemia

- Evidência de esteatose hepática ou esteatohepatite

- História familiar de aparência física semelhante e/ou história de perda adiposa

- Musculatura proeminente e flebomegalia em extremidades

- Hiperfagia

- Hipogonadismo secundário (homens) ou amenorreia (mulheres)

SOP: Síndrome dos Ovários Policísticos

\subsection{LIPODISTROFIA PARCIAL FAMILIAR}

Entre as lipodistrofias hereditárias, o subtipo parcial familiar tem sido alvo de diversas pesquisas, contribuindo para compreensão das funções metabólicas do tecido adiposo subcutâneo. A primeira descrição da síndrome de LPF foi realizada por Wier-Mitchell em 1885 (9). Quase 90 anos depois, foi identificado o primeiro gene relacionado à doença (o gene $L M N A)$ e, desde então, foram identificados 
outros genes associados à síndrome, permitindo classificar a LPF em seis subtipos principais. A maior parte dos pacientes apresenta padrão de herança autossômica dominante $(2,3,6,9)$. A real prevalência da LPF não é bem estabelecida, por depender de casos esparsos relatados, dada a raridade da doença (9). Além disso, estima-se um provável subdiagnóstico desses pacientes $(2,7)$.

A LPF tipo 1 é também denominada síndrome de Kobberling, em alusão ao autor que a descreveu em 1975, caracterizando-a como perda significativa do tecido adiposo subcutâneo nos membros e glúteos em pacientes com diabetes e hipertrigliceridemia. Trata-se de entidade rara, com menos de 20 casos descritos na literatura e ainda não se conhece seu padrão de herança e etiologia. A maior parte dos casos publicados foi no sexo feminino (9). Um recente estudo questionou se seria mais uma condição subdiagnosticada do que propriamente rara (25).

A LPF tipo 2 é destacada como a variante mais comum, com prevalência estimada de 1 em 15 milhões de casos (5) e com a maior quantidade de casos descritos na literatura (> 300 casos). Também recebe a denominação de Síndrome de Dunnigan, em alusão ao autor que descreveu a doença pela primeira vez no ano de 1974 (9). A base genética envolve o gene que codifica a lamina A/C (LMNA), com 12 exons e localizado no cromossomo 1q21-22 (26,27). Um aspecto interessante da LPF tipo 2 é sua grande variabilidade fenotípica, mesmo entre pacientes com uma mesma mutação $(2,11,28)$.

Os mecanismos resultantes da mutação no LMNA parecem envolver tanto alterações estruturais da lamina nuclear, quanto interferências nos comandos de transcrição, na organização da heterocromatina ou na função e posicionamento dos poros nucleares $(13,27)$. Neste subtipo da LPF, são encontradas formas típicas e atípicas de lipodistrofia parcial; nestas últimas a perda periférica de tecido adiposo subcutâneo é mais sutil $(27,28)$. Mutações no $L M N A$ podem resultar em outras doenças, entre elas distrofias musculares, cardiomiopatias e defeitos da condução nervosa. Esse amplo espectro fenotípico caracteriza as chamadas "laminopatias", termo que vem sendo utilizado para descrever as várias doenças relacionadas a mutações neste gene $(13,22,27,28)$. No caso da síndrome de Dunnigan, a característica clínica predominante é a resistência insulínica, de forma que esta variante de LPF é referida como uma "laminopatia metabólica". Além disso, há indícios de que a presença de mutações no $L M N A$ não seja tão incomum em portadores de SM, sem os achados clássicos da síndrome de Dunnigan (29). 
A LPF tipo 3 está associada ao gene que codifica um fator de transcrição com importante função na adipogênese e na homeostase metabólica: o receptor gama ativado por proliferadores peroxissomais (PPAR $\gamma$ ). Esta forma de LPF parece ser a segunda mais frequente e o primeiro caso foi relatado em 2003 (9). O PPAR membro da superfamília dos receptores nucleares e regula a expressão de genes envolvidos na diferenciação adipocitária, metabolismo lipídico, resposta inflamatória, sensibilidade insulínica e proliferação celular. Mutações no PPARY que acarretam LPF são consideradas de baixa frequência na literatura, com estimativa de $1 \mathrm{em}$ 100.000 casos nos descendentes norte-europeus (30).

Existem dois mecanismos propostos para explicar a fisiopatogenia da LPF por mutações do PPARY: a "dominância negativa" (interferência direta do produto do alelo mutado sobre a função do alelo sem mutação) ou "haploinsuficiência", que acarretaria redução da expressão do gene em $50 \%$ (13). Os pacientes com essa forma de LPF apresentam um fenótipo mais leve de perda de tecido adiposo subcutâneo periférico, porém as complicações metabólicas da resistência insulínica aparecem com maior gravidade, o que sugere que a mutação do PPARG tenha impacto sobre outros sítios chave da ação da insulina, além do tecido adiposo $(3,13)$.

Por representarem os dois subtipos mais frequentemente descritos de LPF, é possível encontrar na literatura algumas comparações entre a LPF tipo 2 e a LPF tipo 3, conforme apresentado no Quadro 4.

Quadro 4 - Comparações entre as duas variantes mais comuns de lipodistrofia parcial familiar (13)

\begin{tabular}{|c|c|c|}
\hline Características & LPF tipo 2 & LPF tipo 3 \\
\hline Idade comum de início & Puberdade & Mais tardio \\
\hline Perda adiposa periférica subcutânea & Mais grave & Sutil (MMII: predomínio distal) \\
\hline Depósito troncular & Menor & Maior \\
\hline Acantose nigricans & Presente & Tipicamente presente \\
\hline Hirsutismo & Raro & Comum \\
\hline SOP & Infrequente & Frequente \\
\hline Complicações metabólicas & gravidade & Maior gravidade e mais precoces \\
\hline
\end{tabular}

LPF: lipodistrofia parcial familiar; MMII: membros inferiores; SOP: síndrome dos ovários policísticos; DM: diabetes mellitus. 
O subtipo 4 da LPF envolve mutação missense no gene $v$-AKT murine thymoma oncogen homolog 2 (AKT2) ou gene da proteinoquinase $\mathrm{B}(P K B)$, que exerce importante papel na sinalização insulínica. Esta mutação foi descrita no ano de 2004, em uma família com quadro de resistência insulínica acentuada, na idade adulta, exibindo transmissão dominante em heterozigoze (31). Em estudo posterior que objetivou investigar o papel deste gene nas lipodistrofias parciais e em doenças metabólicas comuns, foi observada baixa frequência de mutações no $A K T 2 / P K B$ entre portadores de LPF e não foi observada associações entre variantes comuns deste gene e alterações metabólicas frequentes, como diabetes mellitus tipo 2 (32).

A LPF tipo 5, com padrão de herança autossômica dominante (33), está relacionada à mutação no gene que codifica a perilipina 1 ( $P$ LIN1), localizado no cromossomo $15 q 26$. Esta proteína está presente de forma abundante na gotícula de gordura no adipócito, mais especificamente em sua superfície, e desempenha funções críticas na regulação do armazenamento lipídico e da lipólise (27). A proteína mutada apresenta falha no seu papel de inibir a lipólise em condição basal e resulta em gotículas lipídicas de tamanho reduzido no adipócito, com fibrose e infiltração de macrófagos no tecido adiposo (11). Recentemente, foi descrita uma nova mutação frameshift em heterozigoze em duas famílias não relacionadas, em indivíduos que apresentavam resistência insulínica grave e componentes da síndrome metabólica, refratários a tratamento clínico (34).

O subtipo 6 da LPF foi descrito inicialmente como uma forma de lipodistrofia de padrão de herança autossômico recessivo em uma paciente jovem, com fenótipo de perda adiposa subcutânea periférica, associada a hipertrigliceridemia acentuada e diabetes com perfil resistente à insulina (35). O gene associado à LPF tipo 6 é o CIDEC, codificador da proteína cell death-inducing Dffa-like effector $C$, que participa da diferenciação do pré-adipócito e da formação da gotícula de gordura. A proteína mutante apresenta falha na capacidade de aumentar o tamanho da gotícula de gordura, levando-a a um aspecto multiloculado (27).

Esses três últimos subtipos de LPF são bastante raros, com casos isolados descritos na literatura. A caracterização fenotípica desses pacientes ainda não é bem definida (9).

A elucidação da base genética de algumas formas de LPF estabeleceu a importância de cinco genes para a biologia do tecido adiposo e a identificação de mutações dos genes PLIN1 e CIDEC, especificamente, definiu a importância da 
gotícula de gordura no adipócito, como uma organela funcional crítica para a homeostase energética $(3,22,27)$. Uma representação esquemática da formação da gotícula lipídica é apresentada na Figura 2.

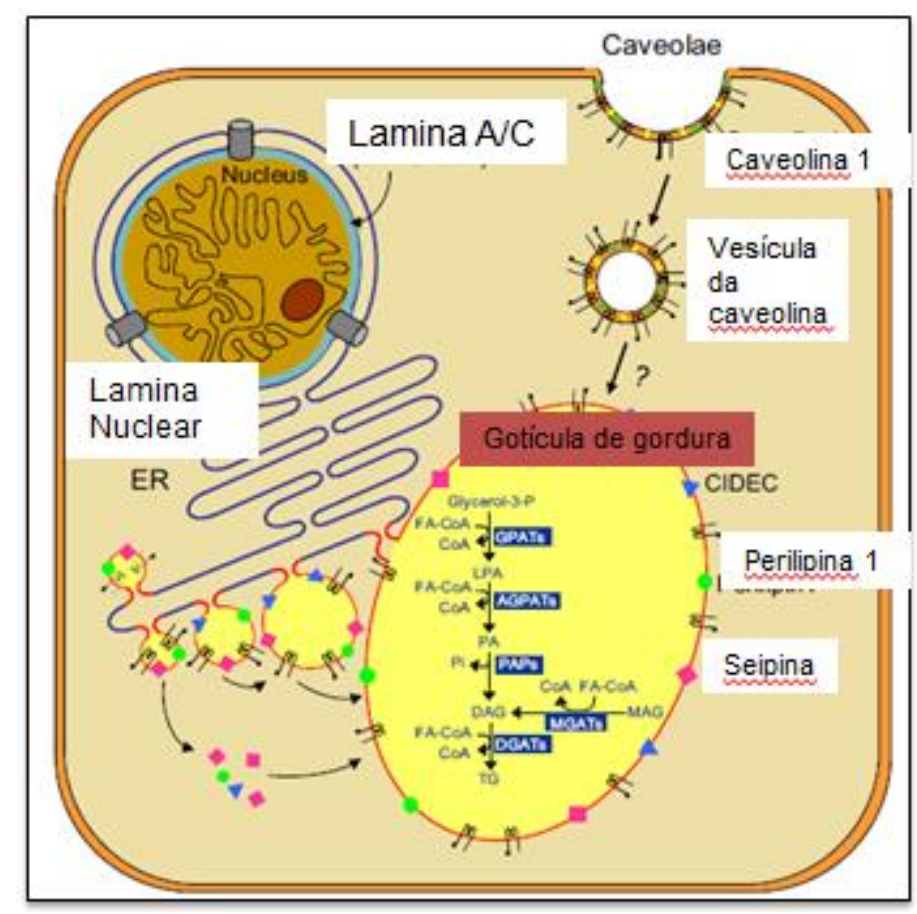

Figura 2. Formação da gotícula de gordura no adipócito. Adaptado de 2.

Apesar dos avanços da biologia molecular, um número considerável de pacientes permanece sem elucidação da base genética da LPF. Análises genômicas de sequências conhecidas dos genes $\angle M N A$ e PPARG demonstraram que aproximadamente $50 \%$ dos pacientes não apresentam nenhuma mutação (13). Essa dificuldade de determinação genotípica remete à hipótese de que possivelmente existam outros genes candidatos da doença, que ainda precisam ser identificados.

\subsubsection{Achados Clínicos para Suspeita Diagnóstica}

Os achados clínicos semelhantes a todas as formas de LPF descritas incluem perda de gordura subcutânea nas extremidades e região glútea, resultando em pseudohipertrofia muscular e flebomegalia. Esses aspectos classicamente ocorrem próximo do período puberal, mas a idade de início pode variar e acontecer fora da puberdade $(1,6,7)$. O reconhecimento fenotípico é mais fácil nas mulheres, o que justifica o maior número de casos descritos na literatura serem do sexo feminino $(6,7)$. Nos homens, além da dificuldade de percepção dos aspectos de 
pseudohipertrofia muscular e flebomegalia, soma-se 0 fato de naturalmente apresentarem menor quantidade de tecido adiposo na região glútea e pernas (3).

Comorbidades metabólicas são frequentes na LPF, muitas relacionadas ao processo de resistência insulínica acentuada. Dentre os componentes da SM e suas complicações, destacam-se diabetes mellitus tipo 2, hipertrigliceridemia grave (risco de pancreatite), baixas concentrações séricas de lipoproteína de alta densidade (HDL), doença hepática gordurosa não alcoólica, hipertensão arterial sistêmica e doença arterial coronariana (que pode se manifestar antes dos 40 anos) (2-7). A história familiar, com a presença de fenótipo lipodistrófico, complementa a suspeita clínica da doença (7).

No Quadro 5, estão descritas as características clínicas da LPF.

Quadro 5 - Achados clínicos no subtipo de lipodistrofia parcial familiar (7)

\begin{tabular}{|c|c|}
\hline Idade de início & Infância até idade adulta \\
\hline Locais de perda de gordura & $\begin{array}{c}\text { Extremidades superiores }^{a} \\
\text { Extremidades inferiores }^{a} \\
\text { Glúteo }^{\mathrm{a}} \\
\text { Tronco }^{\mathrm{b}}\end{array}$ \\
\hline Locais de acúmulo/depósito de gordura & $\begin{array}{l}\text { Face e pescoço } \\
\text { Intra-abdominal }^{\mathrm{b}}\end{array}$ \\
\hline Outros achados & $\begin{array}{c}\text { Acantose nigricans }{ }^{\mathrm{b}} \\
\text { Hepatomegalia ou Esteatose hepática }^{\mathrm{b}} \\
\text { Hirsutismo }^{\mathrm{b}} \\
\text { Hiperandrogenemia em mulheres }^{\mathrm{b}} \\
\text { Hiperfagia }^{\mathrm{b}}\end{array}$ \\
\hline
\end{tabular}

\subsubsection{Eixos Hormonais}

\subsubsection{Eixo Hipotálamo-Hipófise-Adrenal}

Alterações periféricas e/ou centrais da ação do cortisol parecem estar envolvidas no desenvolvimento da SM associada à obesidade. Alterações discretas da atividade do eixo hipotálamo-hipófise-adrenal (HHA), tais como elevação das 
concentrações circulantes de ACTH pela manhã e alterações de sua pulsatilidade (36), maior responsividade do eixo HHA a neuropeptídeos (37), aumento da produção de cortisol (38) e diminuição da supressão do cortisol em resposta a baixas doses de dexametasona (39-41) são observadas na SM. Estudos recentes mostram maior produção periférica de cortisol especialmente no tecido adiposo,

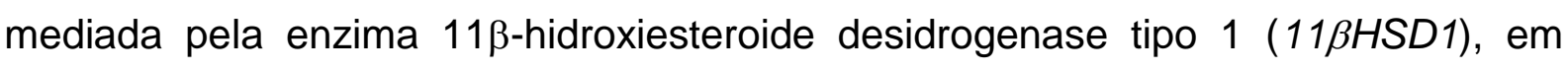
concordância com as observações de aumento da expressão e atividade desta enzima em depósitos de gordura visceral de indivíduos obesos e/ou com SM, o que sugere o possível papel do hipercortisolismo tecidual na síndrome (42-44).

Obesidade, síndrome metabólica e também o diabetes não compensado podem representar situações de provável hipercortisolismo funcional, em que é possível que não ocorra supressão da secreção do cortisol em resposta a baixas doses de dexametasona oral, mas somente em resposta a doses mais elevadas (2 $\mathrm{mg}$ ), o que sugere que nestas situações haja maior ativação do eixo HHA (45).

A presença de características da SM na LPF e as similaridades fenotípicas da LPF com o hipercortisolismo justificam que frequentemente indivíduos com LPF sejam confundidos com portadores de síndrome de Cushing $(1,2,11)$. Entretanto, não existem estudos sobre a atividade do eixo HHA na LPF, para nosso conhecimento, descritos na literatura. É possível que exista hiperativação do mesmo, à semelhança do que ocorre na SM comum, não relacionada especificamente à LPF. Contudo, esse aspecto ainda não foi explorado.

\subsubsection{Outros eixos hormonais}

Alterações de outros eixos hormonais já foram observadas na LPF. Em mulheres portadoras desta condição, são frequentes oligomenorreia $e$ hiperandrogenemia (sobretudo hirsutismo), atribuídas à resistência insulínica sobre a atividade ovariana, caracterizando um quadro compatível com SOP $(2,7,9,11)$. A fertilidade, entretanto, pode estar preservada, mesmo em pacientes com características da SOP $(5,7)$.

Estudos envolvendo o eixo tireoideano são pouco frequentes, porém já foram sugeridas alterações do metabolismo tecidual dos hormônios tireoideanos, nas regiões lipoatróficas de pacientes com LPF tipo 2 (46). Não há dados a respeito do eixo somatotrófico e do metabolismo ósseo especificamente em pacientes com LPF, 
para nosso conhecimento.

\subsubsection{Adipocinas na Síndrome Lipodistrófica}

A lipodistrofia, em geral, cursa com redução das concentrações circulantes de adiponectina e leptina $(10,47)$, compatível com a perda do tecido adiposo

subcutâneo. As concentrações dessas adipocinas parecem ser inversamente proporcionais ao grau de resistência insulínica e a redução sérica das mesmas está associada a aumento do risco cardiovascular na doença (47).

Estudos envolvendo outras adipocinas não são frequentes. Concentrações circulantes de TNF- $\alpha$ (citocina pró-inflamatória) estão aumentadas e parecem proporcionais à massa de gordura total. As concentrações séricas de IL-6, IL-1 $1 \beta$ e resistina, por sua vez, não demonstraram correlação com características da SM em pacientes com LPF 2 (47).

\subsubsection{Métodos de Avaliação da Composição Corporal}

Métodos não invasivos de avaliação objetiva da composição corporal são empregados em pacientes com LPF, com o intuito de caracterizar melhor o perfil de redistribuição da gordura corporal e avaliar critérios que permitam diferenciar os subtipos da síndrome.

Em estudo com imagens de ressonância magnética $(R M)$, envolvendo 22 mulheres com diferentes tipos de lipodistrofias (48), foi observado aumento significativo da quantidade de gordura supraclavicular na LPF tipo 2 e diminuição da gordura subcutânea abdominal, dos membros inferiores (coxas e panturrilhas) e da região glútea. Pacientes com LPF tipo 3, por sua vez, apresentaram nesse estudo aumento da gordura subcutânea abdominal e da supraclavicular, e demonstraram menor magnitude de perda nas regiões dos membros inferiores e glúteos, quando comparados com portadores da síndrome de Dunnigan (LPF tipo 2). A quantidade de gordura visceral foi significativamente aumentada nestes pacientes (48).

Um potencial marcador das lipodistrofias, nos exames de RM, parece ser a região média das coxas, que exibe perda adiposa significativa nos pacientes lipodistróficos (13).

Tischa Joy et al. (2009) estudaram 13 mulheres portadoras de LPF tipo 2, 
com o objetivo de correlacionar a adiposidade no tronco medida por RM com medidas clínicas simples, como índice de massa corporal (IMC), circunferência abdominal ( $C A$ ) e relação cintura/quadril (RCQ); e medidas determinadas pelo método de bioimpedanciometria (BIA). Observaram que houve correlação do IMC com a massa de tecido adiposo subcutâneo, ao passo que nenhuma medida clínica antropométrica se correlacionou com a massa de tecido adiposo visceral. A porcentagem de gordura total foi a variável que melhor se correlacionou com as adiposidades visceral e subcutânea (49). Nesse mesmo estudo, os autores tentaram validar uma equação preditora de adiposidade que fosse de fácil aplicabilidade clínica, a partir de variáveis simples e medidas de BIA. Concluíram que a equação era adequada apenas para estimar gordura visceral e que a medida do tecido adiposo subcutâneo é mais confiável quando realizada por meio de exames como tomografia computadorizada (TC) e RM (49).

$O$ método de absorciometria de raio $X$ de dupla energia (DEXA) também é avaliado em pacientes lipodistróficos e tem a vantagem de apresentar maior facilidade de execução na prática clínica. A maioria desses estudos é conduzida em portadores de lipodistrofia relacionada à infeção pelo vírus da imunodeficiência humana (HIV) e há poucos estudos envolvendo, especificamente, portadores de LPF. Em estudo com portadores de lipodistrofia por HIV, foi estabelecida uma forma objetiva de quantificação da perda de gordura subcutânea, por meio da determinação da razão da massa de gordura ("fat mass ratio" ou FMR), que representa a razão entre a porcentagem da massa de gordura do tronco e dos membros inferiores (50). Em outro estudo, com portadores de LPF tipo 2, foi possível sugerir o ponto de corte da FMR de 1,2 para caracterizar esta forma de LPF, e enfatizando a DEXA como um método útil para avaliação objetiva da composição corporal neste subgrupo de pacientes (51). Os autores também compararam, em outro estudo, o valor da FMR de portadores de diferentes subtipos de lipodistrofia e observaram que esta medida pode ajudar a diferenciar formas parciais adquiridas $(F M R<1,0)$ das parciais familiares $(F M R>1,0)(52)$.

\subsubsection{Perspectivas Terapêuticas}

Não há, até o momento, abordagem terapêutica capaz de reverter a perda de tecido adiposo na LPF, de forma que o principal objetivo terapêutico é a melhora das 
alterações metabólicas (2). Mudanças no estilo de vida, com medidas dietéticas e de atividade física, são consideradas necessárias, porém não há estudos clínicos que avaliem o impacto destas mudanças em pacientes com lipodistrofia (8).

Frequentemente, terapias convencionais das alterações metabólicas, como metformina, estatinas, fibratos e glitazonas, são inefetivas, embora frequentemente prescritas. $\mathrm{O}$ uso das glitazonas, especificamente, pode induzir a adipogênese em determinados sítios de tecido adiposo, mas não é estabelecido como o tratamento de escolha nestes pacientes $(2,8)$.

A cirurgia plástica pode ajudar na distribuição anormal da gordura corporal, visto que grande parte desses pacientes apresentam desabilidades sociais devido à imagem corporal lipodistrófica $(2,8,11)$. Cirurgia bariátrica, pela técnica do bypass gástrico, já foi realizada em pacientes com LPF e demonstra benefícios metabólicos glicêmicos e lipídicos, sugerindo ser uma opção terapêutica viável nos casos refratários ao tratamento clínico, independente do grau da obesidade $(53,54)$.

Uma terapia específica que vem se mostrando promissora e segura é a administração subcutânea da metreleptina, um análogo da leptina humana. No momento, é aprovada nos Estados Unidos para casos de lipodistrofias generalizadas, mas está sendo estudada também em pacientes com lipodistrofias parciais. Os resultados deste tratamento na LPF incluem melhora da sensibilidade insulínica e da lipotoxicidade periférica, com redução da hipertrigliceridemia, melhora do controle glicêmico e da esteatose hepática (55-58). Sua efetividade parece ser independente do grau de hipoleptinemia (59), porém um estudo recente sugeriu que seja menor em pacientes com leptinemia superior a $4 \mathrm{ng} / \mathrm{mL}$ (55). Pacientes com alterações metabólicas leves da doença (triglicérides $<500 \mathrm{mg} / \mathrm{dL}$ e/ou hemoglobina glicada $<8 \%$ ) parecem também não se beneficiar da terapia com metreleptina (55). 


\section{OBJETIVOS}

\subsection{OBJETIVO GERAL}

Investigar alterações clínicas, metabólicas e bioquímicas em portadores de lipodistrofia parcial familiar.

\subsection{OBJETIVOS ESPECÍFICOS}

- Estudar nos portadores de LPF:

- Os eixos gonadotrófico, somatotrófico, tireotrófico e corticotrófico.

- O metabolismo mineral.

- A composição corporal, pelo método de DEXA.

- O rastreamento de doença arterial coronariana (DAC).

- A presença de esteatose hepática.

- A correlação de medidas antropométricas e relacionadas à composição corporal com variáveis clínicas, metabólicas e hormonais. 


\section{MÉTODOS}

\subsection{CONSIDERAÇÕES ÉTICAS}

O estudo foi aprovado pelos Comitês de Ética em Pesquisa com Seres Humanos, da Faculdade de Ciências da Saúde da Universidade de Brasília (parecer número 547817, ANEXO I), do Hospital Geral de Goiânia (parecer número 1020651, ANEXO II) e do Hospital das Clínicas da Universidade Federal de Goiás (parecer número 1095631, ANEXO III). O estudo foi conduzido de acordo com a Resolução número 466/2012 do Conselho Nacional de Saúde. Os pacientes tiveram a participação condicionada à assinatura do Termo de Consentimento Livre e Esclarecido, após receberem informações detalhadas sobre a pesquisa e seus objetivos.

\subsection{DESENHO DO ESTUDO E CRITÉRIOS DE SELEÇÃO}

Trata-se de estudo observacional e transversal, com componentes descritivo e analítico, que incluiu pacientes com critérios clínicos de LPF, acompanhados ambulatorialmente nos serviços de Endocrinologia de duas instituições públicas de Goiânia (Hospital Geral de Goiânia Dr Alberto Rassi - HGG - e Hospital das Clínicas da Universidade Federal de Goiás - HC/UFG).

Foram incluídos pacientes de ambos os sexos, com diagnóstico clínico de LPF, definido de acordo com as características clínicas que aumentam a suspeição de lipodistrofia, propostas pela Associação Americana de Endocrinologia ( $A A C E$, American Association of Clinical Endocrinologists) (7). Essas características incluem: (i) perda progressiva e gradual de gordura subcutânea na região glútea e extremidades; (ii) pseudohipertrofia muscular e/ou flebomegalia nos membros; (iii) depósitos de tecido gorduroso nas regiões facial, cervical ou intra-abdominal; (iv) presença de acantose nigricans ou características clínicas compatíveis com síndrome dos ovários policísticos, (v) hipertrigliceridemia, disglicemias, doença hepática gordurosa não alcoólica; e (vi) história familiar com aparência física semelhante ao fenótipo de LPF. 
Foram excluídos indíviduos com síndrome metabólica sem o fenótipo lipodistrófico e pacientes em tratamento para doenças autoimunes ou em uso de terapia antirretroviral.

\subsection{CARACTERÍSTICAS CLÍNICAS E ANTROPOMÉTRICAS}

A coleta dos dados clínicos foi realizada por uma única pesquisadora, médica endocrinologista, por meio de avaliação clínica detalhada e revisão do prontuário médico.

$\mathrm{Na}$ anamnese, foram coletadas informações a respeito das seguintes variáveis:

- Idade (anos).

- Sexo.

- Motivo inicial da procura a atendimento médico.

- $\quad$ Percepção própria do paciente a respeito da distribuição anormal de gordura e em que idade ocorreu o início dessa anormalidade.

- Sintomas apresentados pelo paciente.

- Irregularidade menstrual (mulheres).

- Comorbidades existentes.

- Medicações em uso.

- $\quad$ Antecedentes gestacionais (mulheres).

- Hábitos de vida (tabagismo, etilismo, atividade física e dieta).

- História familiar de fenótipo lipodistrófico e/ou de doença arterial coronariana precoce.

No exame físico, foram observadas características clínicas compatíveis com a síndrome lipodistrófica, sobretudo o aspecto central da perda adiposa em extremidades e glúteo, associada ou não a depósitos anormais de gordura (face, pescoço, supraclavicular, tronco e abdome). As demais observações clínicas encontram-se a seguir, assim como as medidas realizadas na avaliação física:

- $\quad$ Sinais de resistência insulínica, como a acantose nigricans.

- Avaliação da pilificação corporal em mulheres, com avaliação da pontuação do escore de Ferriman (60), considerando hirsutismo quando pontuação $\geq 8$. 
- $\quad$ Peso $(\mathrm{kg})$, altura $(\mathrm{m})$ e cálculo do índice de massa corporal (peso em kg dividido pela altura em metros, ao quadrado, $\mathrm{kg} / \mathrm{m}^{2}$ ).

- Circunferência (perímetro) abdominal (medida no ponto médio entre o rebordo costal e a crista ilíaca, em cm).

- Circunferência (perímetro) do quadril (medida na linha transtocanteriana, em $\mathrm{cm})$.

- Relação cintura/quadril (razão entre a medida da cintura e a circunferência do quadril).

- $\quad$ Pressão arterial (aferida no membro superior - braço, em mmHg).

O índice de adiposidade corporal (IAC) foi obtido em porcentagem (\%), com a seguinte fórmula (61):

$$
\text { (circunferência do quadril/ estatura }{ }^{1,5} \text { ) }-18
$$

O estado nutricional, com base no valor do IMC, foi classificado de acordo com as recomendações da Organização Mundial da Saúde (62), conforme apresentado no Quadro 6.

Quadro 6. Classificação do IMC, segundo a Organização Mundial da Saúde (62)

\begin{tabular}{|c|c|}
\hline IMC $\left(\mathbf{k g} / \mathbf{m}^{2}\right)$ & Classificação \\
\hline$<18,5$ & Abaixo do peso \\
\hline 18,5 a 24,9 & Saudável \\
\hline 24,9 a 29,9 & Sobrepeso \\
\hline 30,0 a 34,9 & Obesidade grau I \\
\hline 35,0 a 39,9 & Obesidade grau II \\
\hline$\geq 40$ & Obesidade grau III \\
\hline
\end{tabular}

A circunferência (perímetro) abdominal foi classificada em aumentada (o) de acordo com os valores recomendados pela Federação Internacional de Diabetes (IDF), ou seja, acima de $80 \mathrm{~cm}$ para mulheres e de $90 \mathrm{~cm}$ para homens (63). A relação cintura/quadril (RCQ) foi considerada aumentada de acordo com os critérios recomendados pela Organização Mundial de Saúde (62), ou seja, acima de 0,85 para mulheres e de 0,9 para homens. 
Os critérios adotados para diagnóstico de SM foram os recomendados pela Federação Internacional de Diabetes (63), apresentados no Quadro 7.

Quadro 7 - Critérios diagnósticos para síndrome metabólica (63)

\begin{tabular}{|c|}
\hline Diagnóstico na presença de 3 ou mais critérios \\
\hline 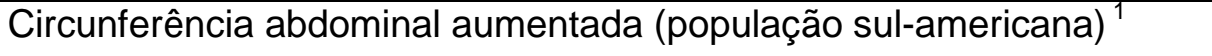 \\
\hline Homens > $90 \mathrm{~cm}$ \\
\hline Mulheres $>80 \mathrm{~cm}$ \\
\hline Triglicerídeos $^{2} \geq 150 \mathrm{mg} / \mathrm{dL}$ \\
\hline HDL-colesterol $^{2}$ \\
\hline Homens $<40 \mathrm{mg} / \mathrm{dL}$ \\
\hline Mulheres $<50 \mathrm{mg} / \mathrm{dL}$ \\
\hline Pressão arterial ${ }^{2} \geq 130 / 85 \mathrm{mmHg}$ \\
\hline Glicemia jejum $\geq 100 \mathrm{mg} / \mathrm{dL}$ ou diagnóstico prévio de diabetes \\
\hline
\end{tabular}

\subsection{AVALIAÇÃO BIOQUÍMICA E HORMONAL BASAL}

Em uma primeira etapa, os pacientes foram submetidos à coleta de amostra de sangue venoso, às 8 horas da manhã, após jejum noturno de 12 horas, para dosagem das variáveis descritas no Quadro 8. Apenas a glicemia pós-prandial não foi avaliada nessas condições. 
Quadro 8 - Variáveis bioquímicas e hormonais determinadas nos sujeitos participantes do estudo

\begin{tabular}{|c|c|c|}
\hline Variável & Método & Valor de referência \\
\hline Glicose em jejum & Enzimático & 70 a 99 mg/dL \\
\hline Glicose $2 \mathrm{~h}$ pós $75 \mathrm{~g}$ de dextrosol via oral ${ }^{1}$ & Enzimático & $<140 \mathrm{mg} / \mathrm{dL}$ \\
\hline Glicose pós-prandial $^{2}$ & Enzimático & $<140 \mathrm{mg} / \mathrm{dL}$ \\
\hline Hemoglobina glicada (HbA1c) & HPLC & $<6,5 \%{ }^{3}$ \\
\hline Insulinemia em jejum ${ }^{4}$ & Quimioluminescência & $\leq 29 \mu \mathrm{U} / \mathrm{mL}$ \\
\hline Colesterol total & Vitalab Selectra & $<200 \mathrm{mg} / \mathrm{dL}$ \\
\hline Colesterol LDL & Vitalab Selectra & $<130 \mathrm{mg} / \mathrm{dL}$ \\
\hline Colesterol HDL & Vitalab Selectra & $\begin{array}{l}>45 \mathrm{mg} / \mathrm{dL}(\mathrm{H}) \\
>50 \mathrm{mg} / \mathrm{dL}(\mathrm{M})\end{array}$ \\
\hline Triglicerídeos & Vitalab Selectra & $<150 \mathrm{mg} / \mathrm{dL}$ \\
\hline Aspartato aminotransferase (AST) & $\begin{array}{l}\text { Automatizado } \\
\text { Architect }\end{array}$ & 5-34 U/L \\
\hline Aspartato alaninotransferae (ALT) & $\begin{array}{l}\text { Automatizado } \\
\text { Architect }\end{array}$ & $\leq 55 \mathrm{U} / \mathrm{L}$ \\
\hline Gamaglutamiltransferase (GGT) & $\begin{array}{l}\text { Automatizado } \\
\text { Architect }\end{array}$ & 9-36 U/L \\
\hline Ácido úrico & Selectra/Architect & $\begin{array}{l}3,5-7,2 \mathrm{mg} / \mathrm{dL}(\mathrm{H}) \\
2,6-6,0 \mathrm{mg} / \mathrm{dL}(\mathrm{M})\end{array}$ \\
\hline Leptina & Radioimunoensaio & $\begin{array}{l}<7,4 \mathrm{ng} / \mathrm{mL}(\mathrm{H}) \\
<14,7 \mathrm{ng} / \mathrm{mL}(\mathrm{M})\end{array}$ \\
\hline $\begin{array}{l}\text { Proteína C reativa ultrassensível } \\
\text { TSH }\end{array}$ & $\begin{array}{l}\text { Nefelometria } \\
\text { Quimioluminescência }\end{array}$ & $\begin{array}{c}<1 \mathrm{mg} / \mathrm{dL} \\
0,3-4,9 \mu \mathrm{lU} / \mathrm{mL}\end{array}$ \\
\hline T4 livre & Quimioluminescência & $0,7-1,48 \mathrm{ng} / \mathrm{dL}$ \\
\hline T3 livre & Quimioluminescência & $1,7-3,7 \mathrm{pg} / \mathrm{mL}$ \\
\hline Cálcio & Selectra/Architect & $8,4-10,2 \mathrm{mg} / \mathrm{dL}$ \\
\hline Fóforo & Selectra/Architect & $2,3-4,7 \mathrm{mg} / \mathrm{dL}$ \\
\hline Paratormônio (PTH) & Quimioluminescência & $15-68 \mathrm{pg} / \mathrm{mL}$ \\
\hline 25-hidroxivitamina D & Quimioluminescência & $\geq 30 \mathrm{ng} / \mathrm{mL}$ \\
\hline $\begin{array}{l}\text { Fator de crescimento semelhante à insulina } \\
\text { (IGF-1) }\end{array}$ & Quimioluminescência & Conforme faixa etária \\
\hline Prolactina & Quimioluminescência & $\begin{array}{l}3,3-19,4 \mathrm{ng} / \mathrm{mL}(\mathrm{H}) \\
5,1-26,5 \mathrm{ng} / \mathrm{mL}(\mathrm{M})\end{array}$ \\
\hline Testosterona total & Quimioluminescência & $\begin{array}{c}142-923(\mathrm{H}) \\
10,8-56,9(\mathrm{M})\end{array}$ \\
\hline $\begin{array}{l}\text { Globulina ligadora de esteroides sexuais } \\
\text { (SHBG) }\end{array}$ & Quimioluminescência & $11,7-137 \mathrm{nmol} / \mathrm{L}$ \\
\hline Hormônio foliculoestimulante (FSH) & Quimioluminescência & $\begin{array}{l}0,9-11,9 \mathrm{mUl} / \mathrm{mL}(\mathrm{H}) \\
3,0-8,0(\mathrm{M})^{5}\end{array}$ \\
\hline Hormônio luteinizante (LH) & Quimioluminescência & $\begin{array}{l}0,5-12,0 \mathrm{mUl} / \mathrm{mL}(\mathrm{H}) \\
1,8-11,7(\mathrm{M})^{5}\end{array}$ \\
\hline
\end{tabular}

Avaliada somente em pacientes sem diagnóstico prévio de diabetes mellitus e com glicemia de jejum $<126 \mathrm{mg} / \mathrm{dL}$.

${ }^{2}$ Avaliada somente em pacientes com diagnóstico prévio de diabetes mellitus.

${ }^{3}$ Valores entre 5,7 e $6,4 \%$ representam pré-diabetes.

${ }_{5}^{4}$ Avaliada na ausência de uso de insulina.

${ }^{5}$ Fase folicular do ciclo.

$\mathrm{H}$ : homens; M: mulheres

A partir dos resultados da glicemia em jejum e da insulinemia em jejum, foi calculado o HOMA-IR (homeostatic model assessement, insulin resistance), com a 
utilização da seguinte fórmula (64):

$$
\begin{aligned}
& \text { HOMA-IR = glicemia }(e m \mathrm{mmol} / \mathrm{L}) \times \text { insulinemia }(\mathrm{mUl} / \mathrm{mL}) \\
& 22,5
\end{aligned}
$$

A evidência de resistência insulínica foi considerada se HOMA-IR > 2,7.

Nas mulheres com irregularidade menstrual, com 0 intuito de investigar a presença da SOP, foi realizada a determinação da concentração circulante de outros androgênios, apresentados no Quadro 9.

Quadro 9 - Androgênios séricos avaliados para investigação da síndrome dos ovários policísticos $^{1}$

\begin{tabular}{|l|c|c|}
\hline \multicolumn{1}{|c|}{ Variável $^{2}$} & Método & Valor de referência \\
\hline Deidroepiandrosterona (DHEA) & Radioimunoensaio & $0,8-10,5 \mathrm{ng} / \mathrm{mL}$ \\
17-hidroxiprogesterona & Radioimunoensaio & $\begin{array}{c}\text { Folicular: } 11-108 \mathrm{ng} / \mathrm{dL} \\
\text { Luteal: } 95-500 \mathrm{ng} / \mathrm{dL}\end{array}$ \\
Sulfato de Deidroepiandrosterona (SDHEA) & Quimioluminescência & $\begin{array}{c}\text { Conforme faixa etária } \\
\text { Androstenediona }\end{array}$ \\
\hline
\end{tabular}

${ }^{1}$ Além da dosagem da testosterona total.

${ }^{2}$ Avaliação realizada na ausência de uso de contraceptivos hormonais orais.

A presença da SOP foi investigada de acordo com os critérios recomendados no Consenso Internacional de Rotterdam (65), apresentado no Quadro 10.

Quadro 10 - Critérios do Consenso Internacional de Rotterdam para diagnóstico da síndrome dos ovários policísticos

\section{Diagnóstico na presença de 2 dos 3 critérios:}

1. Oligomenorreia e/ou anovulação

2. Sinais clínicos e/ou bioquímicos de hiperandrogenismo ${ }^{1}$

3. Ovários policísticos caracterizados por exame ultrassonográfico ${ }^{2}$

${ }^{1}$ excluindo outras etiologias de hiperandrogenismo

${ }^{2}$ presença de pelo menos um dos seguintes achados: 12 ou mais folículos medindo entre 2-9 mm de diâmetro ou volume ovariano aumentado $\left(>10 \mathrm{~cm}^{3}\right)$

\subsection{AVALIAÇÃO DO EIXO HIPOTÁLAMO-HIPÓFISE-ADRENAL}

O eixo HHA foi avaliado com as dosagens basais apresentadas no Quadro 11 e também por meio de testes dinâmicos. 
Quadro 11 - Avaliação basal do eixo hipotálamo-hipófise-adrenal

\begin{tabular}{|c|c|c|}
\hline Variável & Método & Valor de referência \\
\hline Hormônio adrenocorticotrófico (ACTH) & Eletroquimioluminescência & $7,2-63,3 \mathrm{pg} / \mathrm{mL}$ \\
Cortisol às 8h & Quimioluminescência & $3,7-19,4 \mu \mathrm{g} / \mathrm{dL}$ \\
Cortisol livre urinário de 24 $\mathrm{h}$ (3 amostras) & Quimioluminescência & $4,3-176 \mu \mathrm{g}$ \\
Cortisol salivar às 23h & Eletroquimioluminescência & $<9,7 \mathrm{nmol} / \mathrm{L}$ \\
Globulina ligadora de cortisol (CBG) & Radioimunoensaio & $25-55 \mathrm{mcg} / \mathrm{L}(\mathrm{H})$ \\
& & $40-154 \mathrm{mcg} / \mathrm{L}(\mathrm{M})$ \\
\hline
\end{tabular}

Em uma segunda etapa, após intervalo de até 15 dias da realização das dosagens hormonais basais, procedeu-se a avaliação da supressibilidade do eixo HHA, por meio dos testes de supressão com baixas doses de dexametasona. Foi realizada supressão com $0,5 \mathrm{mg}$ de dexametasona e, após 7 dias, teste de supressão com $1 \mathrm{mg}$ de dexametasona, ambos administrados às 23 horas da noite e coleta da amostra de sangue venoso para dosagem sérica de cortisol às 8 horas da manhã do dia seguinte. Foi considerada ausência de supressão do cortisol em resposta à dexametasona a presença de cortisol sérico maior que 1,8 $\mu \mathrm{g} / \mathrm{dL}$. Os pacientes que não apresentassem supressão em resposta à administração de $1 \mathrm{mg}$ de dexametasona, seriam submetidos ao teste de supressão com $2 \mathrm{mg}$ de dexametasona. Este teste consiste na administração de 1 comprimido de 0,5 mg de dexametasona a cada 6 horas, durante 2 dias, com coleta de amostra de sangue venoso para dosagem sérica de cortisol às 8 horas da manhã do dia seguinte (terceiro dia), conforme recomendação da Sociedade Endócrina Norte-Americana para avaliação de prováveis casos de estados "pseudocushing" (45).

\subsection{AVALIAÇÃO DA COMPOSIÇÃO CORPORAL}

O estudo da composição corporal foi realizado pelo método de absorciometria de raio $X$ de dupla energia (DEXA, dual-energy $X$-ray absorptiometry), com o densitômetro GE Lunar iDXA System (Encore 2011). Essa avaliação permitiu a determinação das seguintes variáveis:

- gordura corporal total (\%).

- gordura troncular (\%).

- gordura nos membros inferiores (\%).

- gordura dos membros superiores (\%).

- taxa da massa de gordura androide/ginoide (T A/G), correspondendo à divisão da massa androide pela massa ginecoide. 
A taxa de massa adiposa (fat mass ratio - $F M R$ ) foi calculada com a fórmula: $\mathrm{FMR}=[$ gordura no tronco (\%)] / [de gordura nos membros inferiores (\%)] (66).

\subsection{AVALIAÇÃO ULTRASSONOGRÁFICA E CARDIOVASCULAR}

Todos os pacientes foram avaliados quanto à presença de esteatose hepática com a realização de ultrassonografia do abdome superior (aparelho Philips HD.XE, transdutor $3,5 \mathrm{MHz}$ ). As mulheres também foram submetidas à avaliação complementar de SOP com ultrassom pélvico, com o uso do mesmo equipamento.

Os pacientes foram submetidos à avaliação cardiovascular, com ecodopplercardiograma e teste ergométrico. Neste último exame, foram avaliados critérios clínicos e eletrocardiográficos de insuficiência coronariana (avaliados nas condições de repouso, durante o esforço e durante a recuperação).

\subsection{ANÁLISE DOS RESULTADOS}

Os dados clínicos, antropométricos e os resultados dos exames realizados foram organizados em tabelas, de forma a descrever o perfil dos pacientes com LPF. Os resultados foram apresentados de forma descritiva, devido ao pequeno número amostral.

As variáveis clínicas (idade), antropométricas (CA, IMC e RCQ) e relacionadas à composição corporal por DEXA (\%gordura total, \%gordura troncular, FMR e taxa $A / G$ ), foram correlacionadas com variáveis metabólicas e hormonais, aplicando-se o coeficiente de correlação de Spearman, com a utilização do programa GraphPad Prism, versão 5.0. Foram considerados significativos resultados de valor $p<0,05$. Valores de $r$ positivos abaixo de 0,5 foram considerados sugestivos de correlação positiva fraca, valores entre 0,5 e 0,8 , de correlação positiva moderada, e superiores a 0,8 , de correlação positiva forte. $O$ mesmo padrão foi considerado para correlações negativas $(r<-0,8$, correlação negativa forte; $r$ entre $-0,8$ e - $-0,5$, correlação negativa moderada; $r>-0,5$, correlação negativa fraca). 


\section{RESULTADOS}

Foram incluídos seis pacientes com achados clínicos centrais sugestivos da síndrome de LPF (P1 a P6). Serão apresentadas, inicialmente, as características clínicas, bioquímicas e hormonais dos pacientes incluídos e, em seguida, os resultados das correlações verificadas entre algumas dessas variáveis.

\subsection{CARACTERÍSTICAS CLÍNICAS DOS PORTADORES DE LIPODISTROFIA PARCIAL FAMILIAR ESTUDADOS}

Cinco pacientes analisados eram do sexo feminino e um paciente do sexo masculino (P2). A faixa de idade variou de 17 a 42 anos (Tabela 1). Os pacientes pertenciam a quatro famílias não relacionadas, com graus de parentesco entre os pacientes 1 e 2 (tia e sobrinho) e 5 e 6 (mãe e filha).

Todos os pacientes apresentaram a característica central da lipodistrofia parcial familiar, representada pela perda de tecido adiposo nos membros e/ou região glútea. Contudo, os fenótipos de perda foram variados e a perda foi atípica (sutil) nos três pacientes mais jovens (P2, P4 e P6). Os aspectos de pseudohipertrofia muscular e flebomegalia foram mais aparentes nas pacientes $\mathrm{P} 1, \mathrm{P} 3$ e P5, que apresentaram o fenótipo típico da perda adiposa periférica da LPF (Figuras 4, 5 e 6). A redistribuição da gordura corporal, com aumento do depósito adiposo nas regiões de face e pescoço, foi um achado comum no exame físico dos pacientes. Com exceção da paciente $\mathrm{P} 1$, o acúmulo de gordura também foi observado nas regiões troncular e abdominal, com intensidades variáveis. 


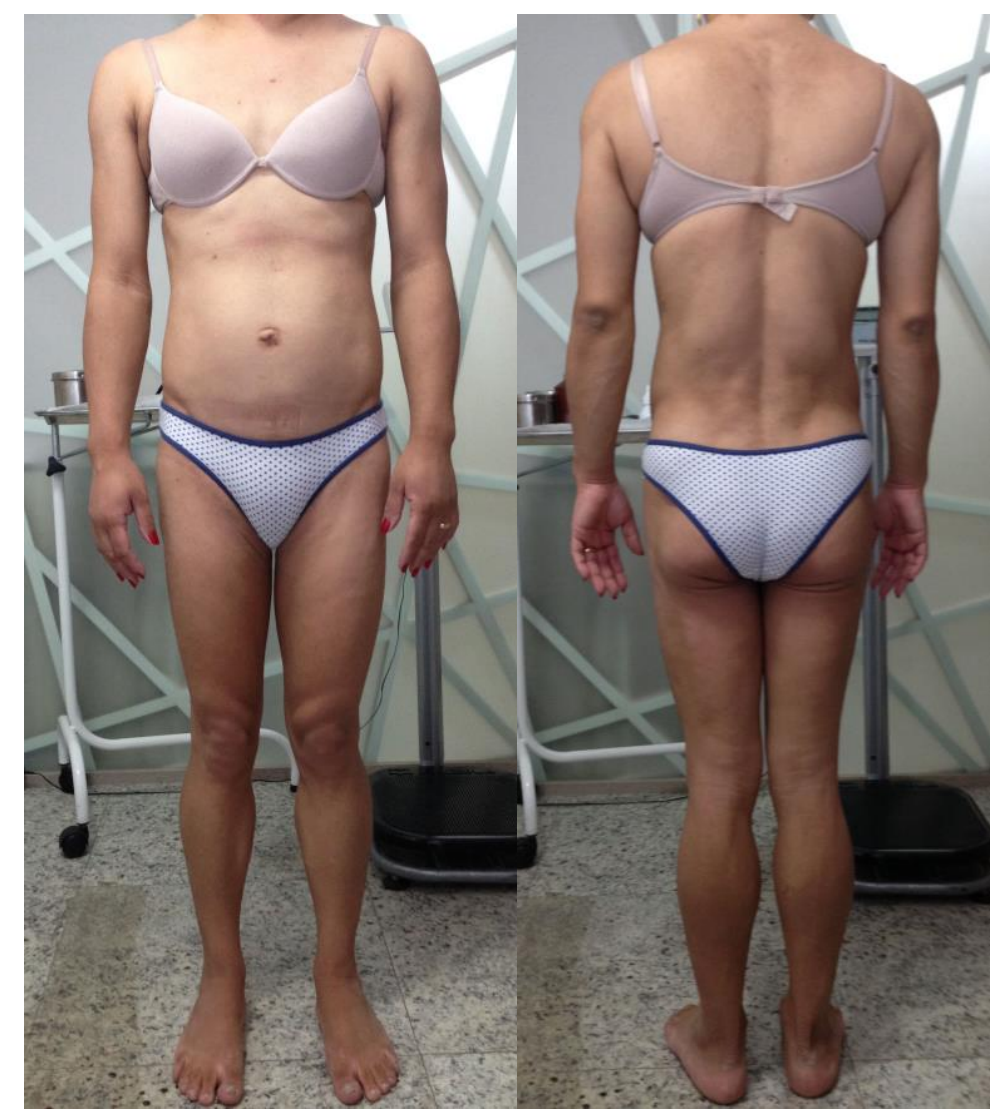

Figura 3. Fotografias da paciente $\mathrm{P} 1$, com fenótipo típico da lipodistrofia (perda de gordura em regiões de membros e glúteo), evidenciando o aspecto de pseudohipertrofia muscular e flebomegalia.

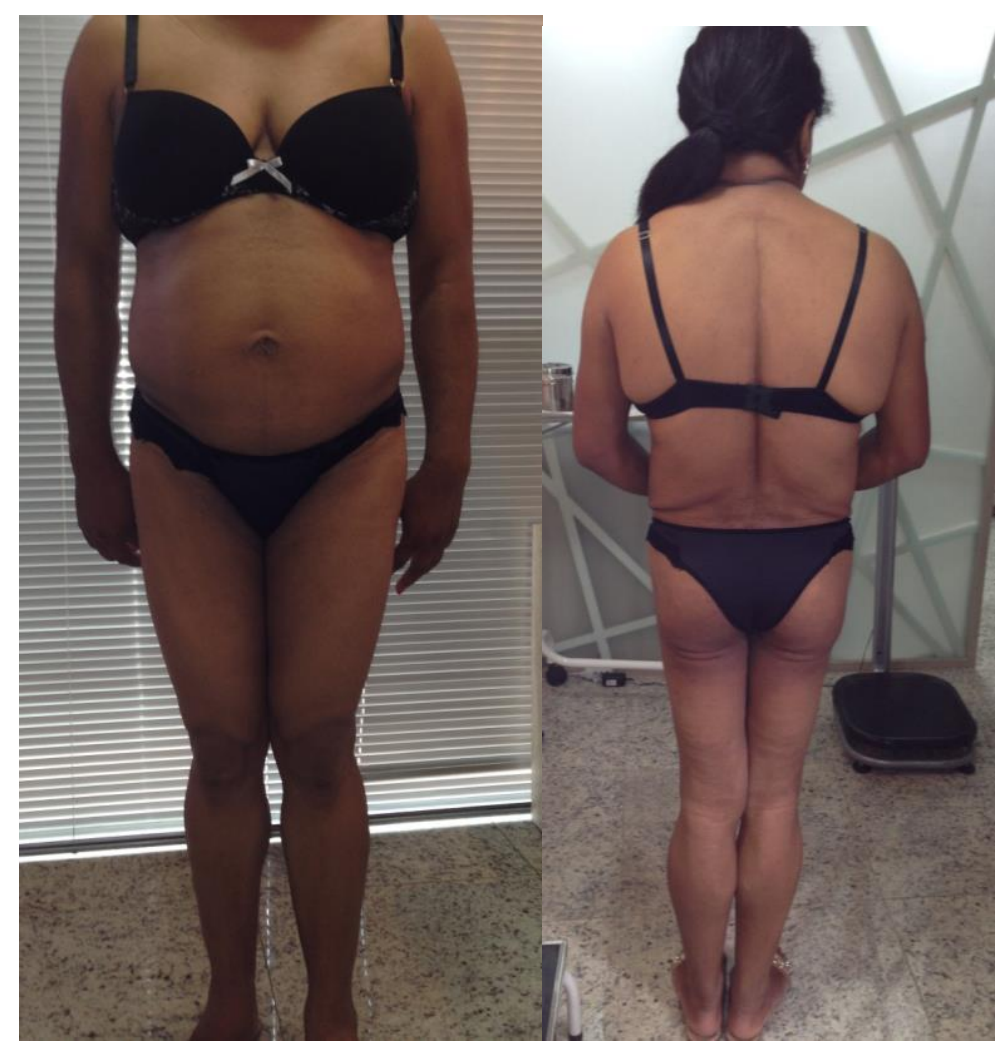

Figura 4. Fotografias da paciente $\mathrm{P} 3$, também com fenótipo típico de perda adiposa periférica da lipodistrofia parcial familiar. Nota-se o acúmulo adiposo dorsocervical, troncular e abdominal. 


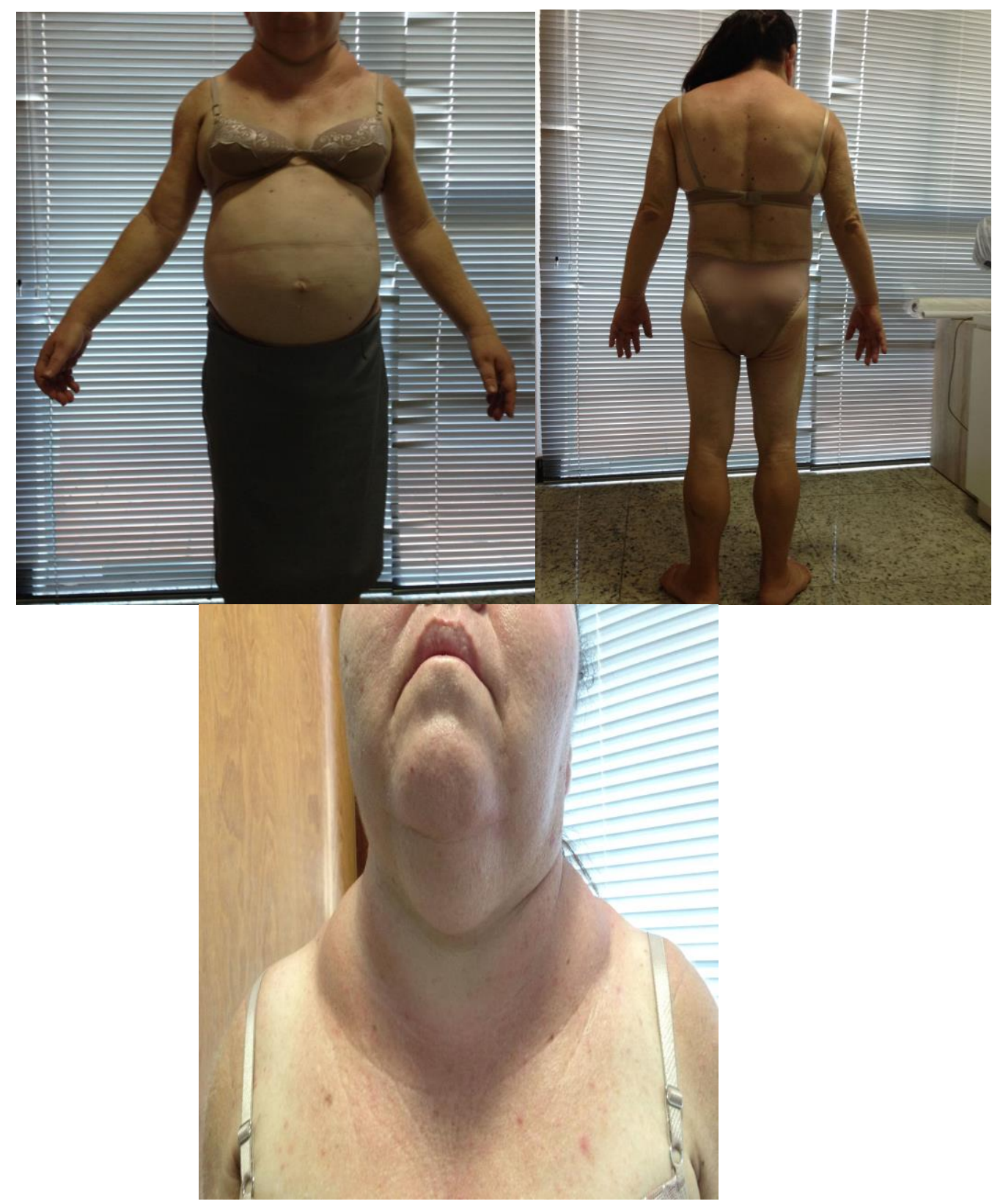

Figura 5. Fotografias da paciente P5, com apresentação fenotípica lipodistrófica. Os locais de acúmulo anormais de gordura são evidentes (face, pescoço, supraclavicular, tronco e abdome), com aspecto cushingoide.

Acantose nigricans foi evidente em todos os pacientes, sobretudo nas regiões cervical e axilar (Figura 7). Entre os sinais físicos de hiperandrogenemia nas mulheres, hirsutismo foi o mais frequentemente observado. 


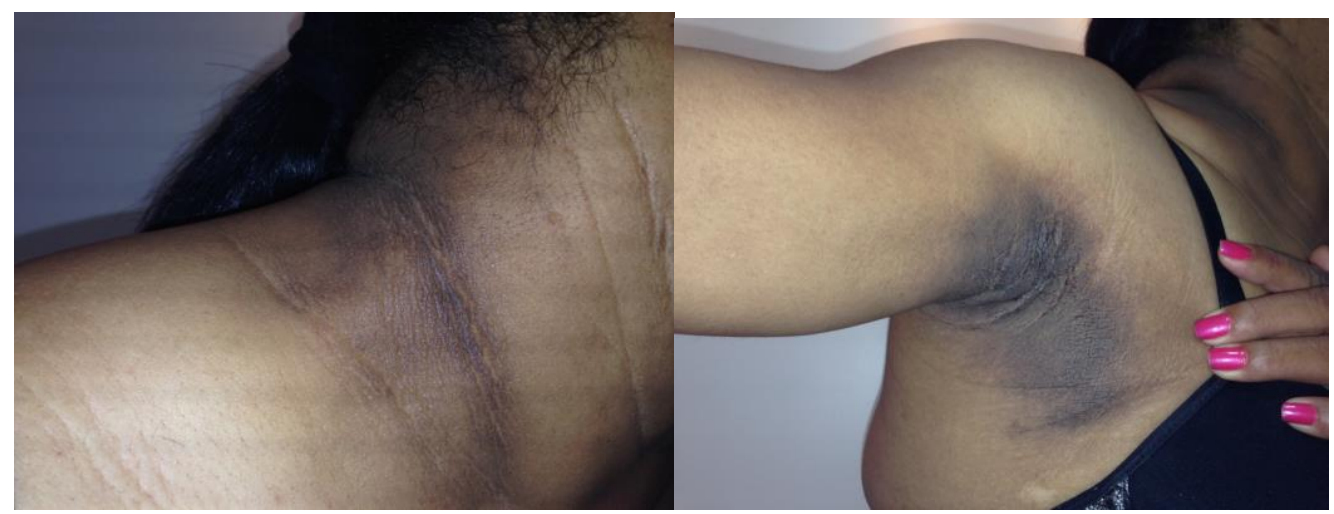

A

B

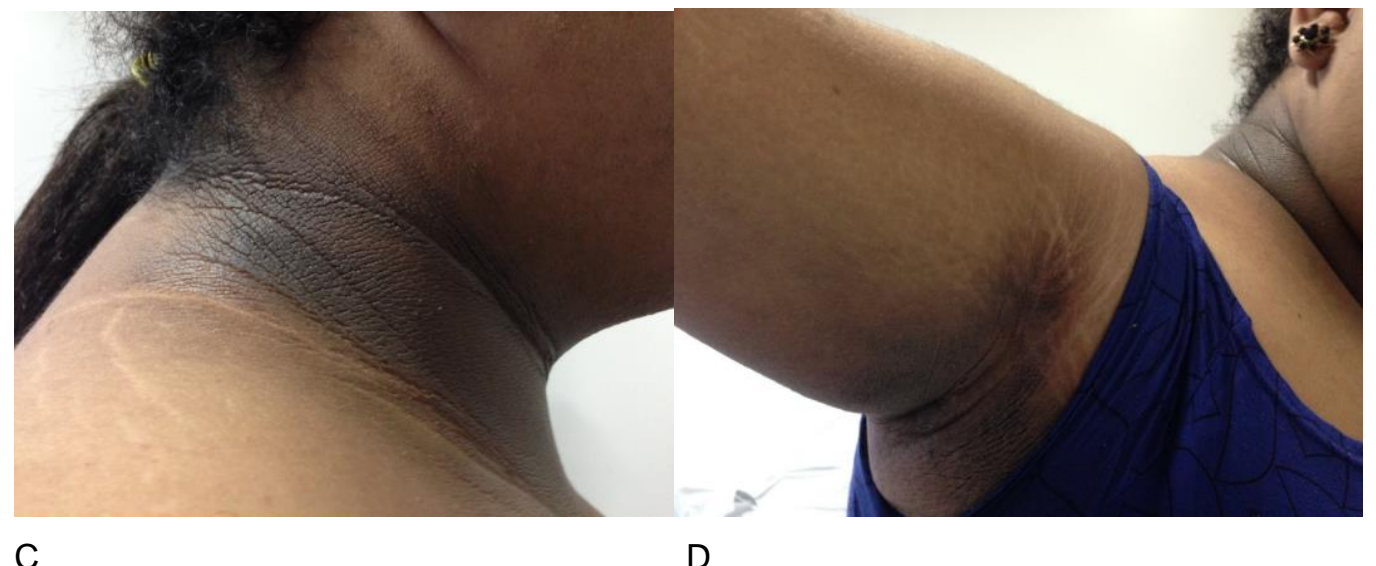

C

Figura 6. Fotografias das pacientes P3 (A, B) e P4 (C, D), mostrando acantose nigricans acentuada em regiões cervical e axilar.

A distribuição anormal do tecido adiposo não se destacou como manifestação clínica inicial descrita pelos pacientes. Esse aspecto foi mencionado apenas quando os pacientes foram questionados sobre a percepção de alterações na gordura corporal, e a idade em que isso ocorreu variou entre 8 a 25 anos, correspondendo ao período puberal na paciente $\mathrm{P} 1$. Em três mulheres, o motivo inicial de busca de atendimento no serviço de Endocrinologia foi relacionado a características da síndrome dos ovários policísticos (como hirsutismo e irregularidade menstrual). Uma das mulheres (P5) foi encaminhada ao serviço de Endocrinologia após diagnóstico de doença arterial coronariana precoce (infarto agudo do miocárdio aos 36 anos), para investigação de síndrome de Cushing. Os outros dois pacientes (P2 e P6) eram familiares de duas pacientes em acompanhamento e foram convidados para avaliação no serviço de Endocrinologia em razão da semelhança do fenótipo. 
Tabela 1 - Características clínicas dos seis pacientes com diagnóstico clínico sugestivo de lipodistrofia parcial familiar

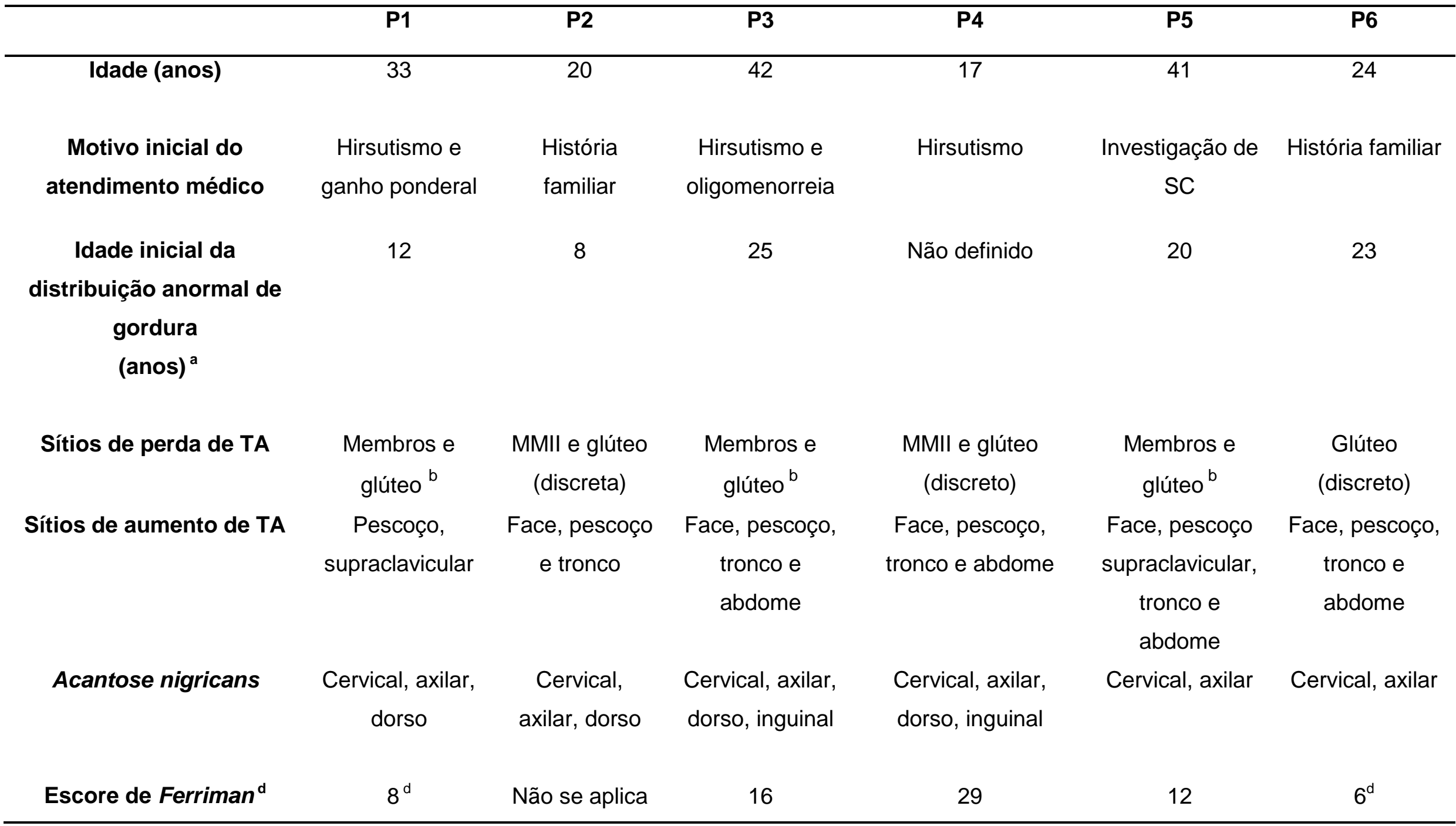


Tabela 1 - Características clínicas dos seis pacientes com diagnóstico clínico sugestivo de lipodistrofia parcial familiar (continuação)

\section{P1}

P2

P3

P4

P5

P6

\begin{tabular}{|c|c|c|c|c|c|c|}
\hline $\begin{array}{c}\text { Outras } \\
\text { (incluindo diagnósticos } \\
\text { prévios) }\end{array}$ & 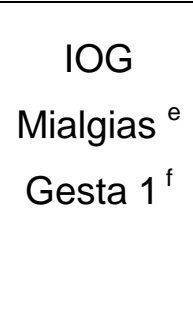 & Humor deprimido & $\begin{array}{c}\text { DM2 (36 a) } \\
\text { HAS / DLP } \\
\text { Sem mutação LMNA } \\
\text { g }\end{array}$ & Déficit cognitivo $^{h}$ & $\begin{array}{c}\text { DM2 (34 a) } \\
\text { HAS/ DLP } \\
\text { IAM (36 a) } \\
\text { Gesta } 1^{\dagger} \\
\text { Sem mutação LMNA }\end{array}$ & - \\
\hline Número de achados clínicc & & & & & & \\
\hline $\operatorname{LPF}^{\mathrm{i}}$ & 7 & 4 & 6 & 4 & 7 & 5 \\
\hline
\end{tabular}

${ }^{a}$ Percepção própria do paciente quando questionado sobre o fato.

${ }^{\mathrm{b}}$ Pacientes que apresentaram aspecto de pseudohipertrofia muscular e flebomegalia.

${ }^{c}$ Avaliação do hirsutismo ao exame físico.

Avaliação prejudicada devido processo depilatório dos pelos.

e Eletroneuromiografia sem alterações.

† antecedente de uma gestação prévia, sem intercorrências.

${ }^{9}$ estudo genético para rastreamento LPF 2 realizado na Escola Paulista de Medicina em 2010.

${ }^{\mathrm{h}}$ Sequela meningite diagnosticada aos 22 dias de vida.

'considerando todas as avaliações do estudo, baseando nas recomendações do consenso da AACE (7).

SC: síndrome de cushing; MMII: membros inferiores; IOG: intolerância à glicose; DM 2: Diabetes mellitus tipo 2; HAS: hipertensão arterial sistêmica; DLP: dislipidemia; IAM: infarto agudo do miocárdio. 
Três pacientes (P2, P4 e P6) apresentaram IMC compatível com obesidade $\left(\right.$ IMC $\left.\geq 30 \mathrm{~kg} / \mathrm{m}^{2}\right)$. Foi observada obesidade abdominal avaliada pelo aumento da circunferência abdominal, com exceção da paciente $\mathrm{P} 1$. A relação cintura/quadril foi elevada em todos os indivíduos estudados (Tabela 2).

Tabela 2 - Características antropométricas dos seis pacientes com diagnóstico clínico sugestivo de lipodistrofia parcial familiar

\begin{tabular}{ccccccc}
\hline Variável & P1 & P2 & P3 & P4 & P5 & P6 \\
\hline Peso $(\mathrm{kg})$ & 60,3 & 100,7 & 71 & 111,6 & 62 & 98,3 \\
Altura $(\mathrm{m})$ & 1,63 & 1,78 & 1,6 & 1,68 & 1,49 & 1,53 \\
IMC $\left(\mathrm{kg} / \mathrm{m}^{2}\right)$ & 22,5 & 31,7 & 27,7 & 39,5 & 27,9 & 41,9 \\
CA $(\mathrm{cm})$ & 78 & 96 & 93 & 122 & 92 & 110 \\
CQ $(\mathrm{cm})$ & 84,5 & 104 & 91 & 114,5 & 92 & 107,5 \\
RCQ & 0,92 & 0,92 & 1,02 & 1,07 & 1,0 & 1,02 \\
IAC $(\%)$ & 22,6 & 25,8 & 27,0 & 34,6 & 32,4 & 39,4
\end{tabular}

IMC: índice de massa corporal; CA: circunferência abdominal; CQ: circunferência do quadril; RCQ: relação cintura/quadril; IAC: índice de adiposidade corporal.

\subsection{CARACTERÍSTICAS BIOQUÍMICAS DOS PORTADORES DE LIPODISTROFIA PARCIAL FAMILIAR ESTUDADOS}

A avaliação bioquímica, apresentada na Tabela 3, evidenciou componentes da síndrome metabólica, além de confirmar a presença de resistência insulínica, que demontrou ser acentuada em quatro pacientes, dos quais três não tinham a classificação de obesidade pelo IMC. O diagnóstico da SM conforme as recomendações Federação Internacional de Diabetes (63) somente não ocorreu nas pacientes P1 (por não pontuar o critério obrigatório da circunferência abdominal aumentada) e P6 (por apresentar dois critérios). 
Tabela 3 - Características bioquímicas dos seis pacientes com diagnóstico clínico sugestivo de lipodistrofia parcial familiar

\begin{tabular}{ccccccc}
\hline Variável & P1 & P2 & P3 & P4 & P5 & P6 \\
\hline GJ (mg/dL) & 78 & 72 & 95 & 107 & 142 & 89 \\
GPP ou & 199 & 67 & 194 & 105 & 158 & 135 \\
G pós 75g (mg/dL) & & & & & & \\
Insulina (mcUl/mL) & 132,9 & 19,4 & 34,3 & 190,6 & 159,3 & 25,4 \\
HOMA-IR & 25,57 & 3,45 & 16,5 & 47,67 & 55,81 & 5,64 \\
A1c (\%) & 5,8 & 5,8 & 8,9 & 5,8 & 7,6 & 5,5 \\
PCRUS (mg/dL) & 0,6 & 0,3 & 2,57 & 9,1 & 0,3 & 1,08 \\
AST (U/L) & 19 & 13 & $79 / 30^{c}$ & 99 & 27 & NA \\
ALT (U/L) & 22 & 21 & $66 / 47^{\mathrm{c}}$ & 96 & 33 & 18 \\
GGT (U/L) & 60 & 52 & $151 / 63^{\mathrm{c}}$ & 77 & 28 & 37 \\
Ácido úrico (mg/dL) & 6,3 & 7,1 & 7,0 & 5,4 & 3,8 & 9,5 \\
CT (mg/dL) & 239 & 153 & 117 & 204 & 178 & 235 \\
HDL (mg/dL) & 26 & 30 & 21 & 45 & 22 & 55 \\
LDL (mg/dL) & NA & 90 & NA & 107 & 99 & 150 \\
TG (mg/dL) & 582 & 163 & $500^{d}$ & 258 & $287^{\mathrm{e}}$ & 152 \\
\hline
\end{tabular}

${ }^{a}$ em uso dos hipoglicemiantes orais gliclazida e metformina nos pacientes P3 e P5.

${ }^{\mathrm{b}} \mathrm{GPP}$ nos diabéticos (P3 e P5) e G pós $75 \mathrm{~g}$ nos não diabéticos (P1,P2,P4,P6).

${ }^{c}$ avaliado em duas ocasiões.

${ }^{d}$ Em uso fibrato.

${ }^{\mathrm{e}}$ Em uso de estatina, fibrato, ezetimiba e ômega-3.

NA: não avaliado; GJ: glicemia de jejum; GPP: glicemia pós-prandial; G pós $75 \mathrm{~g}$ : glicemia pós $75 \mathrm{~g}$ de dextrosol por via oral; HOMA-IR: homeostatic model assessement of insulin resistance; A1c: hemoglobina glicada; PCRUS: proteína $C$ reativa ultrassensível; AST: aspartato aminotransferase; ALT: aspartato alaninotransferase; CGT: gamaglutamiltransferase; $\mathrm{CT}$ : colesterol total; $\mathrm{HDL}$ : lipoproteína de alta densidade; LDL: lipoproteína de baixa densidade; TG: triglicerídeos.

\subsection{CARACTERÍSTICAS HORMONAIS DOS PORTADORES DE LIPODISTROFIA} PARCIAL FAMILIAR ESTUDADOS

A Tabela 4 apresenta os resultados das concentrações séricas basais de leptina, prolactina e de hormônios e outros elementos relacionados ao eixo tireotrófico, eixo somatotrófico, eixo reprodutivo e metabolismo mineral.

As concentrações séricas de leptina foram variáveis e valores baixos foram evidenciados em três pacientes (P1, P2 e P3), ao passo que duas pacientes apresentaram valores elevados de leptinemia (P4 e P6). Não foram detectadas alterações hormonais relacionadas ao eixo tireotrófico. Cinco pacientes 
apresentaram concentração sérica de vitamina $D$ abaixo de $30 \mathrm{ng} / \mathrm{mL}$, dos quais dois apresentaram deficiência (abaixo de $20 \mathrm{ng} / \mathrm{mL}$ ). Entretanto, nenhum deles apresentou alteração da calcemia ou da concentração sérica de paratormônio. Dois pacientes (P3 e P5) apresentaram IGF-1 inferior ao limite inferior da faixa de referência para sua faixa etária. A paciente P5, posteriormente, apresentou concentração sérica normal de IGF-1, quando realizada essa dosagem em outra ocasião.

Foi observada hiperandrogenemia laboratorial em quatro das cinco pacientes do sexo feminino estudadas, caracterizada por concentrações séricas aumentadas de testosterona total e, em duas pacientes, também pelo aumento de androstenediona. O paciente do sexo masculino apresentou concentrações circulantes de testosterona no limite superior da faixa de normalidade. O rastreamento de hiperplasia adrenal congênita neste paciente, pela determinação da concentração plasmática de 17-hidroxiprogesterona, foi negativo. 
Tabela 4 - Características hormonais dos seis pacientes com diagnóstico clínico sugestivo de lipodistrofia parcial familiar

\begin{tabular}{|c|c|c|c|c|c|c|}
\hline Variável & P1 & P2 & P3 & P4 & P5 & P6 \\
\hline Leptina $(\mathrm{ng} / \mathrm{mL})$ & 4,1 & 2,8 & 3,7 & 55,5 & 17,7 & 76,6 \\
\hline $\mathrm{TSH}(\mathrm{mcUl} / \mathrm{mL})$ & 1,38 & 0,75 & 1,89 & 1,5 & 1,12 & 3,8 \\
\hline T4L (ng/dL) & 0,96 & 0,83 & 0,99 & 1,04 & 1,09 & 0,97 \\
\hline T3L $(p g / m L)$ & 3,03 & 2,54 & 2,62 & 3,2 & 2,39 & NA \\
\hline Cálcio (mg/dL) & 9,9 & 9,8 & 8,9 & 9,6 & 10,0 & 9,6 \\
\hline Fósforo (mg/dL) & 3,1 & 3,3 & 4,6 & 3,8 & 2,6 & 3,0 \\
\hline Paratormônio (pg/mL) & 45,3 & 24,0 & 17,0 & 27,4 & 17,0 & 50 \\
\hline 25-hidroxivitamina $\mathrm{D}(\mathrm{ng} / \mathrm{mL})$ & 17,6 & 26,5 & 22,3 & 16,0 & 21,9 & 49,3 \\
\hline IGF-1 (ng/mL) & $\begin{array}{c}173 \\
(115-307)^{a}\end{array}$ & $\begin{array}{c}259 \\
(127-424)^{a}\end{array}$ & $\begin{array}{c}88 \\
(101-267)^{a}\end{array}$ & $\begin{array}{c}137 \\
(193-731)^{a}\end{array}$ & $\begin{array}{c}83 / 124 \\
(101-267)^{a}\end{array}$ & $\begin{array}{c}253 \\
(116-358)^{a}\end{array}$ \\
\hline Androstenediona $(\mathrm{ng} / \mathrm{mL})$ & 8,5 & 3,2 & 2,7 & 8,8 & 0,7 & 2,5 \\
\hline Deidroepiandrosterona $(\mathrm{ng} / \mathrm{mL})$ & 1,7 & 4,1 & 1,6 & 2,0 & 1,3 & 3,7 \\
\hline SDHEA (mcg/dL) & $\begin{array}{c}60 \\
(23-266)^{a}\end{array}$ & $\begin{array}{c}293 \\
(24-537)^{a}\end{array}$ & $\begin{array}{c}72 \\
(19-231)^{a}\end{array}$ & $\begin{array}{c}127,5 \\
(61-493)^{a}\end{array}$ & $\begin{array}{c}84 \\
(19-231)^{a}\end{array}$ & $\begin{array}{c}245 \\
(148-407)^{a}\end{array}$ \\
\hline 17-hidroxiprogesterona (ng/dL) & 147 & 150 & 84 & 150 & 140 & 100 \\
\hline SHBG (nmol/L) & 42,2 & 35,4 & 32,9 & 33,6 & 41,5 & NA \\
\hline Testosterona total (ng/dL) & $127 / 92^{b}$ & $943 / 900^{\mathrm{D}}$ & $97 / 74^{\mathrm{D}}$ & 345,9 & 73,1 & 23,4 \\
\hline $\mathrm{LH}(\mathrm{mcUl} / \mathrm{mL})$ & 15,49 & 4,44 & 5,85 & 6,4 & 5,65 & 5,57 \\
\hline $\mathrm{FSH}(\mathrm{mcUl} / \mathrm{mL})$ & 4,64 & 2,21 & 4,83 & 4,09 & 2,96 & 4,37 \\
\hline Prolactina $(\mathrm{ng} / \mathrm{mL})$ & 6,84 & 8,46 & 10,12 & 5,9 & 5,75 & 12,9 \\
\hline
\end{tabular}

faixa de referência para a idade.

${ }^{b}$ avaliada em duas ocasiões.

TSH: tireotrofina; IGF-1: fator de crescimento 1 semelhante à insulina; SDHEA: sulfato de Deidroepiandrosterona; SHBG: globulina ligadora de esteroides sexuais; LH: hormônio luteinizante; FSH: hormônio foliculoestimulante, NA: não avaliado 


\subsection{AVALIAÇÃO DE OUTRAS COMORBIDADES METABÓLICAS E DOENÇA CARDIOVASCULAR}

A avaliação ultrassonográfica do abdome superior identificou esteatose hepática em todos os seis pacientes avaliados, de grau acentuado em três pacientes (P3, P4 e P5).

O critério ultrassonográfico de SOP (64) foi observado nas cinco mulheres do estudo.

A avaliação cardiovascular, com os exames de ecodopplercardiograma e teste ergométrico, não revelou anormalidades nos cinco pacientes sem antecedentes de coronariopatia. A paciente P5, com o histórico de angioplastia prévia após episódio de IAM (aos 36 anos), também não apresentou anormalidades nesses dois exames realizados, como controle do tratamento realizado.

As comorbidades clínicas detectadas nos pacientes, considerando todas as avaliações do estudo, encontram-se apresentadas na Tabela 5. 
Tabela 5 - Comorbidades metabólicas e resultado da avaliação cardiovascular dos seis pacientes com diagnóstico clínico sugestivo de lipodistrofia parcial familiar

\begin{tabular}{|c|c|c|c|c|c|c|}
\hline Comorbidade & P1 & $\mathbf{P 2}$ & P3 & P4 & P5 & P6 \\
\hline Obesidade (pelo IMC) & Não & $\underset{\operatorname{Sim}}{\operatorname{Srau} 1)}$ & Não & $\begin{array}{c}\text { Sim } \\
\text { (grau 2) }\end{array}$ & Não & $\begin{array}{c}\operatorname{Sim} \\
\text { (grau 3) }\end{array}$ \\
\hline Obesidade (pela CA) & Não & Sim & Sim & Sim & Sim & Sim \\
\hline Tolerância à glicose & $\begin{array}{c}\text { IOG } \\
(29 a)^{a}\end{array}$ & Normal & $\begin{array}{c}\text { DM2 } \\
(36 \mathrm{a})^{\mathrm{a}}\end{array}$ & $\begin{array}{l}\text { Gj alterada } \\
(17 \mathrm{a})^{\mathrm{a}}\end{array}$ & $\begin{array}{l}\text { DM2 } \\
(34 \mathrm{a})\end{array}$ & Normal \\
\hline Dislipidemia & HiperTg & HiperTg & HiperTg & HiperTg & HiperTg & HiperTg \\
\hline & HDL baixo & HDL baixo & HDLbaixo & HDL baixo & HDL baixo & LDL alto \\
\hline HAS & Não & Não & Sim & Não & Sim & Não \\
\hline SOP & Sim & - & Sim & Sim & Sim & Sim \\
\hline $\mathrm{EH}$ & $\begin{array}{c}\text { Sim } \\
\text { (moderada) }\end{array}$ & $\begin{array}{c}\text { Sim } \\
\text { (leve) }\end{array}$ & $\begin{array}{c}\text { Sim } \\
\text { (acentuada) }\end{array}$ & $\begin{array}{c}\text { Sim } \\
\text { (acentuada) }\end{array}$ & $\begin{array}{c}\text { Sim } \\
\text { (acentuada) }\end{array}$ & $\begin{array}{l}\text { Sim } \\
\text { (leve) }\end{array}$ \\
\hline DAC & $\begin{array}{c}\text { Rastreamento } \\
\text { negativo }\end{array}$ & $\begin{array}{c}\text { Rastreamento } \\
\text { negativo }\end{array}$ & $\begin{array}{c}\text { Rastreamento } \\
\text { negativo }\end{array}$ & $\begin{array}{c}\text { Rastreamento } \\
\text { negativo }\end{array}$ & $\begin{array}{c}\text { IAM } \\
(36 \mathrm{a})^{\mathrm{a}}\end{array}$ & $\begin{array}{c}\text { Rastreamento } \\
\text { negativo }\end{array}$ \\
\hline
\end{tabular}




\subsection{AVALIAÇÃO DO EIXO HIPOTÁLAMO-HIPÓFISE-ADRENAL}

A avaliação específica, basal e dinâmica, do eixo HHA encontra-se representada na Tabela 6 . Foi observada tendência de valores mais baixos de concentrações circulantes de cortisol às $8 \mathrm{~h}$ da manhã (basal). Do mesmo modo, observaram-se concentrações circulantes de ACTH basal no terço inferior da faixa de normalidade em cinco pacientes e, ainda, foi observado valor suprimido em uma paciente (P5). Cinco pacientes não apresentaram anormalidades das concentrações circulantes de $\mathrm{CBG}$ e somente um paciente (P1) demonstrou níveis discretamente abaixo do valor de referência.

O rastreamento do hipercortisolismo, com as dosagens de cortisol salivar noturno (23h) e cortisol livre urinário ( 3 amostras), foi negativo em todos os seis pacientes estudados. Foi observada, ainda, tendência de valores médios reduzidos do cortisol livre urinário.

$\mathrm{Na}$ avaliação dinâmica, a supressão do cortisol pós- $1 \mathrm{mg}$ de dexametasona foi preservada $(<1,8 \mathrm{mcg} / \mathrm{dL})$ em todos os portadores da síndrome de LPF estudados. Desta forma, não foi realizado o teste de supressão com $2 \mathrm{mg}$ do corticoide. Apenas a paciente P4 não apresentou supressão da secreção de cortisol após a dose de 0,5 mg. 
Tabela 6 - Avaliação do eixo hipotálamo-hipófise-adrenal dos seis pacientes com diagnóstico clínico sugestivo de lipodistrofia parcial familiar

\begin{tabular}{|c|c|c|c|c|c|c|}
\hline Variável & P1 & $\mathbf{P 2}$ & P3 & P4 & P5 & P6 \\
\hline Cortisol basal (mcg/dL) & 10,3 & 5,4 & 9,0 & 6,4 & 9,1 & 7,6 \\
\hline ACTH basal (pg/mL) & 16,3 & 9,8 & 12,7 & 8,2 & $2,2 / 5,2$ & 17,1 \\
\hline CBG $(\mathrm{mcg} / \mathrm{L})$ & 36,6 & 28,3 & 42,4 & 57,4 & 65,0 & 42,2 \\
\hline \multicolumn{7}{|l|}{ Cortisol livre urinário (mcg/24h) } \\
\hline $1^{\mathrm{a}}$ medida & 55,4 & 41,8 & 39,1 & 30,5 & 12,0 & 42,8 \\
\hline $2^{\mathrm{a}}$ medida & 46,4 & 40,5 & 33,8 & 48,3 & 14,3 & 31,0 \\
\hline $3^{\mathrm{a}}$ medida & 35,4 & 26,5 & 21,6 & 72,4 & 5,0 & 19,8 \\
\hline Cortisol salivar às $23 \mathrm{~h}$ (nmol/L) & 2,9 & 9,4 & 5,9 & 4,3 & 8,4 & 5,0 \\
\hline CPD 0,5 mg (mcg/dL) & 0,5 & 1,0 & 1,1 & 2,9 & 1,5 & 0,7 \\
\hline CPD 1 mg (mcg/dL) & 0,5 & 0,3 & 0,7 & 1,0 & 1,5 & 0,5 \\
\hline
\end{tabular}

ACTH: hormônio adrenocorticotrófico; CPD: cortisol pós-dexametasona.

Valores de referência: cortisol basal 3,7 - 19,4 mcg/dL; ACTH 7,2 - 63,3 pg/mL; CBG sexo masculino 25 - 55 e sexo feminino 40 - 154 mcg/L; CLU 4,3 - 176 $\mathrm{mcg} / 24 \mathrm{~h}$; cortisol salivar às $23 \mathrm{~h}<9,7 \mathrm{nmol} / \mathrm{L} ; \mathrm{CPD}<1,8 \mathrm{mcg} / \mathrm{dL}$. 


\subsection{ANÁLISE DA COMPOSIÇÃO CORPORAL POR DEXA}

Os resultados da avaliação da composição corporal por DEXA, apresentados na Tabela 7, mostraram aumento do percentual de gordura corporal total em três dos seis pacientes estudados. Foi observada perda variável de gordura nos membros, com maior tendência de perda nos membros inferiores. Notou-se o aumento da adiposidade na região troncular, com exceção da paciente P1. O índice FMR foi superior a 1,2 em todos os pacientes e observou-se uma tendência a valores aumentados da taxa de gordura androide / ginoide.

Tabela 7 - Avaliação da composição corporal por DEXA dos seis pacientes com diagnóstico clínico sugestivo de lipodistrofia parcial familiar

\begin{tabular}{lcccccl}
\hline \multicolumn{1}{c}{ \% gordura } & $\mathbf{P 1}$ & $\mathbf{P 2}$ & $\mathbf{P 3}$ & $\mathbf{P 4}$ & $\mathbf{P 5}$ & P6 \\
\hline Corporal total & 19,8 & 22,3 & 22,8 & 41,3 & 31,3 & 45,8 \\
Tronco & 23,8 & 26,7 & 26,8 & 46,6 & 38,4 & 49,1 \\
Braços & 16,7 & 18,9 & 22,7 & 40,7 & 26,1 & 48,3 \\
Pernas & 14,0 & 17,1 & 16,3 & 34,5 & 20,8 & 38 \\
FMR $^{\mathrm{a}}$ & 1,70 & 1,56 & 1,64 & 1,35 & 1,84 & 1,29 \\
Taxa A/G $^{\text {b }}$ & 1,35 & 1,39 & 1,66 & 1,43 & 1,14 & 1,29
\end{tabular}

a gordura tronco/membros inferiores

${ }^{\mathrm{b}}$ taxa de gordura androide/ginoide

\subsection{RESULTADOS ANALÍTICOS}

Considerando que a LPF é caracterizada por perda progressiva do tecido adiposo subcutâneo em sítios periféricos (7), em geral a partir da puberdade, foi avaliada a correlação entre a idade e variáveis antropométricas; medidas da composição corporal por DEXA e variáveis metabólicas. Embora nenhuma correlação tenha sido estatisticamente significativa, houve correlação negativa moderada da idade com o IMC e a CA; correlação positiva moderada com a FMR; correlação positiva moderada com a concentração sérica de triglicerídeos e correlação negativa forte com a concentração sérica de HDL (Tabela 8). 
Tabela 8 - Correlação entre a idade e variáveis antropométricas, medidas da composição corporal (DEXA) e metabólicas, nos seis pacientes com diagnóstico clínico de LPF

\begin{tabular}{lcccccccc}
\hline & $\mathrm{IMC}\left(\mathrm{kg} / \mathrm{m}^{2}\right)$ & $\mathrm{CA}$ & $\mathrm{RCQ}$ & IAC & $\%$ TBF & \%Gordura troncular & FMR & A/G \\
\hline Rs & $-0,66$ & $-0,71$ & 0,21 & $-0,26$ & $-0,26$ & $-0,26$ & 0,66 & $-0,09$ \\
$\mathrm{P}$ & 0,17 & 0,14 & 0,71 & 0,66 & 0,66 & 0,66 & 0,18 & 0,92 \\
& & & & & & & & \\
& leptina & Insulina & HOMA-IR & GJ & TG & HDL & & \\
\hline rs & $-0,26$ & $-0,03$ & 0,20 & 0,26 & 0,60 & $-0,83$ & & \\
p & 0,66 & 1,0000 & 0,71 & 0,66 & 0,24 & 0,06 & & \\
\hline
\end{tabular}

IMC: índice de massa corporal; CA: circunferência abdominal; RCQ: relação cintura-quadril, IAC: índice de adiposidade corporal, \%TBF: percentual de gordura corporal total; FMR: taxa de massa de gordura (gordura central/periférica); AG: taxa androide/ginoide, GJ: glicemia de jejum; TG: triglicerídeo; HDL: lipoproteína de alta densidade; rs: coeficiente de correlação de Spearman; p: valor p.

Considerando que a perda da massa adiposa periférica, com preservação ou mesmo aumento da massa adiposa central, é considerada mecanismo fisiopatológico central da resistência insulínica e alterações metabólicas da LPF, foi analisada a correlação entre a FMR e variáveis metabólicas (Tabela 9). Embora nenhuma das correlações tenha sido estatisticamente significativa, foi possível observar melhor correlação da FMR com alterações metabólicas (Tabela 9), quando comparada à CA (Tabela 10), incluindo aumento do HOMA-IR e concentração sérica de triglicerídeos, e redução da concentração sérica de HDL e leptina.

Tabela 9 - Correlação entre a FMR e variáveis metabólicas, nos seis pacientes com diagnóstico clínico de LPF

\begin{tabular}{ccccccc}
\hline & GJ & Insulina & HOMA & TG & HDL & Leptina \\
\hline Rs & 0,26 & 0,31 & 0,54 & 0,77 & $-0,83$ & $-0,43$ \\
$P$ & 0,66 & 0,56 & 0,29 & 0,10 & 0,06 & 0,42
\end{tabular}

GJ: glicemia de jejum; TG: triglicerídeo; HDL: lipoproteína de alta densidade; rs: coeficiente de correlação de Spearman; $p$ : valor $p$.

Tabela 10 - Correlação entre a CA e variáveis metabólicas, nos seis pacientes com diagnóstico clínico de LPF

\begin{tabular}{ccccccc}
\hline & GJ & Insulina & HOMA & TG & HDL & Leptina \\
\hline Rs & 0,09 & $-0,03$ & $-0,26$ & $-0,77$ & 0,71 & 0,43 \\
$P$ & 0,92 & 1,00 & 0,66 & 0,10 & 0,14 & 0,42 \\
\hline
\end{tabular}

GJ: glicemia de jejum; TG: triglicerídeo; HDL: lipoproteína de alta densidade; rs: coeficiente de correlação de Spearman; $p$ : valor $p$. 


\section{DISCUSSÃO}

\subsection{RECONHECIMENTO CLÍNICO DA LIPODISTROFIA PARCIAL FAMILIAR}

A história clínica dos seis pacientes estudados sugeriu que as alterações da distrubuição da gordura corporal não representam o principal motivo que os direciona ao atendimento médico. Essa dificuldade de percepção pelo paciente contribui para o atraso no diagnóstico e, de fato, os dados do presente estudo indicam que o primeiro contato com o serviço de saúde pode ocorrer anos depois, em vigência de comorbidades e complicações metabólicas associadas à resistência insulínica. Essa observação é consistente entre diversos estudos $(7,11,13)$ e reforça a importância da suspeição clínica da doença $(8,11)$.

A perda do tecido adiposo subcutâneo periférico variou em intensidade nos pacientes estudados e foi observada perda mais sutil, com fenótipo considerado atípico, nos três pacientes mais jovens. Esse achado é consistente com a descrição de que a perda adiposa na LPF é gradual e progressiva $(2,5,7,11)$.

A resistência insulínica, avaliada clinicamente pela presença de acantose nigricans, foi observada em todos os pacientes, e em três deles, sua extensão foi desproporcional ao IMC. No consenso para detecção das síndromes lipodistróficas, publicado pela Associação Americana de Endocrinologistas Clínicos em 2013 (7), a SOP é considerada achado clínico de resistência insulínica da mesma magnitude da acantose nigricans. A hiperinsulinemia, decorrente da resistência insulínica, acarreta anovulação e hiperandrogenismo $(11,67)$. Características clínicas de SOP foram observadas nas cinco mulheres avaliadas, destacando-se a irregularidade menstrual e o hirsutismo. A prevalência da SOP na LPF foi estimada em cerca de $25 \%$ (2), porém é possível que esta represente uma subestimativa. Cabe destacar que características sugestivas da SOP podem constituir o motivo de busca inicial ao serviço de saúde por portadoras de LPF e, assim, a avaliação da distribuição de gordura corporal deve ser considerada diante dessas pacientes, sobretudo daquelas com indícios de resistência insulínica acentuada.

A presença de obesidade, definida pelo IMC, não é comum entre portadores de LPF (7). No presente estudo, foi observado maior grau de obesidade (IMC $>35$ $\mathrm{kg} / \mathrm{m}^{2}$ ) em dois dos seis pacientes avaliados. O IMC elevado, contudo, não exclui o diagnóstico de síndrome lipodistrófica (68), apenas dificulta seu reconhecimento 
baseado no exame físico. Além disso, lipodistrofia e obesidade parecem levar a consequências metabólicas semelhantes e, quando coexistem, há possibilidade de sinergismo de seu impacto metabólico (68).

Outro aspecto importante para o reconhecimento clínico precoce da LPF é o histórico familiar e, também, o rastreamento dos parentes de portadores da síndrome. No presente estudo, dois pacientes apresentaram familiar com fenótipo semelhante e, quando avaliados, exibiram características compatíveis com a LPF. Dayse Caldas et al. (2013), em estudo envolvendo familiares de duas portadoras brasileiras de LPF do tipo 2, observaram que a determinação fenotípica clínica de lipodistrofia, nos parentes das pacientes, foi um bom preditor para identificação de portadores da mutação no gene LMNA (69).

\subsection{ACHADOS BIOQUÍMICOS E METABÓLICOS}

No presente estudo, a avaliação bioquímica confirmou o perfil metabólico de resistência insulínica dos pacientes lipodistróficos. Os componentes da SM foram frequentes e de início precoce, sobretudo a alteração da circunferência abdominal, dislipidemia (hipertrigliceridemia e HDL baixo) e as disglicemias. A intensidade da resistência insulínica, avaliada pelo HOMA-IR, foi acentuada na maior parte dos pacientes, compatível com estudos anteriores $(2-7,9)$.

As disglicemias são comuns entre portadores de LPF (7). No presente estudo, o metabolismo da glicose foi avaliado por meio da glicemia de jejum, glicemia pósprandial, hemoglobina glicada e teste de tolerância à glicose oral. Embora em todos os pacientes tenha sido observada resistência insulínica, apenas duas pacientes (as com idade mais elevada, 41 e 42 anos) apresentavam diabetes. Uma paciente (17 anos) apresentou glicemia de jejum alterada, uma paciente (33 anos) apresentou intolerância oral à glicose e dois pacientes (homem de 20 anos e mulher de 24 anos) apresentaram tolerância normal à glicose. Em estudo anterior envolvendo portadores de LPF, foi observado que o diabetes manifesta-se posteriormente a outros achados sugestivos de resistência insulínica, como SOP e acantose nigricans (69). Consistentemente, no presente estudo observou-se a presença de diabetes em pacientes possivelmente com tempo mais prolongado de doença (idade mais avançada), ao passo que a tolerância normal à glicose foi observada em dois pacientes jovens. 
Com relação a outras características secundárias relacionadas à $\mathrm{SM}$, a esteatose hepática, detectada pelo US, foi observada em todos os pacientes avaliados. A concentração sérica de enzimas hepáticas apresentou baixa sensibilidade para a pesquisa dessa condição clínica, na medida em que quatro dos pacientes não apresentaram elevação de seus valores. Hiperuricemia foi encontrada em um dos seis pacientes avaliados e, assim, não foi uma condição frequente nessa série de pacientes com a doença.

Dois achados foram discordantes dos descritos na literatura. Um deles foi o valor da concentração sérica de PCR, normal em quatro pacientes avaliados. A PCR é uma proteína inflamatória e, embora inespecífica, é considerada preditora de risco cardiovascular. Dessa forma, seu aumento poderia ser esperado nos pacientes lipodistróficos, sobretudo em uma das pacientes, portadora de coronariopatia precoce (antes dos 40 anos). Em um estudo prévio envolvendo 35 portadores de LPF tipo 2, foi detectado aumento da concentração sérica de PCR, cujo valor médio foi superior em mulheres (5,9 mg/L nas mulheres vs 2,9 mg/L nos homens) (70). Outro achado discordante refere-se às concentrações séricas da proteína ligadora dos hormônios sexuais (SHBG), que em geral diminuem em situações de resistência insulínica, como a SOP $(71,72)$. Cabe destacar, entretanto, que o número amostral reduzido do presente estudo não permite excluir a PCR como preditor de risco cardiovascular na lipodistrofia parcial, ou constatar que SHBG tenha suas concentrações séricas normais na síndrome.

No presente estudo o único paciente do sexo masculino incluído apresentou fenótipo mais leve (características clínicas e perfil metabólico) quando comparado à sua parente de primeiro grau (tia) e às outras quatro pacientes avaliadas. Embora a inclusão de um único paciente impossibilite conclusões definitivas, este achado está de acordo com outras descrições na literatura, que sugerem que as manifestações clínicas da LPF e suas complicações sejam mais precoces e graves em pacientes do sexo feminino $(2,13,73-75)$.

\subsection{PERFIL HORMONAL}

\subsubsection{Leptinemia}

A concentração sérica de leptina foi variável entre os seis pacientes 
estudados e em três deles foi observada redução de pelo menos $40 \%$ na sua concentração, compatível com a média de redução encontrada em outro estudo (76). Em um paciente observou-se valor próximo ao limite superior da faixa de referência e dois pacientes apresentaram hiperleptinemia. $\mathrm{O}$ achado de leptinemia normal ou elevada não é esperado, uma vez que a perda de tecido adiposo subcutâneo é acompanhada de deficiência de leptina (7).

Embora o esperado na lipodistrofia seja a hipoleptinemia, o valor aumentado desta adipocina não é capaz de excluir o diagnóstico, uma vez que, até o momento, o conhecimento a respeito da variabilidade dos níveis de leptinemia ainda é limitado nos pacientes com diagnóstico de lipodistrofia parcial $(3,7)$. Além disso, os ensaios de avaliação do hormônio ainda não foram padronizados e os valores de referência também não são bem definidos (7). É possível que a inclusão de um grupo controle no presente estudo, pareado de acordo com a idade e IMC, auxiliasse a interpretação dos valores de leptinemia encontrados nos pacientes.

Um conceito bem estabelecido é a correlação direta da leptinemia com a massa de gordura corporal (77). Embora o IMC não reflita a composição corporal, foi positivamente correlacionado com a leptinemia em indivíduos não portadores de lipodistrofia e também em portadores da doença (47). Entre pacientes lipodistróficos, essa correlação não parece ser consistentemente observada, na medida em que outro estudo, envolvendo pacientes brasileiros, não evidenciou correlação da leptinemia com o IMC em portadores de síndrome de Dunnigan, mas somente em não portadores de lipodistrofia (69). No presente estudo, não foi observada esta correlação.

Não foram encontradas, também, correlações significativas entre leptinemia e indicadores da composição corporal neste estudo (antropométricos e parâmetros avaliados por DEXA). Entretanto, observou-se tendência de correlação positiva forte $(p=0,05)$ da leptinemia com o índice de adiposidade corporal (IAC), com a gordura troncular (\%) e com a gordura corporal total (\%). Esses achados estão de acordo com o estudo de Godoy-Matos et al. (2012), os quais observaram correlação positiva moderada significativa entre a leptinemia e o IAC $(r=0,57 ; p=0,01)$, gordura troncular $(r=0,72 ; p<0,001)$ e gordura corporal total $(r=0,77 ; p<0,001)$, em 13 mulheres portadoras de LPF tipo 2 (78). Neste mesmo estudo, também não foi observada correlação significativa entre leptinemia e IMC ou circunferência abdominal (78).

Os achados do presente estudo sugerem que a leptinemia, na LPF, pode 
variar conforme o fenótipo e, especificamente, conforme a intensidade da perda de tecido adiposo (menores valores de leptinemia observados nas duas pacientes com perda mais acentuada) e, também, conforme a intensidade do acúmulo de tecido adiposo em outros sítios, como a região troncular. Assim, a redução da leptinemia parece não constituir marcador definitivo das formas parciais de lipodistrofia (11) e é provável que essa adipocina seja secretada de forma diferenciada, de acordo com os diferentes depósitos de tecido adiposo (68).

\subsubsection{Atividade do Eixo Hipotálamo-Hipófise-Adrenal}

A avaliação específica da atividade do eixo HHA na LPA representa aspecto inédito do presente estudo, para nosso conhecimento. A atividade desse eixo, contudo, já foi explorada na lipodistrofia parcial associada à terapia antirretroviral $(79,80)$.

A associação entre a síndrome de LPF e a hiperatividade do eixo HHA é biologicamente plausível por alguns aspectos. Entre eles, destaca-se o fenótipo cushingoide de portadores de LPF, devido à redistribuição de gordura corporal característica da síndrome $(7,11)$, e as alterações metabólicas, como o diabetes de difícil controle e aquelas que compõem a síndrome metabólica, descritas como estados "pseudocushing" (45). Nestas situações, é característico o aumento moderado da concentração urinária de cortisol livre $(<2$ vezes o valor de referência superior do método) e a supressão incompleta do cortisol após baixa dose (1 mg) de dexametasona (81). Entretanto, no presente estudo não foi evidenciada nenhuma alteração da atividade do eixo HHA, seja por medidas basais ou testes dinâmicos, à exceção da concentração circulante reduzida de ACTH basal em um dos pacientes avaliados, porém não acompanhado de outras alterações na avaliação do eixo HHA. Destaca-se, ainda, que entre os seis pacientes avaliados, apenas um não apresentou supressão da secreção de cortisol em resposta à dose de $0,5 \mathrm{mg}$ de dexametasona oral. A supressão com baixas doses de dexametasona oral já foi reportada em pacientes obesos pré-diabéticos, inclusive com dose de $0,25 \mathrm{mg}$ do corticoide, sugerindo que, nessa condição clínica, a supressão fisiológica do cortisol ocorra com baixas doses de dexametasona e a dose de $1 \mathrm{mg}$ represente mais uma supressão farmacológica (82).

O estudo das possíveis interações entre tecido adiposo e glândula adrenal 
pode contribuir para a interpretação da falta de evidência de hipercortisolismo funcional nos pacientes estudados, porém a maior parte dos estudos que explora essa interação, avalia a obesidade e não especificamente as síndromes lipodistróficas. A maioria destes estudos sugere hiperatividade do eixo HHA, relacionada à obesidade e síndrome metabólica $(12,36-41,83,84)$.

Nesta série de seis pacientes lipodistróficos, não foram encontrados indícios de hipercortisolismo. Foram observados tendência a valores baixos de cortisol e ACTH basais, assim como valor médio das três medidas de CLU nos limites inferiores da faixa de normalidade. Achados semelhantes de valores reduzidos de CLU já foram descritos em mulheres com obesidade abdominal, não portadoras de síndrome lipodistrófica (84), e também em indivíduos portadores de lipodistrofia por uso de antirretrovirais (85). O achado de concentrações basais baixas de cortisol já foi descrito na síndrome metabólica (12) e atribuído ao aumento da depuração de cortisol observado na obesidade abdominal (24). Considerando esses achados, seria esperado encontrar correlação entre cortisol basal ou ACTH basal com medidas de obesidade abdominal nos portadores de LPF (antropométricas, como $C A$ e RCQ, ou obtidas por meio da DEXA, como FMR e taxa $A / G$ ). Entretanto, essas correlações não foram encontradas no presente estudo, que incluiu um pequeno número de pacientes. Também não foi encontrada correlação desses níveis basais de cortisol e ACTH com os parâmetros DEXA de gordura troncular e de gordura total. Da mesma forma, não foram encontradas correlações entre o CLU e o cortisol salivar com as citadas medidas antropométricas e ou da composição corporal por DEXA.

A interação entre a leptina e o eixo HHA já foi previamente estudada, sendo observado efeito inibitório da leptina sobre a esteroidogênese adrenal e também sobre a secreção de cortisol estimulada pelo ACTH (83). No entanto, a leptina não parece influenciar as concentrações séricas basais de cortisol e não está bem definido se a hipoleptinemia acarreta hiperatividade do eixo HHA (83). Em nosso estudo, não encontramos correlação da leptinemia com as variáveis relacionadas à avaliação basal ou dinâmica do eixo HHA.

Nota-se, portanto, que grande parte das interações descritas entre tecido adiposo e eixo HHA considera essencialmente estados de obesidade visceral "comum". Uma vez que nos pacientes com lipodistrofia parcial familiar o distúrbio primário não representa o acúmulo de gordura visceral, mas sim a perda de tecido 
adiposo subcutâneo, os achados do presente estudo podem sugerir que esses dois tipos de tecido adiposo contribuam de formas distintas para os mecanismos de resistência insulínica, de suas repercussões metabólicas e interferências em outros eixos hormonais. A possível estimulação da hiperinsulinemia sobre o eixo HHA representa uma questão ainda não definida e que necessita melhor investigação (84).

É interessante comentar, ainda, que a concentração sérica de CBG foi normal em cinco pacientes com LPF, avaliados no presente estudo e, assim, possivelmente não interferiu nas medidas de avaliação do eixo HHA que envolveram a dosagem sérica do cortisol total. Entretanto, há que se considerar que a concentração sérica desta proteína não é capaz de avaliar sua afinidade pelo cortisol e que esta variável (afinidade) poderia influenciar os valores basais desse hormônio (86). Em conformidade com os achados do estudo, a concentração sérica de CBG parece não representar um marcador de resistência insulínica $(70,87)$.

Estudos subsequentes que avaliem o eixo HHA em um número maior de pacientes com LPF serão valiosos para elucidar a atividade deste eixo hormonal na lipodistrofia e, talvez, correlacioná-la a aspectos específicos da distribuição da gordura corporal.

\subsubsection{Outros Eixos Hormonais}

A avaliação do eixo gonadotrófico foi indicativa de SOP em todas as cinco mulheres avaliadas. A hiperandrogenemia laboratorial, detectada pelo aumento da concentração circulante de testosterona ou androstenediona, foi observada em 4 das 5 mulheres. A concentração circulante de DHEA não apresentou utilidade na determinação de hiperandrogenismo, à similaridade de artigo prévio envolvendo a avaliação de mulheres com SOP (88). Duas pacientes apresentaram gestação prévia sem intercorrências, o que corrobora as descrições de que a fertilidade pode estar preservada na LPF (5-7). As concentrações séricas normais de prolactina reforçam que a hiperprolactinemia não representa uma entidade clínica associada à SOP (89).

A ausência de hipogonadismo no paciente masculino do estudo está de acordo com o conceito de que o estado hipogonadotrófico da síndrome metabólica encontra-se mais relacionado à quantidade de gordura visceral $(12,24)$ e ao 
comprometimento da sensibilidade insulínica (90), uma vez que o paciente da presente série não apresentava aumento significativo do IMC, da circunferência abdominal e do valor do HOMA-IR.

$O$ presente estudo não identificou alterações dos eixos tireoideano e somatotrófico. É importante destacar, contudo, as limitações da avaliação basal do eixo somatotrófico, empregada no estudo, para determinação de sua atividade. A dinâmica de pulsatilidade do $\mathrm{GH}$, quando avaliada em pacientes com lipodistrofia pelo HIV, não demonstrou anormalidades nas concentrações séricas de IGF-1 e na frequência dos pulsos de $\mathrm{GH}$, porém as concentrações basais e médias desse hormônio, assim como a amplitude de sua pulsatilidade, apresentaram-se reduzidas nos pacientes portadores deste subtipo parcial de lipodistrofia (91).

Considerando a hiperinsulinemia, fato que ocorre na LPF independente do valor de IMC, existe a observação de que concentrações elevadas de insulina estariam associadas a menores valores das proteínas de ligação IGFBPs e, consequentemente, valores reduzidos de IGF-1 total $(12,24)$. O aumento da fração livre de IGF-1 acarreta redução da liberação hipofisária de GH nos pacientes com SM e a insulina também parece exercer um efeito inibitório direto sobre a célula somatrotrófica produtora de GH (12). Na presente série de casos, somente duas pacientes apresentaram valores reduzidos de IGF-1 e uma destas, apresentou valor normal da proteína em uma segunda ocasião. É possível que ocorra variabilidade das concentrações de IGF-1 na LPF, semelhante ao descrito na obesidade (24).

\subsection{AVALIAÇÃO DA COMPOSIÇÃO CORPORAL}

A avaliação da composição corporal foi realizada por DEXA, que permitiu determinar a porcentagem de gordura corporal total e segmentar; estes últimos, em particular, representam ferramenta importante para determinar a distribuição da gordura corporal e fortalecer o diagnóstico clínico das lipodistrofias. Em pacientes com lipodistrofia, de forma geral, a porcentagem de gordura corporal total se mostrou próxima ao valor de $23 \%$, em comparação com o valor de referência de $30 \%$ (11). Valores inferiores a $30 \%$ foram encontrados em três dos seis pacientes avaliados no presente estudo. É possível que essa divergência se deva à redistribuição da gordura corporal observada na LPF, com perda de alguns depósitos e aumento de outros, fato que pode não reduzir a gordura corporal total. 
As medidas relacionadas à redistribuição da gordura corporal, fornecidas pela DEXA, foram sugestivas da LPF em todos os pacientes. Todos apresentaram FMR superior a 1,2. Esse ponto de corte foi sugerido em estudo prévio envolvendo pacientes brasileiros portadores de LPF tipo 2, em que foi demonstrada sensibilidade de $88,9 \%$ e especificidade de $93,8 \%$ para reconhecimento deste subtipo de lipodistrofia (51). Cabe destacar, ainda, a tendência observada de valores mais elevados da FMR nas pacientes de fenótipo mais típico, ou seja, com maior evidência de perda de gordura periférica. Tal achado corrobora a relevância do índice de FMR, não apenas como critério para suporte diagnóstico, mas também prognóstico, como indicador do grau de perda de gordura periférica. O achado, no presente estudo, de melhor correlação da FMR com variáveis metabólicas (HOMA$I R$, trigliceridemia e concentrações de $H D L$ ), quando comparado à $C A$, reforça o conceito de que na LPF a gravidade das complicações metabólicas seja determinada principalmente pelo grau de perda do tecido adiposo subcutâneo $(2,3,7,9)$, ilustrando seu efeito metabolicamente protetor.

A taxa androide/ginoide $(A / G)$ representa outro marcador de centralização da gordura, uma vez que gordura androide corresponde à adiposidade troncular (que pode estar aumentada na LPF), ao passo que a ginoide avalia adiposidade glúteofemoral (perdida na LPF). No mesmo estudo brasileiro mencionado acima (51), a média dos valores da taxa $A / G$ foram maiores nos 18 pacientes com fenótipo de lipodistrofia, quando comparados ao grupo controle (1,17 vs 0,92; respectivamente). Os seis pacientes do presente estudo também apresentaram valores semelhantes, com tendência a valores aumentados.

Esses achados, em conjunto, reforçam a utilidade do método DEXA na avaliação da distribuição da gordura corporal em pacientes com suspeita clínica de LPF. Cabe destacar, entretanto, que embora seja considerado padrão-ouro para avaliação da porcentagem da massa de gordura total (11), a obesidade pode comprometer sua acurácia (20).

Não foi observada, como seria plausível, correlação entre variáveis antropométricas e obtidas por DEXA com variáveis bioquímicas ou hormonais indicativas de alterações metabólicas. Apesar dessas medidas corporais não serem destacadas na literatura como preditores de alterações metabólicas na síndrome, para comparação com os resultados do presente estudo, é possível que a ausência de correlação observada seja devida à pequena amostra estudada, dada a raridade 
da doença. De modo análogo, em um estudo brasileiro envolvendo seis pacientes com LPF tipo 2, não foi observada correlação entre a quantidade de gordura epicárdica (teórico marcador de risco cardiovascular) e variáveis antropométricas, bioquímicas e parâmetros DEXA (92).

\subsection{CONSIDERAÇÕES FINAIS E PERSPECTIVAS FUTURAS}

O presente estudo apresenta algumas limitações. Uma delas é representada pela pequena amostra estudada, embora seja compreensível, devido à raridade das lipodistrofias. De fato, a maior parte dos estudos relacionados às lipodistrofias também envolve pequeno número de pacientes. Outra limitação refere-se à ausência de grupo controle, pareado de acordo com a idade e IMC. Destaca-se, ainda, a ausência de diagnóstico molecular dos pacientes avaliados. Contudo, uma extensão do projeto estará no estudo genético desses pacientes, buscando identificar presença de mutações nos cinco genes candidados da LPF, especialmente o gene PPARG.

Vale destacar, no entanto, que o estudo explorou aspectos inéditos na LPF, como a atividade do eixo HHA, e reforçou o possível papel de um método acessível, quando comparado ao teste genético, para a definição do diagnóstico clínico da síndrome, representado pela avaliação da distribuição da gordura corporal pela DEXA. 


\section{CONCLUSÃO}

O diagnóstico de lipodistrofia parcial familiar frequentemente ocorre de forma tardia, na vigência de complicações metabólicas da doença na fase adulta. O motivo inicial de procura ao atendimento médico, na nossa série de casos, não envolveu a percepção de perda adiposa periférica.

A consideração diagnóstica deve estar presente diante de evidências de RI acentuada, incluindo presença clínica de SOP e componentes da SM, sobretudo se início precoce e quando a gravidade é desproporcional ao IMC. A história familiar pode ser o primeiro passo para o reconhecimento de casos novos e atípicos.

O exame clínico pode apresentar pouca sensibilidade para reconhecimento dos fenótipos atípicos e iniciais, quando a perda adiposa periférica é sutil.

A avaliação objetiva da composição corporal auxilia no diagnóstico clínico de LPF. O método DEXA demonstrou aplicabilidade clínica e maior sensibilidade do que medidas antropométricas para evidenciar as modificações da distribuição de gordura na doença.

A leptinemia parece variável nas formas parciais de lipodistrofias, conforme apresentação fenotípica.

Não foi evidenciado hipercortisolismo nos seis pacientes avaliados com diagnóstico clínico de LPF. 


\section{REFERÊNCIAS BIBLIOGRÁFICAS}

1. Nolis, T. Exploring the pathophysiology behind the more common genetic and acquired lipodystrophies.J Hum Genet. 2014 Jan;59(1):16-23.

2. Garg A. Lipodystrophies: genetic and acquired body fat disorders. J Clin Endocrinol Metab. 2011; 96:3313-25.

3. Capeau J, Magré J, Caron-Debarle M, Lagathu C, Antoine B, Béréziat V, Lascols O, Bastard JP, Vigouroux C. Human lipodystrophies: genetic and acquired diseases of adipose tissue. Endocr Dev. 2010;(19):1-20.

4. Garg A, Agarwal AK. Lipodystrophies: Disorders of adipose tissue biology. Biochim Biophys Acta. 2009 June; 1791(6): 507-513.

5. Garg A. Acquired and inherited lipodystrophies. N Engl J Med. 2004; (350): 1220-1234.

6. GODOY-MATOS, A.F.; VALERIO, C.M. As Lipodistrofias como modelo de estudo de Síndrome Metabólica. In: GODOY-MATOS, A.F. Endocardiometabologia na prática clínica. Rio de Janeiro: Guanabara Koogan, 2011. p. 23-36.

7. Handelsman Y., Oral EA, et al. The clinical approach to the detection of lipodystrophy - An AACE Consensus Statement. Endocr Pract. 2013; (19):107-116.

8. Fiorenza CG, Chou SH, Mantzoros CS. Lipodystrophy: pathophysiology and advances in treatment. Nat Rev Endocrinol. 2011 Mar;7(3): 137-50.

9. Cortés VA, Fernández-Galilea M Lipodystrophies: adipose tissue disorders with severe metabolic implications. J Physiol Biochem. 2015 Apr.

10. Haque WA, Shimomura I, et al. Serum Adiponectin and Leptin Levels in Patients with Lipodystrophies. J Clin Endocrinol Metab, May 2002, 87(5):2395-2398.

11. Vantyghem MC, Balavoine AS, Douillard C, Defrance F, Dieudonne L, Mouton F, Lemaire C, Bertrand-Escouflaire $\quad \mathrm{N}$, Bourdelle-Hego MF, Devemy $\quad F$, Evrard A, Gheerbrand $\quad$ D, Girardot C, Gumuche $\quad S$, Hober C, Topolinski H, Lamblin B, Mycinski B, Ryndak A, Karrouz W, Duvivier E, Merlen E, Cortet C, Weill J, Lacroix D,Wémeau JL. How to diagnose a lipodystrophy syndrome. Ann Endocrinol (Paris). 2012 Jun;73(3):170-89.

12. Godoy Matos AF, Moreira RO, Guedes EP. Neuroendocrinology of the Metabolic Syndrome. Arq Bras Endocrinol Metab. 2003 Aug; 47 (4): 410-421. 
13. Hegele RA, Joy TR, Al-Attar SA, Rutt BK. Thematic review series: Adipocyte Biology. Lipodystrophies: windows on adipose biology and metabolism. J Lipid Res. 2007 Jul; 48(7):1433-44.

14. Huang-Doran I, Sleigh A, Rochford JJ, O'Rahilly S, Savage DB. Lipodystrophy: metabolic insights from a rare disorder. Journal of Endocrinology 2010; 207: 245-255.

15. Fève B. Adipogenesis: cellular and molecular aspects. Best Pract Res Clin Endocrinol Metab. 2005 Dec;19(4):483-99.

16. Kershaw EE, Flier JS. Adipose tissue as an endocrine organ. J Clin Endocrinol Metab. 2004 Jun;89(6):2548-56.

17. Blüher M, Mantzoros CS. From leptin to other adipokines in health and disease: facts and expectations at the beginning of the 21 st century. Metabolism. 2015 Jan;64(1):131-45.

18. Blüher M. Clinical relevance of adipokines. Diabetes Metab J. 2012 Oct;36(5):317-27.

19. Cristancho AG, Lazar MA. Forming functional fat: a growing understanding of adipocyte differentiation. Nat Rev Mol Cell Biol. 2011 Sep 28;12(11):722-34.

20. Hocking S, Samocha-Bonet D, et al. Adiposity and Insulin Resistance in Humans: The Role of the Different Tissue and Cellular Lipid Depots. Endocr Rev 2013, Apr 2.

21. Kovacs P1, Stumvoll M. Fatty acids and insulin resistance in muscle and liver. Best Pract Res Clin Endocrinol Metab. 2005 Dec;19(4):625-35.

22. Vatier C, Bidault G, Briand N, Guénantin AC, Teyssières L, Lascols $\mathrm{O}$, Capeau J, Vigouroux $\mathrm{C}$. What the genetics of lipodystrophy can teach us about insulin resistance and diabetes. Curr Diab Rep. 2013 Dec;13(6):757-67.

23. Shulman Gl. Ectopic fat in insulin resistance, dyslipidemia, and cardiometabolic disease. N Engl J Med. 2014; 371(12):1131-41.

24. Wajchenberg BLO. Subcutaneous and Visceral Adipose Tissue: Their Relation to the Metabolic Syndrome. Endocrine Reviews. 2000; 21(6): 697-738.

25. Soutelo J, Grüneisen M, Fritz C, Sordo L, Powazniak Y, Lutfi R. [Familial partial lipodystrophy type 1. A rare or underdiagnosed syndrome?]. Medicina (B Aires). 2015;75(1):41-3.

26. Peters JM, Barnes R, Bennett L, Gitomer WM, Bowcock AM, Garg A. Localization of the gene for familial partial lipodystrophy (Dunnigan variety) to 
chromosome 1q21-22. Nat Genetics. 1998; 18:292-5.

27. Vigouroux $\mathrm{C}$, Caron-Debarle $\mathrm{M}$, et al. Molecular mechanisms of human lipodystrophies: from adipocyte lipid droplet to oxidative stress and lipotoxicity. Int $\mathrm{J}$ Biochem Cell Biol. 2011 Jun; 43(6):862-76.

28. Mory PB, Crispim F, Freire MB, et al. Phenotypic diversity in patients with lipodystrophy associated with LMNA mutations. Eur J Endocrinol 2012 Sep;167 (3):423-31.

29. Dutour A, Roll P, Gaborit B, Courrier S, Alessi MC, Tregouet DA, Angelis F, Robaglia-Schlupp A, Lesavre N, Cau P, Lévy N, Badens C, Morange PE. High prevalence of laminopathies among patients with metabolic syndrome. Hum Mol Genet. 2011 Oct 1;20(19):3779-86.

30. Astapova O, Leff T. PPARy mutations, lipodystrophy and diabetes. Horm Mol Biol Clin Investig. 2014 Nov;20(2):63-70.

31. George S, Rochford JJ, Wolfrum C, Gray SL, Schinner S, Wilson JC, Soos MA, Murgatroyd PR, Williams RM, Acerini CL, Dunger DB, Barford D, Umpleby AM, Wareham NJ, Davies HA,Schafer AJ, Stoffel M, O'Rahilly S, Barroso I. A family with severe insulin resistance and diabetes due to a mutation in AKT2. Science. 2004; 304:1325-1328.

32. Tan K, Kimber WA, Luan J, Soos MA, Semple RK, Wareham NJ, O'Rahilly $\mathrm{S}$, Barroso I. Analysis of genetic variation in Akt2/PKB-beta in severe insulin resistance, lipodystrophy, type 2 diabetes, and related metabolic phenotypes. Diabetes. 2007 Mar;56(3):714-9.

33. Gandotra S, Le Dour C, Bottomley W, Cervera P, Giral P, Reznik Y, Charpentier G, Auclair M, Delépine M, Barroso I, Semple RK, Lathrop M, Lascols O,Capeau J, O'Rahilly S, Magré J, Savage DB, Vigouroux C. Perilipin deficiency and autosomal dominant partial lipodystrophy. N Engl J Med. 2011 Feb 24;364(8):740-8.

34. Kozusko K, Tsang VH, Bottomley W, Cho YH, Gandotra S, Mimmack M, Lim K, Isaac I, Patel S, Saudek V, O'Rahilly S, Srinivasan S, Greenfield JR, Barroso I, Campbell LV, Savage DB. Clinical and molecular characterization of a novel PLIN1 frameshift mutation identified in patients with familial partial lipodystrophy. Diabetes. 2015 Jan; 64(1):299-310.

35. Rubio-Cabezas O, Puri V, Murano I, Saudek V, Semple RK, Dash S et al. Partial lipodystrophy and insulin resistant diabetes in a patient with a homozygous nonsense mutation in CIDEC. EMBO Mol Med. 2009 Aug;1(5):280-7. 
36. Lijung T, Holm G, Friberg P, Bjorn A, Bengtsson B-A, Svenson J, et al. The activity of the hypothalamic-pituitary-adrenal axis and the sympathetic nervous system in relation to waist hip circumference in men. Obes Res 2000; 8:487-495.

37. Pasquali R, Vicennati V. Activity of the hypothalamic-pituitary-adrenal axis in different obesity phenotypes. Int J Obes Relat Metab Disord. 2000 Jun;24 Suppl 2:S47-9.

38. Purnell JQ, Brandon DD, Isabelle LM, Louriax DL, Samuel MH. Association of $24 \mathrm{~h}$ cortisol production rates, cortisol blinding globulin, and plasma free cortisol level with body composition, leptin leves and aging in adult men and women. J Clin Endocrinol Metab 2004; 89:281-287.

39. Ljung T, Andresson B, Begtson BA, Bjorntorp P, Marin P. Inhibition of cortisol secretion by dexamethasone in relation to body fat distribution: a dose response study. Obes Res 1996; 4:277-282.

40. Jessop DF, Dallman MF, Flaming D, Lightman SL. Resistence to glucocorticoid feedback in obesity. J Clin Endocrinol Metab 2001; 86: 4109-4114.

41. Pasquali R, Ambrosi B, Armanini D, Cavagenini F, Uberti ED, Del Rio G, et al. Cortisol and ACTH response to oral dexamethasone in obesity and effects of sex, body fat distribution, and dexamethasone concentrations: a dose-response study. J Clin Endocrinol Metab 2002; 87:16-75.

42. Wake DJ, Walker BR. 11ß-Hydroxysteroid dehydrogenase type 1 in obesity and the metabolic syndrome. Mol Cell Endocrinol 2004; 215:45-54.

43. Espíndola-Antunes D, Kater CE. Adipose tissue expression of 11Bhidroxysteroid dehydrogenase type 1 in Cushing's syndrome and obesity. Arq Bras Endocrinol Metab 2007; 51: 1397-1403.

44. Dube S, Norby BJ, Pattan V, Carter RE, Basu A, Basu R. $11 \beta$ hydroxysteroid dehydrogenase types 1 and 2 activity in subcutaneous adipose tissue in humans: implications in obesity and diabetes. J Clin Endocrinol Metab. 2015 Jan;100(1):E70-6.

45. Guignat L, Bertherat J. The diagnosis of Cushing's syndrome: an Endocrine Society Clinical Practice Guideline: commentary from a European perspective. Eur J Endocrinol. 2010 Jul;163(1):9-13.

46. Lado-Abeal J, Calvo RM, et al. Regional decrease of subcutaneous adipose tissue in patients with type 2 familial partial lipodystrophy is associated with changes in thyroid hormone metabolism. Thyroid. 2010 Apr; 20(4):419-24. 
47. Wong SP, Huda M, English P, Bargiotta A, Wilding JP, Johnson A, Corrall $\mathrm{R}$, Pinkney $\mathrm{JH}$. Adipokines and the insulin resistance syndrome in familial partial lipodystrophy caused by a mutation in lamin A/C. Diabetologia. 2005 Dec;48 (12):2641-9.

48. Al-Attar SA, Pollex RL, Robinson JF, Miskie BA, Walcarius R, Little $\mathrm{CH}$, Rutt BK, Hegele RA. Quantitative and qualitative differences in subcutaneous adipose tissue stores across lipodystrophy types shown by magnetic resonance imaging. BMC Med Imaging. 2007 Mar 12;7:3.

49. Joy T, Kennedy BA, Al-Attar S, Rutt BK, Hegele RA. Predicting abdominal adipose tissue among women with familial partial lipodystrophy. Metabolism. 2009 Jun;58(6):828-34.

50. Bonnet E, Delpierre C, Sommet A: Total body composition by DXA of $241 \mathrm{HIV}$ negative men and $162 \mathrm{HIV}$-infected men: proposal of reference values for defining lipodystrophy. J Clin Densitom. 2005, 8(3):287-292.

51. Valerio CM, Godoy-Matos AF et al. Body composition study by dual-energy $\mathrm{x}$ ray absorptiometry in familial partial lipodystrophy: finding new tools for an objective evaluation. Diabetol Metab Syndr.2012 Aug 31;4(1):40.

52. Valerio CM, Godoy-Matos A, Moreira RO, Carraro L, Guedes EP, Moises RS, Mory PB, de Souza LL, Russo LA, Melazzi AC. Dual-energy X-ray absorptiometry study of body composition in patients with lipodystrophy. Diabetes Care. 2007 Jul;30(7):1857-9.

53. Utzschneider, K.M. \& Trence, D.L. Effectiveness of gastric bypass surgery in a patient with familial partial lipodystrophy. Diabetes Care. 2006 (29): 1380-1382.

54. McGrath NM, Krishna G. Gastric bypass for insulin resistance due to lipodystrophy. Obes Surg. 2006 Nov;16(11):1542-4.

55. Diker-Cohen T, Cochran E, Gorden P, Brown RJ. Partial and generalized lipodystrophy: comparison of baseline characteristics and response to metreleptin. J Clin Endocrinol Metab. 2015 May;100(5):1802-10.

56. Park JY, Javor ED, Cochran EK, DePaoli AM, Gorden P. Long-term efficacy of leptin replacement in patients with Dunnigan-type familial partial lipodystrophy.Metabolism 2007 Apr;56(4):508-16.

57. Chong AY1, Lupsa BC, Cochran EK, Gorden P. Efficacy of leptin therapy in the different forms of human lipodystrophy. Diabetologia. 2010 Jan;53(1):27-35. 
58. Chan JL, Lutz K, Cochran E, Huang W, Peters Y, Weyer C, Gorden P. Clinical effects of long-term metreleptin treatment in patients with lipodystrophy. Endocr Pract. 2011 Nov-Dec;17(6):922-32.

59. Simha V, Subramanyam L, Szczepaniak L, Quittner C, Adams-Huet B, Snell P, Garg A. Comparison of efficacy and safety of leptin replacement therapy in moderately and severe Hypoleptinemic patients with familial partial lipodystrophy of the Dunnigan variety. J Clin Endocrinol Metab. 2012 Mar; 97(3): 785-92.

60. Paparodis $R$, Dunaif $A$. The hirsute woman: challenges in evaluation and management. Endocr Pract. 2011; 17:807-18.

61. Bergman RN, Stefanovski D, Buchanan TA, Sumner AE, Reynolds JC, Sebring NG, Xiang AH, Watanabe RM. A better index of body adiposity. Obesity (Silver Spring). 2011 May;19(5):1083-9.

62. World Health Organization. Obesity: preventing and managing the global epidemic. Report of a World Health Organization Consultation. Geneva: World Health Organization, 2000. p. 256. WHO Obesity Technical Report Series, n. 284

63. AlbertiKG,EckeIRH,GrundySM,Zimmet PZ, Cleeman JI, Donato KA, Fruchart JC, James WP, Loria CM, Smith SC, Jr. Harmonizing the metabolic syndrome: a joint interim statement of the International Diabetes Federation Task Force on Epidemiology and Prevention; National Heart, Lung, and Blood Institute; American Heart Association; World Heart Federation; International Atherosclerosis Society; and International Association for the Study of Obesity. Circulation. 2009;120:1640-1645.

64. Matthews DR, Hosker JP, Rudenski AS, Naylor BA, Treacher DF, Turner RC. Homeostasis model assessment: insulin resistance and beta-cell function from fasting plasma glucose and insulin concentrations in man. Diabetologia.1985 Jul;28(7):412-9.

65. The Rotterdam ESHRE/ASRM-sponsored PCOS consensus workshop group. Revised 2003 consensus on diagnostic criteria and long-term health risks to polycystic ovary syndrome (PCOS). Hum Reprod 2004; 19(1):41-7

66. Freitas $P$, Santos AC, Carvalho D, Pereira J, Marques $R$, Martinez E, Sarmento A, Medina JL. Fat mass ratio: an objective tool to define lipodystrophy in hiv-infected patients under antiretroviral therapy. J Clin Densitom. 2010 AprJun;13(2):197-203.

67. Pahuja I, Sharma N, et al. Polycystic ovarian syndrome in patients with 
lipodystrophy: Report of 2 cases with review of literature. Indian J Endocrinol Metab. 2012 Nov-Dec; 16(6): 1022-1025.

68. Rother KI, Brown RJ. Novel forms of lipodystrophy: why should we care? Diabetes Care. 2013 Aug;36(8):2142-5.

69. Caldas D, Silva Júnior WS, Simonetti JP, Costa EV, Farias ML. Biochemical, hormonal and genetic evaluation of the families of two Brazilian patients with type 2 familial partial lipodystrophy. Arq Bras Endocrinol Metabol. 2013 Nov;57(8):583-93.

70. Hegele RA, Kraw ME, Ban MR, Miskie BA, Huff MW, Cao H. Elevated serum C-reactive protein and free fatty acids among nondiabetic carriers of missense mutations in the gene encoding lamin $A / C$ (LMNA) with partial lipodystrophy. Arterioscler Thromb Vasc Biol. 2003 Jan 1;23(1):111-6.

71. Lewis JG, Borowski KK, Shand BI, George PM, Scott RS. Plasma sex hormone-binding globulin, corticosteroid-binding globulin, cortisol, and free cortisol levels in outpatients attending a lipid disorders clinic: a cross-sectional study of 1137 subjects. Horm Metab Res. 2010 Apr;42(4):274-9.

72. Silva Rdo C, Pardini DP, Kater CE. Polycystic ovary syndrome, metabolic syndrome, cardiovascular risk and the role of insulin sensitizing agents. Arq Bras Endocrinol Metabol. 2006 Apr;50(2):281-90.

73. Garg A. Gender diferences in the prevalence of metabolic complications in familial partial lipodystrophy (Dunnigan variety). J Clin Endocrinol Metab. 2000 May; 85 (5): 1776-82.

74. Araújo-Vilar D, Loidi L, Domínguez F, Cabezas-Cerrato J. Phenotypic gender differences in subjects with familial partial lipodystrophy (Dunnigan variety) due to a nuclear lamin A/C R482W mutation. Horm Metab Res. 2003 Jan;35(1):29-35.

75. Laudes M, Oberhauser F, Walgenbach K, Schubert M, Schulte DM, Faust $\mathrm{M}$, Krone W. Comparison of phenotypes in male and female individuals of a new family with Dunnigan type of familial partial lipodystrophy due to a lamin A/C R482W mutation. Horm Metab Res. 2009 May;41(5):414-7.

76. Hegele RA, Cao H, Huff MW. LMNA R482Q mutation associated with reduced plasma leptin concentration. J Clin Endocrinol Metab 2000, 85(9): 3089-93.

77. Chehab FF. Minireview: Obesity and LipOdystrophy-Where Do the Circles Intersect? Endocrinology. 2008 Mar; 149(3): 925-934.

78. Godoy-Matos AF, Moreira RO, Valerio CM, et al. A new method for body fat 
evaluation, body adiposity index, is useful in women with familial partial lipodystrophy. Obesity (Silver Spring) 2012 Feb;20(2):440-3.

79. Chrousos GP, Zapanti ED. Hypothalamic-pituitary-adrenal axis in HIV infection and disease. Endocrinol Metab Clin North Am. 2014 Sep;43(3):791-806.

80. Zapanti E, Terzidis K, Chrousos G. Dysfunction of the hypothalamic-pituitaryadrenal axis in HIV infection and disease. Hormones (Athens). 2008 JulSep;7(3):205-16.

81. Pecori Giraldi F. PseudoCushing: why a clinical challenge? J Endocrinol Invest. 2015 Apr 28.

82. Casulari LA, Dondi D, Celotti F, da Silva FV, Reis CE, da Costa TH. Effects of caloric restriction and low glycemic index diets associated with metformin on glucose metabolism and cortisol response in overweight/obese subjects: a case series study. Diabetol Metab Syndr. 2015 Jul 22;7:65..

83. Kargi AY, lacobellis G. Adipose tissue and adrenal glands: novel pathophysiological mechanisms and clinical applications. Int J Endocrinol. 2014; 2014: 614074.

84. Vicennati V, Pasquali R. Abnormalities of the hypothalamic-pituitary-adrenal axis in nondepressed women with abdominal obesity and relations with insulin resistance: evidence for a central and a peripheral alteration. J Clin Endocrinol Metab. 2000 Nov;85(11):4093-8.

85. Martin IP, Breen PA, Weigle DS. Absence of hypersensitivity to glucocorticoids in antiretroviral-associated lipodystrophy. Obes Res. 2003 Jan;11(1):21-4.

86. Chan WL, Carrell RW, Zhou A, Read RJ. How changes in affinity of corticosteroid-binding globulin modulate free cortisol concentration. J Clin Endocrinol Metab. 2013 Aug;98(8):3315-22.

87. Lewis JG, Shand BI, Elder PA, Scott RS. Plasma sex hormone-binding globulin rather than corticosteroid-binding globulin is a marker of insulin resistance in obese adult males. Diabetes Obes Metab. 2004 Jul;6(4):259-63.

88. Marcondes JA, Barcellos CR, Rocha MP. Difficulties and pitfalls in the diagnosis of polycystic ovary syndrome. Arq Bras Endocrinol Metabol. 2011 Feb;55(1):6-15.

89. Filho RB, Domingues L, Naves L, Ferraz E, Alves A, Casulari LA. Polycystic ovary syndrome and hyperprolactinemia are distinct entities. Gynecol Endocrinol. 2007 May;23(5):267-72. 
90. Casulari LA, Caldas AD, Domingues Casulari Motta L, Lofrano-Porto A. Effects of metformin and short-term lifestyle modification on the improvement of male hypogonadism associated with metabolic syndrome. Minerva Endocrinol. 2010 Sep;35(3):145-51.

91. Rietschel P, Hadigan C, Corcoran C, Stanley T, Neubauer G, Gertner J, Grinspoon S. Assessment of growth hormone dynamics in human immunodeficiency virus-related lipodystrophy. J Clin Endocrinol Metab. 2001 Feb;86(2):504-10.

92. Godoy-Matos AF, Valério CM, Bragança JB, Oliveira Rde A, Zagury RL, Lustosa Rde P, Camargo GC, Nascimento CA, Moreira RO. Evaluation of epicardial adipose tissue in familial partial lipodystrophy. Diabetol Metab Syndr. 2015 Apr 1;7:29. 
ANEXO I - PARECER DE APROVAÇÃO DO PROJETO DE PESQUISA PELO COMITÊ DE ÉTICA EM PESQUISA COM SERES HUMANOS DA FACULDADE DE CIÊNCIAS DA SAÚDE DA UNIVERSIDADE DE BRASÍLIA 


\section{FACULDADE DE CIÊNCIAS DA SAÚDE DA UNIVERSIDADE DE Plotoporma BRASÍLIA - CEP/FS-UNB}

P.

\section{DADOS DO PROJETO DE PESQUISA}

Título da Pesquisa: Lipodistrofia Parcial Familiar: caracterização genética, metabólica e de eixos hormonais

Pesquisador: Cecilia Pacheco Elias

Área Temática: Genética Humana:

(Trata-se de pesquisa envolvendo Genética Humana que não necessita de análise ética por parte da CONEP;);

Versão: 2

CAAE: 22365413.0.0000.0030

Instituição Proponente: Faculdade de Ciências da Saúde da Universidade de Brasilia

Patrocinador Principal: Financiamento Próprio

\section{DADOS DO PARECER}

\section{Número do Parecer: 547.817}

Data da Relatoria: 05/02/2014

\section{Apresentação do Projeto:}

$\mathrm{O}$ tecido adiposo humano tem se revelado um assunto de grande interesse científico, sobretudo devido às suas repercussões metabólicas. Entre as doenças humanas associadas ao tecido adiposo, destacam-se as lipodistrofias, que envolvem um grupo heterogêneo de doenças raras e associadas à perda total ou seletiva de tecido adiposo, essencialmente subcutâneo. Considerando as lipodistrofias hereditárias, o subtipo parcial familiar tem sido foco de diversas pesquisas, por representar um modelo natural para compreensão das funções metabólicas do tecido adiposo.Pacientes com lipodistrofia parcial familiar (LPF) apresentam uma diversidade fenotípica, sendo descritas quatro variantes: tipo 1(Kobberling), tipo 2 (Dunnigan), tipo 3 e mandibuloacral. Todas estas formas apresentam achados clínicos comuns, como a relevante perda de gordura subcutânea em extremidades e regiāo glútea, resultando em pseudo-hipertrofia muscular e flebomegalia. Classicamente, a lipodistrofia é observada na puberdade, mas pode se iniciar no final da infância ou início da vida adulta. Manifestações metabólicas são comuns na LPF, destacando-se a resistência insulínica e síndrome metabólica (SM). Dentre os componentes da SM e suas complicações, podem-se encontrar diabetes mellitus tipo 2 de início precoce,

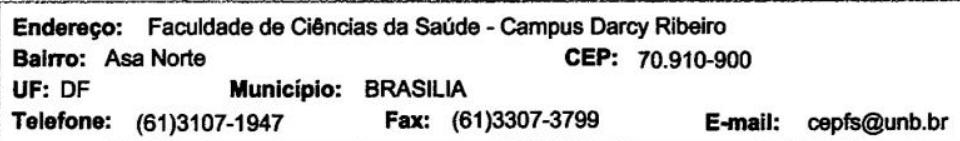




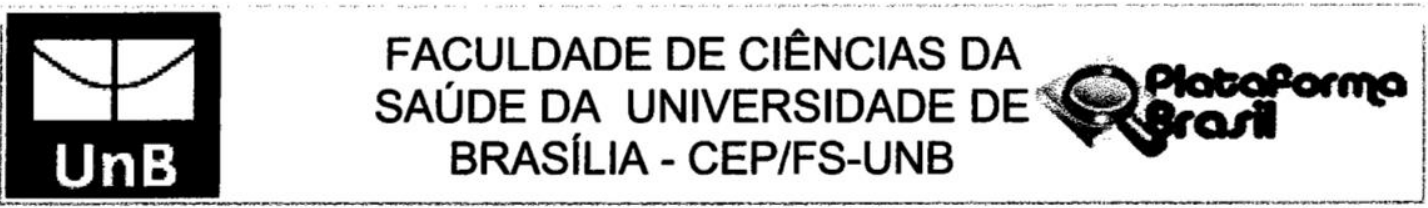

Continuaçāo do Parecer: 547.817

hipertrigliceridemia, baixas concentrações séricas de lipoproteina de alta densidade (HDL), doença hepática gordurosa não aicoólica, hipertensão arterial sistêmica, doença arterial coronariana, aiém de obesidade visceral. A gravidade das complicações parece estar mais relacionada ao grau de perda de gordura subcutânea.

Objetivo da Pesquisa:

Objetivo Primário:

-Caracterizar pacientes portadores de LPF do ponto de vista clínico, metabólico e genético.

Objetivo Secundário:

-Avaliar se existem diferenças clínicas e metabólicas entre a LPF e a Síndrome Metabólica clássica.

-Analisar se o-estudo genético.é compativel-com casos descritos na literatura.

Avaliação dos Riscos e Beneficios:

Apresentada a magnitude dos benefícios em relação aos risco, considerando os procedimentos invasivos e administração de medicamento previstos na execução do estudo.

Comentários e Considerações sobre a Pesquisa:

-Apresentado delineamento do estudo, bem como critérios de inclusão e exclusão.

-O protocolo de coleta e obtenção dos dados foi descrito pela pesquisadora.

-Foi apresentado pela pesquisadora as características exigidas para composição da amostra.

-Apresentado instrumento que será adotado para coleta de dados.

-Realizado detalhamento das providências e cautelas que serão empregadas para evitar ou reduzir efeitos e condições adversas que poderão causar algum dano ou desconforto ao paciente.

Consideraçōes sobre os Termos de apresentação obrigatória:

Todos os termos obrigatórios foram apresentados adequadamente.

Recomendações:

- Ponderar com clareza o delineamento do estudo, bem como critérios de inclusão e exclusão; PENDÊNCIA ATENDIDA

- Descrever como ocorrerá o protocolo de coleta e obtenção dos dados (quem ou qual serviço/profissional fará a coleta e realização dos exames...);PENDÊNCIA ATENDIDA

- Apresentar Termo de concordância do Laboratório de Farmacologia Molecular da Universidade de Brasilia;PENDÊNCIA ATENDIDA

-Apresentar currículo Lattes dos pesquisadores;PENDÊNCIA ATENDIDA

- Descrever com clareza a amostra do estudo;PENDÊNCIA ATENDIDA

- Apresentar o instrumento de coleta de dados. PENDÊNCIA ATENDIDA

Endereço: Faculdade de Ciências da Saúde - Campus Darcy Ribeiro

Bairro: Asa Norte

UF: DF Municiplo: BRASILIA

Telefone: (61)3107-1947 Fax: (61)3307-3799 E-mail: cepfs@unb.br 


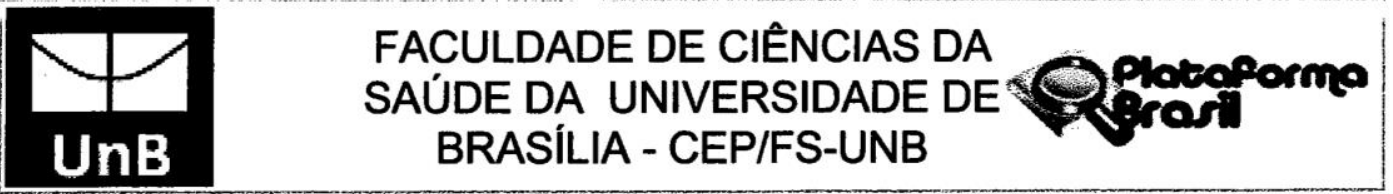

Continuaçăo do Parecer: $\mathbf{5 4 7 . 8 1 7}$

Conclusões ou Pendências e Lista de Inadequações:

Âprovado

Situação do Parecer:

Aprovado

Necessita Apreciação da CONEP:

Não

Considerações Finais a critério do CEP:

BRASILIA, 06 de Março de 2014

Assinador por:

Natan Monsores de Sá

(Coordenador)

Endereço: Faculdade de Ciências da Saúde - Campus Darcy Ribeiro

Bairro: Asa Norte CEP: $70.910-900$

UF: DF Municipio: BRASILIA

Telefone: (61)3107-1947 Fax: (61)3307-3799 E-mail: cepfs@unb.br 
ANEXO II - PARECER DE APROVAÇÃO DO PROJETO DE PESQUISA PELO COMITÊ DE ÉTICA EM PESQUISA COM SERES HUMANOS DO HOSPITAL ALBERTO RASSI - HGG 


COMITE DE ÉTICA EM
PESQUISA DO HOSPITAL
ALBERTO RASSI - HGG Pflocenorma

W.1.

DADOS DO PROJETO DE PESQUISA

Título da Pesquisa: Caracterização genética, metabólica e de eixos hormonais em pacientes com Lipodistrofia Parcial Familiar

Pesquisador: Cecília Pacheco Elias

Area Temática: Genética Humana:

(Trata-se de pesquisa envolvendo Genética Humana que não necessita de análise ética por parte da CONEP;);

Versão: 1

CAAE: 42659915.2 .0000 .0035

Instituição Proponente: Hospital Geral de Goiânia - HGG

Patrocinador Principal: Financiamento Próprio

DADOS DO PARECER

Número do Parecer: 1.020 .651

Data da Relatoria: 09/04/2015

Apresentação do Projeto:

Nº DO PROTOCOLO NO CEPHGG: 781/50

Apresentação do projeto conforme informações do pesquisador Responsável:

ÁREA TEMÁTICA: Trata-se de um Protocolo nacional, unicêntrico, pertecente a área temática NÃO especial, Área do conhecimento Ciências da Saúde - Área 4.

PROPÓSITO DO ESTUDO: Objetivo acadêmico (Dissertação de Mestrado).

DESENHO DO ESTUDO: Estudo transversal, descritivo. A coleta de dados será realizada em um mesmo momento temporal para caracterizar e descrever aspectos da doença de Lipodistrofia Parcial Familiar.

INTRODUÇÃO: O tecido adiposo humano tem se revelado um assunto de grande interesse científico, sobretudo devido às suas repercussões metabólicas. Entre as doenças humanas

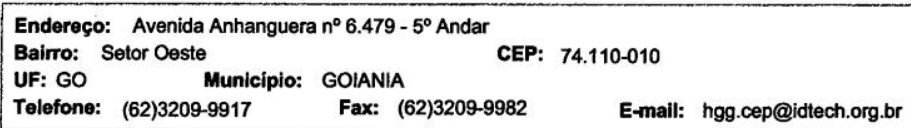




COMITÉ DE ÉTICA EM
PESQUISA DO HOSPITAL
ALBERTO RASSI - HGG Pflocoforma

Continuaçăo do Parecer: 1.020.651

associadas, destacam-se as síndromes lipodistróficas, que envolvem um grupo heterogêneo de doenças raras e associadas à perda total ou seietiva de tecido adiposo, essenciaimente subcutâneo. A ciassificação das lipodistrofias é baseada na extensão ou padrão de perda de gordura (generalizada ou parcial), assim como em seu caráter genético ou adquirido.Considerando as lipodistrofias hereditárias, o subtipo parcial familiar tem sido foco de diversas pesquisas, por representar um modelo "natural" para compreensão das funções metabólicas do tecido adiposo. Pacientes com lipodistrofia parcial familiar (LPF) apresentam uma diversidade fenotípica, com seis variantes descritas, destacando a tipo 2 (Dunnigan)como forma mais frequente. Todas estas formas apresentam achados clínicos comuns, como a relevante perda de gordura subcutânea em extremidades e região glútea, resultando em pseudo-hipertrofia muscular e flebomegalia. Classicamente, a lipodistrofia é observada na puberdade, mas pode se iniciar no final da infância ou início da vida adulta. Manifestações metabólicas são comuns na LPF, destacando-se a resistência insulínica e síndrome metabólica (SM). Dentre os componentes da SM e suas complicações, podem-se encontrar diabetes mellitus tipo 2 de início precoce, hipertrigliceridemia (com risco de pancreatite), baixas concentrações séricas de lipoproteína de alta densidade (HDL), doença hepática gordurosa não alcoólica, hipertensão arterial sistêmica, doença arterial coronariana, além de obesidade visceral. 0 mecanismo das complicações metabólicas da LPF em modelos animais e humanos parece comum, uma vez que, em ambos, a gravidade das complicações parece estar mais relacionada ao grau de perda de gordura subcutânea. Este mecanismo envolve a redistribuição e deposição ectópica da gordura corporal, com maior acúmulo de triglicerídeos em órgãos como fígado, coração e músculo esquelético. Alterações de outros eixos hormonais também podem ser encontradas na LPF. Em mulheres, a fertilidade parece estar preservada, mas oligomenorreia e hiperandrogenemia (sobretudo hirsutismo) caracterizam um quadro semelhante ao da síndrome de ovários policisticos. Estudos envolvendo o eixo tireoideano são escassos na literatura, porém já foi sugerido alterações no metabolismo dos hormônios tireoideanos conforme o local de distribuição de gordura em pacientes com LPF tipo 2. Avaliações de adipocinas nos pacientes lipodistróficos demonstraram níveis séricos baixos de adiponectina e leptina. Com relação ao eixo somatotrófico e metabolismo ósseo, não há dados publicados especificamente em pacientes com LPF, para nosso conhecimento.Tem sido proposto que anormalidades periféricas e/ou centrais na ação do cortisol sejam responsáveis pela $\mathrm{SM}$ associada à obesidade. Alterações sutis no eixo hipotálamo-hipófise-adrenal (HHA), tais como elevação dos niveis de ACTH pela manhã e alterações de sua pulsatilidade, maior responsividade do eixo corticotrófico a peptídeos exógenos, aumento da produção de cortisol e diminuição da supressão

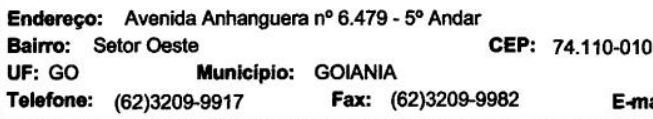




COMITEA DE ÉTICA EM
PESQUISA DO HOSPITAL
ALBERTO RASSI-HGG $\quad$ Pforecoforma

Continuação do Parecer: 1.020.651

do cortisol em resposta a baixas doses de dexametasona são notadas na SM. Estudos recentes mostram maior produção periférica de cortisol especiaimente no tecido adiposo, mediada pela enzima 11 beta-hidroxiesteróide desidrogenase tipo 1 (11 beta-HSD1), em concordância com as observações de aumento da expressão e atividade desta enzima em depósitos de gordura visceral de indivíduos obesos e/ou com SM, confirmando o papel do hipercortisolismo tissular na síndrome. Dada a presença da SM na LPF e as suas similaridades fenotípicas com o hipercortisolismo, frequentemente indivíduos com LPF são confundidos com portadores de sindrome de Cushing. Entretanto, não existem estudos sobre o eixo HHA na LPF, embora seja possivel que exista hiperativação do mesmo, à semelhança da SM comum, não relacionada à LPF.A diversidade de fenótipos na LPF pode estar associada a mutações autossômicas dominantes (mais comum) ou recessivas. Os principais genes identificados foram aqueles que codificam a lamina nuclear A/C (LMNA), receptor gama ativado por proliferadores peroxissomais (PPAR-) e a proteinoquinase $B$ ou AKT-2. No entanto, estudos genéticos envolvendo LPF ainda são poucos e relativamente recentes, enquanto é fato que muitos pacientes com LPF não apresentam mutação em nenhum dos genes candidatos.Diante da grande variabilidade clínica da doença, com formas típicas e atípicas na literatura, percebemos a necessidade de mais estudos envolvendo biologia molecular, assim como melhor avaliação de eixos hormonais e metabólicos. Talvez a raridade da doença deva-se, em parte, ao subdiagnóstico, uma vez que muitos pacientes são considerados portadores de obesidade ou síndrome metabólica comum. Portanto, estudar as bases moleculares e fisiopatogênicas das lipodistrofias poderá contribuir para o reconhecimento mais precoce da doença e de suas complicações e, consequentemente, possivel prevenção de complicações metabólicas graves, estudo dos familiares e melhor abordagem terapêutica. Além disso, estes dados apresentam o potencial de contribuir para melhor entendimento das funções metabólicas do tecido adiposo e de suas interferências com outros sistemas orgânicos.

\section{HIPÓTESE DO ESTUDO:}

H1: Pacientes com LPF podem apresentar aspectos clínicos, metabólicas e/ou hormonais que possibilitem diferenciá-los da síndrome metabólica comum, de forma a permitir uma avaliação diagnóstica peculiar e precoce da doença e,consequentemente, uma abordagem terapêutica mais específica e eficaz.

H2: Mutações em genes associados ao tecido adiposo, em especial PPAR-gama, devem influenciar na fisiopatogenia da doença e no desenvolvimento de suas comorbidades.

H3: Pacientes com LPF podem apresentar ipercortisolismo funcional, por hiperativação do eixo

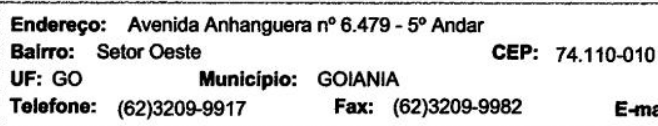




COMITEA DE ÉTICA EM
PESQUISA DO HOSPITAL
ALBERTO RASSI - HGG Placosorma

Continuaçăo do Parecer: 1.020.651

hipotálamo-hipófise-adrenal (HHA), à semelhança do que ocorre na obesidade e síndrome metabólica.

POPULAÇÃO DO ESTUDO: Serão selecionados 6 pacientes com fenótipo da doença, em acompanhamento em dois hospitais públicos da cidade de Goiânia (4 pacientes no Hospital Alberto RassiHGG e 2 pacientes no Hospital das Clínicas-UFG).

NÚMERO DE PARTICIPANTES: 6 participantes.

CRITÉRIOS DE INCLUSÃO: O estudo incluirá quatro pacientes com diagnóstico de Lipodistrofia Parcial Familiar (LPF) atendidos no ambulatório de Endocrinologia Geral do Hospital Geral de Goiânia - Dr Alberto Rassi (período matutivo e vespertino das segundas-feiras; sob esponsabilidade da endocrinologista e pesquisadora responsável Cecília Pacheco). Também serão selecionados duas pacientes que acompanham no ambulatório de Endocrinologia do período matutino da sexta-feira (sob responsabilidade da coorientadora e endocrinologista Dra Daniela Espíndola), no Hospital das Clinicas (HC) da Universidade Federal de Goiás (UFG). Os critérios de inclusão no estudo envolvem pacientes do sexo masculino ou feminino, entre 15 e 60 anos de idade, com diagnóstico clínico de LPF. O diagnóstico clínico de LPF será confirmado se respeitar os critérios clínicos e evidências metabólicas compativeis com a doença. Os critérios diagnósticos serão baseados nos achados comuns a todas as formas clínicas da LPF, em conformidade com as orientações recentes da Associação Americana de Endocrinologia (AACE - American Association of Clinical Endocrinologists), publicadas no artigo The Clinical approach to the detection of Lipodystrophy - an AACE Consensus Statement ENDOCRINE PRACTICE Vol 19 No. 1 January/February 2013). Estes critérios incluem: perda progressiva e gradual de gordura subcutânea em região glútea $e$ extremidades (com consequente pseudo-hipertrofia muscular e/ou flebomegalia); depósitos de tecido gorduroso em regiōes troncular, facial e cervical; presença de acantose nigricans; presença de irregularidade menstrual e hirsutismo (em mulheres) e manifestações metabólicas, tais como: dislipidemia (hipertrigliceridemia e baixo $\mathrm{HDL}$ ), disglicemias (pré-diabetes ou Diabetes Mellitus tipo 2), esteatose hepática, além de história de Doença Arterial Coronariana.

CRITÉRIOS DE EXCLUSÃO: Serão excluídos os indíviduos com transtornos psiquiátricos, alcoolismo, insuficiência renal crônica, hepatopatias crônicas e uso dos anticonvulsivantes fenitoína,

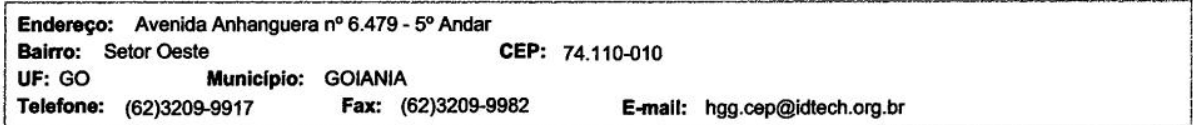




COMITE DE ÉTICA EM
PESQUISA DO HOSPITAL
ALBERTO RASSI - HGG Plowororma

Continuaçăo do Parecer: 1.020 .651

fenobarbital e carbamazepina.

FORMA DE RECUTAMENTO: Os participantes serão recrutados no Hospital Alberto Rassi - HGG e no Hospital das Clínica/UFG, inicialmente através de contato telefônico de pacientes já diagnosticados com Lipodistrofia Parcial Familiar já diagnosticados e de conhecimento da equipe. Estes pacientes são participantes do Ambulatório de Endocrinologia das Instituições citadas.

METODOLOGIA: Serão avaliados pacientes com fenótipo de LPF. A coleta dos dados clínicos será realizada mediante consulta ao prontuário médico e avaliação clínica, pela pesquisadora Cecília, médica Endocrinologista responsável pelo ambulatório de Endocrinologia Geral (segunda-feira) do Hospital Alberto Rassi - HGG, no qual quatro pacientes com LPF são acompanhados periodicamente. $O$ mesmo procedimento será realizado com duas pacientes do Hospital das Clínicas - UFG, no ambulatório de sextafeira,sob supervisão da chefe deste ambulatório, Dra. Daniela Espíndola. Os pacientes que apresentam o diagnóstico clínico já são conhecidos por estas duas pesquisadoras, endocrinologistas que acompanham estes pacientes nos Hospitais HGG e HC-UFG; respectivamente. Estes pacientes serão recrutados por contato telefônico (resgatado, a partir do nome e número do prontuário, no registro dos Hospitais). Neste contato, a pesquisadora responsável fará o convite para participar,voluntariamente, do estudo sobre LPF, averiguando possibilidade de agendar um contato pessoal para que sejam explicitados todos os aspectos da pesquisa. O contatopessoal será no ambulatório de segunda-feira (pacientes do HGG) ou no ambulatório da sexta de manhã (pacientes do HC-UFG). Será agendado, como consulta extra, um paciente por dia de ambulatório e no último horário. Pessoalmente, a pesquisadora responsável explicará sobre a pesquisa (com todos seus itens relacionados) e aplicará o Termo de Consentimento Livre e Esclarecido (TCLE).Em caso de menores de 18 anos, o TCLE deverá ser assinado pelo responsável e haverá o Termo de Assentimento. Somente serão incluídos os pacientes que concordarem em participar da pesquisa e em assinar o TCLE. Estes serão avaliados em quatro consultas médicas extras, realizadas pela pesquisadora responsável. Em primeira consulta, após anamnese detalhada, serão obtidos dados importantes do exame físico: Circunferência abdominal (ponto médio entre o rebordo costal e a crista iliaca); relação cintura/quadril (razão entre a medida da cintura e a maior circunferência do quadril); aferição da Pressão Arterial; verificação de acantose nigricans; avaliação da pilificação (escore de Ferriman para diagnóstico de hirsutismo em mulheres) e do padrão de distrubuição de gordura corporal.Os exames laboratoriais serão realizados no Laboratório Núcleo e Saúde, da cidade de Goiânia.

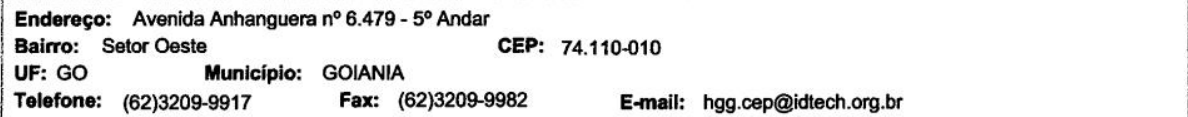




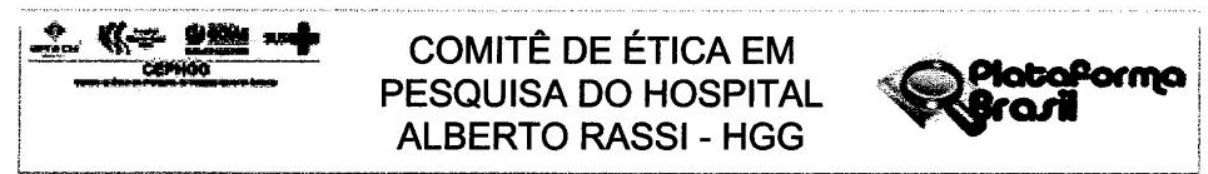

Continuaçăo do Parecer: 1.020.651

Inicialmente, serão colhidos exames basais (com jejum de 12 horas). Teste oral de tolerância a glicose $(75 \mathrm{~g})$ nos sujeitos não diabéticos; ou Glicemia jejum e pós prandial nos diabéticos; Hemoglobina glicada (HPLC); Insulina; Perfil lipídico; TGO, TGP e Gama-GT; IGF-1; Leptina; PCR ultrassensível; TSH, T4 livre e T3 livre; Ca, P, PTH e 25OHD; ACTH, cortisol basal às 8 horas, cortisol salivar (23 h)e cortisol livre urinário 24h ( 3 amostras); testosterona total; Prolactina; FSH e LH. Nas mulheres com irregularidade menstrual,também serão dosados os androgênios DHEA,SDHEA,17OHP e androstenediona.Após 15 dias, procederá a segunda consulta e os exames do eixo HHA: cortisol pós dexametasona $(0,5 \mathrm{mg}$ e, após 7 dias, $1 \mathrm{mg}$ ). Administração da dexa será às 23 horas para coleta do cortisol na manhã seguinte (às $8 \mathrm{~h}$ ). Após estes exames, será agendada terceira consulta, para reavaliação e solicitação dos exames de imagem: USG de abdome superior e pélvico (mulheres) e composição corporal por DEXA; nas Clínicas Ser e IGR, respectivamente. Caso não haja supressão do cortisol pós $1 \mathrm{mg}$ de dexa (valor $>1,8 \mu \mathrm{g} / \mathrm{dL}$ ), será realizado teste de $2 \mathrm{mg}$. $O$ estudo genético será realizado a partir da coleta de amostra de $4 \mathrm{ml}$ de sangue venoso (por bioquímico do laboratório Núcleo).As amostras ficarão armazenadas sob refrigeração e serão transportadas pela pesquisadora responsável para o laboratório Farmol(UnB), aonde será extraído o DNA genômico (método "salting out") e amplificadas as regiōes correspondentes aos éxons dos genes de interesse (PPARg, LMNA e AKT-2) por PCR. O sequenciamento genético será pelo método de Sanger.

CRONOGRAMA:

Previsão de início: 06/04/2015

Previsão de término: 05/10/2015

ORÇAMENTO TOTAL: R\$ 4.577,60

Objetivo da Pesquisa:

Objetivos apresentados pelo Pesquisador Responsável:

OBJETIVOS PRIMÁRIOS: Investigar a presença de mutações nos principais genes associados à LPF (genes que codificam PPAR-gama; LMNA e AKT-2) em portadores da síndrome, assim como caracterizar esses pacientes do ponto de vista clínico, metabólico e hormonal.

OBJETIVOS SECUNDÁRIOS: Avaliar a existência de critérios clínicos, metabólicos ou hormonais

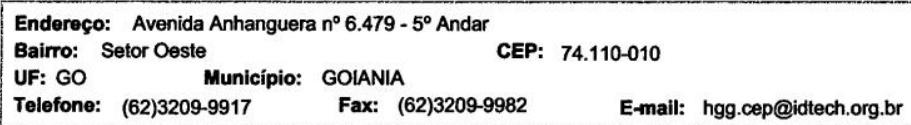




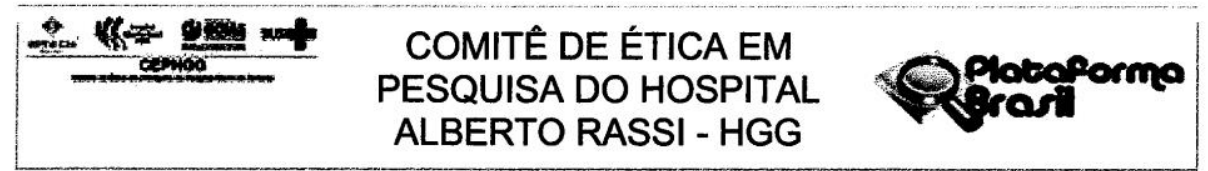

Continuaçăo do Parecer: 1.020 .651

exequivel.

CRITÉRIOS DE INCLUSÃO E EXCLUSÃO: Os critérios de inclusão e exclusão estão claramente definidos e não apresentam restrições éticas.

METODOLOGIA: O Protocolo está bem desenhado e a metodologia está adequada aos objetivos apresentados.

AVALIAÇÃO DOS RISCOS E BENEFÍCIOS: Os riscos estão bem descritos e, apesar de importantes e sérios, justificam os benefícios já descritos até o momento, assim como aqueles esperados para os sujeitos e futuros usuários.

VALOR CIENTÍFICO: O estudo é pertinente e possui valor científico uma vez que permitirá aos pesquisadores obter resultados e dados que poderão auxiliar no tratamento de Lipodistrofia Parcial Familiar.

GARANTIAS ÉTICAS: Constam as garantias éticas necessárias:

-Responsabilidade do pesquisador, da instituição e do patrocinador - Critérios para suspender ou encerrar o estudo

-Previsão de ressarcimento de gastos ou provisão material prévia

-Sigilo, privacidade, anonimato e confidencialidade dos dados coletados

-Propriedade das informações obtidas.

Consideraçōes sobre os Termos de apresentação obrigatória:

Constam no Protocolo os Documentos e Declarações pertinentes em concordância com as normas vigentes, conforme listados abaixo:

-PB_INFORMAÇŐES_BÁSICAS_DO_PROJETO_460109

- Carta de Encaminhamento ao CEP.

- Folha de rosto;

- Projeto na íntegra;

- Autororização Diretoria de Ensino e Pesquisa HGG;

- Autorização Chefia Endocrinologia/HGG;

- Termo de Consentimento Livre e Esclarecido;

Endereço: Avenida Anhanguera $n^{\circ} 6.479-5^{\circ}$ Andar

Bairro: Setor Oeste CEP: $74.110-010$

UF: GO Municipio: GOIANIA

Telefone: (62)3209-9917 Fax: (62)3209-9982 E-mail: hgg.cep@idtech.org.br 


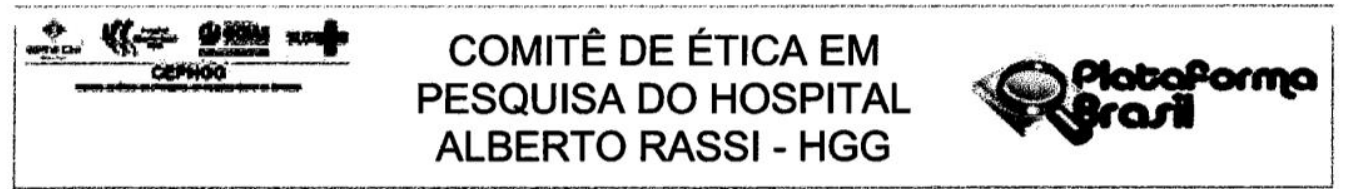

Continuaçăo do Parecer: 1.020.651

- Termo de assentimento;

- Deciaração sobre Processo de Obtenção do TCLE;

- Declaração da Orientadora;

- Declaração de Uso e Manuseio das Amostras;

- Declaração de Inserção dos Resultados na PB;

- Declaração de Recrutamento dos Participantes;

- Declaração de Infraestrutura;

- Declaração de Compromisso do Pesquisador;

- Declaração de Vínculo HGG;

- Curriculum Vitae - Equipe;

- Termo de Concordância Instituição Co Paraticipante;

- Declaração da Chefia Endocrinologia HC/UFG;

- Autorização SAMIS/HC;

- Declaração de Vínculo HC/UFG;

- Termo de Concordância Farmol;

- Orçamento;

- Cronograma;

- Instrumento para Coleta de dados Pacientes.

Considerações do CEP sobre os termos de apresentação obrigatórios:

FOLHA DE ROSTO: A Folha de Rosto encontra-se corretamente preenchida e devidamente assinada pela pesquisadora responsável, Dra. Cecília Pacheco Elias, e pelo responsável Institucional, Dr. José Cláudio Romero, nos respectivos termos de compromisso.

PESQUISA REALIZADA NO HGG: Todas as autorizações necessárias foram devidamente anexadas: Autorização da Diretoria de Ensino e Pesquisa do HGG, Concordância da Chefia do Departamento/Setor ou Seção do HGG e a Autorização da Direção da Instituição / IDTECH.

COPARTICIPANTE: Todas as autorizações pertinentes a coparticipante, Hospital das Clínicas Universidade Federal de Goiás, estão devidamente anexadas.

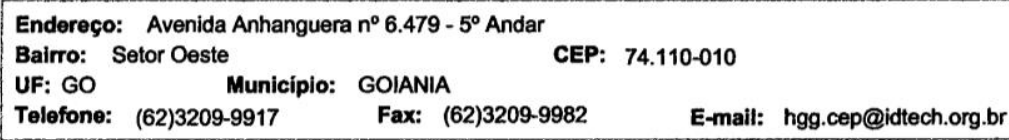




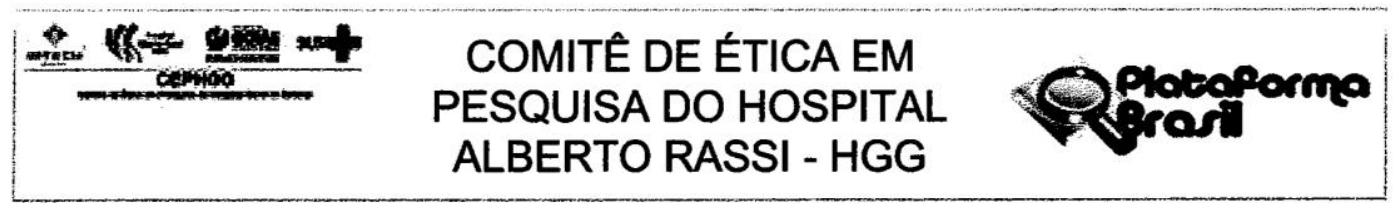

Continuação do Parecer: 1.020 .651

TERMO DE CONSENTIMENTO LIVRE E ESCLARECIDO (TCLE): Foi apresentado um termo de Consentimento Livre e Esciarecido e um Termo de Asssentimento. Constam todas as informações que são pertinentes em um TCLE. São abrangentes e detalhados. A Linguagem está compreensível e adequada ao nivel sócio-cultural. Os objetivos foram claramente informados, bem como a informação de participação voluntária. Apresenta a justificativa para a realização da pesquisa. Todos os procedimentos que serão realizados estão descritos de forma a ser bem compreendido pelo participante. Estão descritos os benefícios, riscos e desconfortos esperados. Garante a liberdade de retirar o consentimento a qualquer. momento sem prejuízo ou perda de benefícios. Há garantia de confidencialidade da participação informando que os dados obtidos não serão divulgados e nem utilizados para outras finalidades que não o estudo em questão. Está informado que o participante estará resguardado e amparado em caso de danos eventualmente provenientes da participação no estudo, e que receberá assistência integral do Investigador e do Patrocinador, esclarecendo o participante sobre as formas de ressarcimento e indenização.Consta informação sobre o ressarcimento de despesas do participante. Apresenta as formas de contato com o CEP responsável pelo acompanhamento do estudo e com o investigador principal e equipe de estudo.Está informado que o participante receberá uma via do TCLE contendo sua assinatura e a de uma pessoa autorizada da equipe. Contém os campos necessários às rubricas e datas, bem como os campos de assinaturas para o participante e Investigador. Em se tratando de uma pesquisa com consulta de dados em Prontuários, esta claro no TCLE a autorização do participante para o acesso e coleta de dados no "Prontuário do Paciente".

INSTRUMENTO DE COLETA DE DADOS: Foi apresentado o Protocolo para coleta de dados dos pacientes, que atende ao objetivo proposto no estudo.

CRONOGRAMA: O cronograma foi devidamente apresentado.

ORÇAMENTO FINANCEIRO: O orçamento detalhado da pesquisa foi apresentado indicando o custo total do estudo em $R \$ 4.577,60$, sendo que:

- Exames laboratoriais: R\$ 1.800 (desconto de $50 \%$ para 4 pacientes e cortesia para 2 pacientes, ofertado pelo Laboratório Núcleo e Saúde, Setor Oeste).

- Exames de Ultrassom: $\mathbf{R} \$ 360,00$ (desconto de $60 \%$ ofertado pela "Clínica Ser" localizada no Bueno Medical Center, Setor Bueno).

- Composição corporal por densitometria (DEXA): cortesia Instituto Goiano de Radiologia, Setor

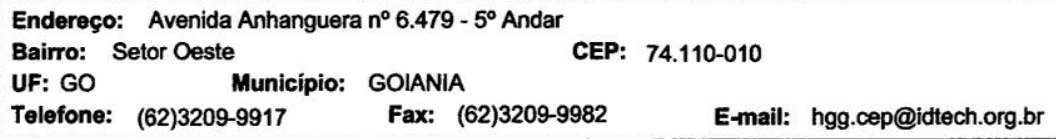




\section{COMITE DEÉTICA EM PESQUISA DO HOSPITAL ALBERTO RASSI - HGG}

Continuação do Parecer: 1.020.651

Bueno.

- Estudo do sequenciamento genético: R\$ 2.000 (serviço terceirizado a ser realizado por geneticista vinculado ao programa de pós-graduação da Universidade de Brasília, que receberá o valor financeiro depositado em conta corrente).

- Despesas com o medicamento dexametasona para rastreamento do hipercortisolismo: $R \$ 17,60$ (total de 4 caixas: cada caixa custa $R \$ 4,40$ e contém 20 comprimidos). Obrigatoriamente serão gastos total de 18 comprimidos para os testes de $0,5 \mathrm{mg}$ ( 1 comprimido por paciente) e $1 \mathrm{mg}$ ( 2 comprimidos por paciente); porém será necessário reserva total de mais 48 comprimidos ( 8 comprimidos por paciente) caso seja necessário o teste de $2 \mathrm{mg}$. Somente serão utilizados esses comprimidos reserva no paciente que não apresentar a supressão do cortisol após o teste de $1 \mathrm{mg}$ (se o cortisol pós $1 \mathrm{mg}$ de dexa for superior ao valor de corte de 1,8 $\mu \mathrm{g} / \mathrm{dL})$.

- Outras despesas estimadas (xérox, transporte da pesquisadora para Brasília, ressarcimento de transporte e alimentação dos pacientes): $R \$ 400,00$, serão pagos pela pesquisadora.

Todas as despesas serão financiadas com recursos próprios dos pesquisadores, que conseguiram um menor orçamento financeiro devido a descontos relevantes $(50 \%-60 \%)$ oferecidos pelo laboratório Núcleo e Saúde e a Clínica Ser; além de contar com a colaboração do laboratório de Farmacologia Molecular da UnB para o estudo de PCR (que possibilitou, para esta etapa do estudo genético, o gasto somente com o sequenciamento). A avaliação da composição corporal não terá custo por ter sido uma cortesia do Instituto Goiano de Radiologia.

Os Hospitais participantes (Hospital Alberto Rassi-HGG e Hospital das Clínicas-UFG) não terão nenhum onus extra. Estas Instituições contribuirão com o espaço físico (uma sala do ambulatório de Endocrinologia), para que sejam realizadas as 4 consultas médicas previstas no protocolo. Também não haverá ônus financeiro para os pacientes participantes da pesquisa.

CURRÍCULO: O currículo da pesquisadora responsável encontra-se disponivel para consulta na Plataforma Lattes e informa que a pesquisadora é graduada em medicina pela Universidade de Ribeirão Preto (2007), com Residência Médica em Clínica Médica e Endocrinologia no Hospital Alberto Rassi - HGG, tendo, portanto, formação acadêmica adequada para a condução do estudo.

\section{Recomendações:}

Nada a recomendar.

\section{Conclusões ou Pendências e Lista de Inadequações:}

Não foram encontradas inadequações ou pendências éticas.

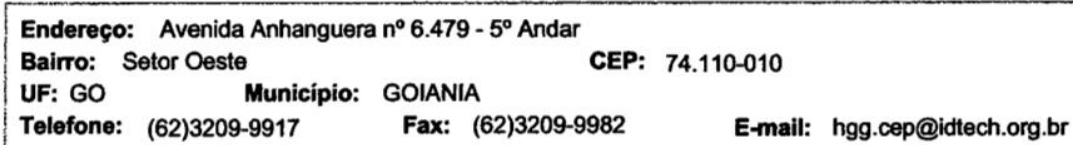




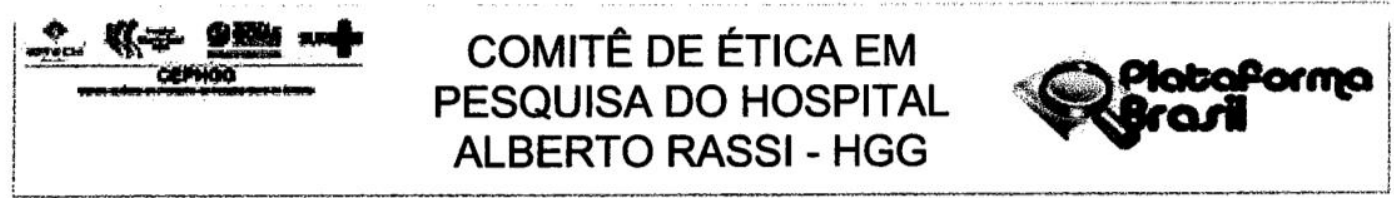

Continuaçăo do Parecer: 1.020 .651

Diante do exposto, o Comitê de Ética em Pesquisa do Hospital Alberto Rassi - HGG, de acordo com as atribuiçōes definidas na Resolução CNS 466/2012 e na Norma Operacional N 001/2013 do CNS, manifesta -se pela aprovação do projeto de pesquisa nos termos que está proposto.

\section{Situação do Parecer:}

Aprovado

Necessita Apreciação da CONEP:

Não

Considerações Finais a critério do CEP:

Em acordo com a Resolução 466/12 CNS, itens X.1.-3.b e XI.2.d, solicitamos ao pesquisador responsável que nos encaminhe os Relatórios Parciais semestralmente, contados a partir da data de aprovação, e o Relatório Final / Encerramento ou Relatório de Suspensão do Estudo. Solicitamos que nos envie possíveis Emendas, Adendos, novos Termos de Consentimento Livre e Esclarecido ou qualquer modificação relevante e que notifique no prazo máximo de dez dias qualquer Evento Adverso Sério ocorrido no Centro acompanhados das avaliações e comentários do Investigador Principal para que possamos fazer o devido acompanhamento deste estudo.

O CEPHGG pode, a qualquer momento, fazer escolha aleatória de estudo em desenvolvimento para avaliação e verificação do cumprimento das normas da Resolução 466/12 e suas complementares.

Para acesso e coleta de dados no Prontuário Médico do Paciente, sob a guarda do Hospital Alberto Rassi HGG, atendendo a Portaria IDTECH n 0065/2014, de 21 de janeiro de 2014 e demais normas legais brasileiras, o pesquisador deverá:

1. Preencher o formulário "Solicitação de acesso ao prontuário médico do paciente" (modelo anexado a Plataforma Brasil);

2. Apresentar o formulário "Solicitação de acesso ao prontuário médico do paciente", devidamente preenchido, à Diretoria Técnica do HGG, para apreciação e assinatura, juntamente com os seguintes documentos: Termo de Consentimento Livre e Esclarecido devidamente assinado pelo participante e Parecer Consubstanciado de aprovação do CEPHGG;

3. Apresentar no Serviço de Arquivo Médico e Estatística - SAME o formulário corretamente preenchido e com as assinaturas devidas.

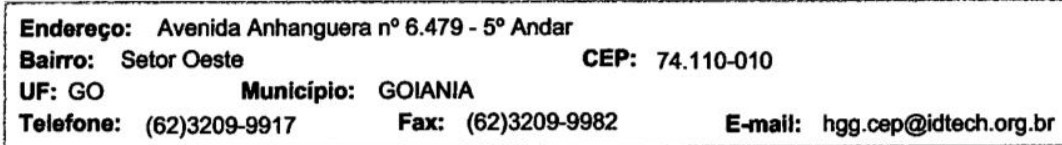




COMITE DE ÉTICA EM
PESQUISA DO HOSPITAL
ALBERTO RASSI-HGG Praconorma

Continuaçăo do Parecer: 1.020.651

GOIANIA, 13 de Abril de 2015

Assinado por:

Andréa Inês Spadeto Aires

(Coordenador)

Endereço: Avenida Anhanguera $n^{\circ} 6.479$ - $5^{\circ}$ Andar

CEP: $74.110-010$

UF: GO

Municipio: GOIANIA

Telefone: (62)3209-9917

Fax: (62)3209-9982

E-mail: hgg.cep@idtech.org.br 
ANEXO III - PARECER DE APROVAÇÃO DO PROJETO DE PESQUISA PELO COMITÊ DE ÉTICA EM PESQUISA COM SERES HUMANOS DO HOSPITAL DAS CLÍNICAS DA UNIVERSIDADE FEDERAL DE GOIÁS 


\section{HOSPITAL DAS CLÍNICAS UNIVERSIDADE FEDERAL DE GOIÁS - GO}

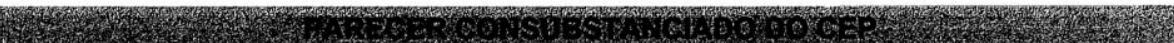

Elaborado pela Instituição Coparticipante

\section{DADOS DO PROJETO DE PESQUISA}

Título da Pesquisa: Caracterização genética, metabólica e de eixos hormonais em pacientes com Lipodistrofia Parcial Familiar

Pesquisador: Cecília Pacheco Elias

Área Temática: Genética Humana:

(Trata-se de pesquisa envolvendo Genética Humana que não necessita de análise ética por parte da CONEP;):

Versão: 1

CAAE: 42659915.2 .3001 .5078

Instituição Proponente: Hospital Geral de Goiânia - HGG

Patrocinador Principal: Financiamento Próprio

\section{DADOS DO PARECER}

Número do Parecer: 1.095 .631

Data da Relatoria: 28/05/2015

\section{Apresentação do Projeto:}

As lipodistrofias representam um grupo heterogêneo de doenças raras e associadas à perda total ou seletiva de tecido adiposo, sobretudo subcutâneo. Considerando as formas hereditárias, destaca-se o subtipo da Lipodistrofia Parcial Familiar (LPF) e sua diversidade fenotípica. Estudos envolvendo as manifestações metabólicas e hormonais, assim como biologia molecular, são relativamente escassos na literatura e a fisiopatogenia

da doença ainda não é totalmente esclarecida. O objetivo do estudo é caracterizar pacientes portadores de LPF do ponto de vista clínico, metabólico, hormonal e genético. Serão selecionados 6 pacientes com fenótipo da doença, em acompanhamento em dois hospitais públicos da cidade de Goiânia (4 pacientes no Hospital Alberto Rassi-HGG e 2 pacientes no Hospital das Clínicas-UFG). Serão avaliados exames metabólicos

(perfil glicêmico, resistência insulínica, perfil lipídico, perfil do cálcio, enzimas hepáticas, PCR ultrassensivel), hormonais (função tireoideana, androgênios, leptina, IGF-1, prolactina e cortisol - sérico, urinário e salivar), além de exames de imagem: ultrassom (US) de abdome superior, US pélvico nas mulheres e composição corporal por absorciometria de dupla energia (DEXA). Será feito estudo genético dos genes associados à

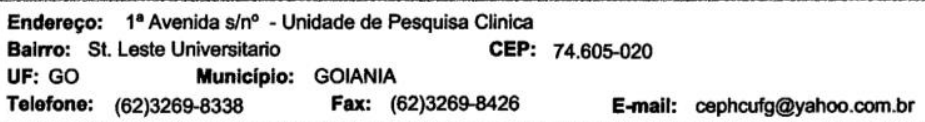




\section{HOSPITAL DAS CLÍNICAS UNIVERSIDADE FEDERAL DE GOIÁS - GO}

Continuaçăo do Parecer: 1.095.631

doença por técnica de PCR e sequenciamento genético. Os dados coletados serão analisados e interpretados por meio de tabelas e gráficos contendo os resultados dos exames e os achados clínicos. Espera-se encontrar resultados já descritos pela literatura em termos de síndrome metabólica, caracterizar melhor o perfil hormonal desses pacientes, principalmente o eixo hipotálamo-hipófise-adrenal e confirmar os padrões de composição corporal buscando, eventualmente, um novo critério clínico que auxilie no diagnóstico da doença. Também é provável a identificação de mutação em alguns dos genes estudados, em especial nos genes PPAR-gama e LMNA.

\section{Objetivo da Pesquisa:}

Objetivo Primário:

Investigar a presença de mutações nos principais genes associados à LPF (genes que codificam PPARgama; LMNA e AKT-2) em portadores da sindrome, assim como caracterizar esses pacientes do ponto de vista clínico, metabólico e hormonal.

Objetivo Secundário:

Avaliar a existência de critérios clínicos, metabólicos ou hormonais específicos da doença, que sejam distintos dos achados em pacientes com a síndrome metabólica clássica (não portadores de LPF).Avaliar se há hipercortisolismo funcional nos pacientes com LPF, à semelhança do que ocorre na obesidade e síndrome metabólica comum.

Avaliação dos Riscos e Beneficios:

Riscos:

Não há riscos previsiveis. Poderá ocorrer algum desconforto com a coleta dos exames de sangue e urina. A dexametasona utilizada para rastreamento diagnóstico do hipercortisolismo será fornecida em baixas dosagens e de forma não continuada, ou seja, apenas para teste diagnóstico, o que habitualmente não acarreta riscos previsiveis para o controle da pressão arterial, peso e glicemia. Além disso, efeitos adversos da

medicação são incomuns nestas baixas dosagens.

Beneficios:

Contribuir para um melhor conhecimento sobre a LPF, buscando critérios específicos de identificaçăo precoce da doença, de forma a não retardar o tratamento e acompanhamento das comorbidades, além de evitar o subdiagnóstico desses pacientes. O estudo genético poderá ajudar a esclarecer aspectos da fisopatologia da doença e auxiliar em estudos futuros envolvendo novas abordagens terapêuticas.

Endereço: $1^{\text {a }}$ Avenida $s / \mathrm{n}^{\circ}$ - Unidade de Pesquisa Clinica

Bairro: St. Leste Universitario CEP: $74.605-020$

UF: GO Municiplo: GOIANIA

Telefone: (62)3269-8338 Fax: (62)3269-8426 E-mail: cephcufg@yahoo.com.br 


\section{HOSPITAL DAS CLÍNICAS \\ UNIVERSIDADE FEDERAL DE Plocenorma GOIÁS - GO}

Continuaçăo do Parecer: 1.095.631

Comentários e Considerações sobre a Pesquisa:

Trata-se de um Protocolo nacional, unicêntrico tendo como instituição proponente o Hospital Geral de Goiânia e como instituição coparticipante o Hospital das Clínicas/UFG.

O estudo é pertinente e possui valor científico uma vez que permitirá aos

pesquisadores obter resultados e dados que poderão auxiliar no tratamento de Lipodistrofia Parcial Familiar.

Considerações sobre os Termos de apresentação obrigatória:

Os termos de apresentação obrigatória para a instituição coparticipante estão anexados e adequados.

\section{Recomendações:}

Conclusões ou Pendências e Lista de Inadequações:

O projeto atende aos aspectos fundamentais das Diretrizes e Normas Regulamentadoras de Pesquisas Envolvendo Seres Humanos - Resolução 466/12 não apresentando nenhum óbice ético. Recomendamos sua aprovação.

Situação do Parecer:

Aprovado

Necessita Apreciação da CONEP:

Não

Considerações Finals a critério do CEP:

Diante do exposto, a Comissão de Ética em Pesquisa do Hospital das Clínicas/UFG - CEP/HC/UFG, de acordo com as atribuições definidas na Resolução CNS n. 466 de 2012 e na Norma Operacional nº 001 de 2013 do CNS, manifesta-se pela aprovação do projeto de pesquisa proposto.

Lembramos que o pesquisador responsável deverá encaminhar ao CEP/HC/UFG, através de Notificação via Plataforma Brasil, os relatórios trimestrais/semestrais do andamento da pesquisa, encerramento, conclusões e publicações.

O CEP/HC/UFG pode, a qualquer momento, fazer escolha aleatória de estudo em desenvolvimento para avaliação e verificação do cumprimento das normas da Resolução 466/12 e suas complementares.

Situação: Protocolo aprovado.

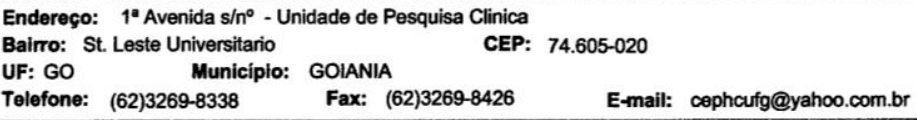

Pagina 03 de 04 
HOSPITAL DAS CLÍNICAS

UNIVERSIDADE FEDERAL DE Placoformo GOIÁS - GO

Continuaçăo do Parecer: 1.095.631

GOIANIA, 08 de Junho de 2015

Assinado por:

JOSE MARIO COELHO MORAES

(Coordenador)

Endereço: $1^{\text {a }}$ Avenida $s / n^{\circ}$ - Unidade de Pesquisa Clinica

Bairro: St. Leste Universitario CEP: 74.605-020

UF: GO Municipio: GOIANIA

Telefone: (62)3269-8338 Fax: (62)3269-8426 E-mail: cephcufg@yahoo.com.br 